\title{
DOE Technology Information Management System Database Study Report
}

Decision and Information Sciences Division

Argonne National Laboratory

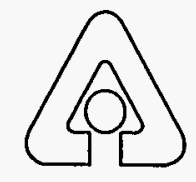

Operated by The University of Chicago, under Contract W-31-109-Eng-38, for the

United States Department of Energy 


\section{Argonne National Laboratory}

Argonne National Laboratory, with facilities in the states of Illinois and Idaho, is owned by the United States Government, and operated by the University of Chicago under the provisions of a contract with the Department of Energy.

This technical memo is a product of Argonne's Decision and Information Sciences (DIS) Division. For information on the division's scientific and engineering activities, contact:

\section{Director, Decision and Information} Sciences Division

Argonne National Laboratory

Argonne, lllinois $60439-4815$

Telephone (708) 252-5464

Presented in this technical memo are preliminary results of ongoing work or work that is more limited in scope and depth than that described in formal reports issued by the DIS Division.

Publishing support services were provided by Argonne's Information and Publishing Division (for more information, see IPD's home page: http:/www.ipd.anl.gov/).

\section{Disclaimer}

This report was prepared as an account of work sponsored by an agency of the United States Government. Neither the United States Government nor any agency thereof, nor any of their employees, makes any warranty, express or implied, or assumes any legal liability or responsibility for the accuracy, completeness, or usefulness of any information, apparatus, product, or process disclosed, or represents that its use would not infringe privately owned rights. Reference herein to any specific commercial product, process, or service by trade name, trademark, manufacturer, or otherwise, does not necessarily constitute or imply its endorsement, recommendation, or favoring by the United States Government or any agency thereof. The views and opinions of authors expressed herein do not necessarily state or reflect those of the United States Government or any agency thereof.

Reproduced directly from the best available copy.

Available to DOE and DOE contractors from the Office of Scientific and Technical Information, P.O. Box 62, Oak Ridge, TN 37831; prices available from (615) 576-8401.

Available to the public from the National Technical Information Service, U.S. Department of Commerce, 5285 Port Royal Road, Springfield, VA 22161. 


\section{DOE Technology Information Management System Database Study Report}

by M.A. Widing, D.W. Blodgett, M.D. Braun, M.J. Jusko, J.M. Keisler, R.J. Love, and G.L. Robinson Decision and Information Sciences Division,

Argonne National Laboratory, 9700 South Cass Avenue, Argonne, Illinois 60439

November 1994

Work sponsored by United States Department of Energy,

Special Technologies Program

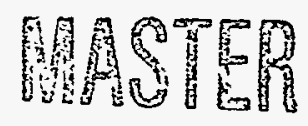

DISTRIBUTION OF THIS DOCUMENT IS UNLIMITEO 
This report is printed on recycled paper. 


\section{CONTENTS}

ACKNOWLEDGMENTS $\ldots \ldots \ldots \ldots \ldots \ldots \ldots \ldots \ldots \ldots \ldots \ldots \ldots \ldots \ldots$ vi

NOTATION $\ldots \ldots \ldots \ldots \ldots \ldots \ldots \ldots \ldots \ldots \ldots \ldots \ldots \ldots \ldots \ldots \ldots \ldots \ldots \ldots \ldots \ldots$

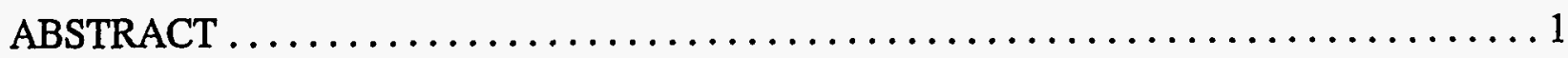

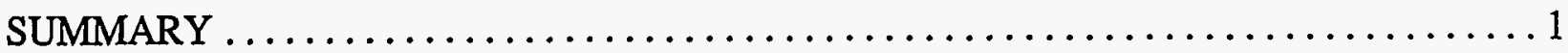

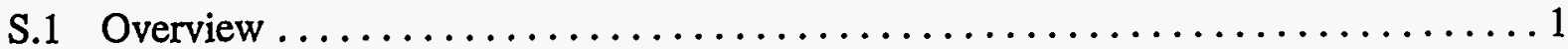

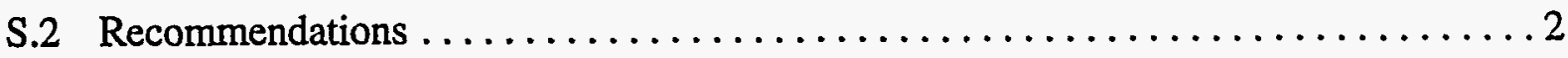

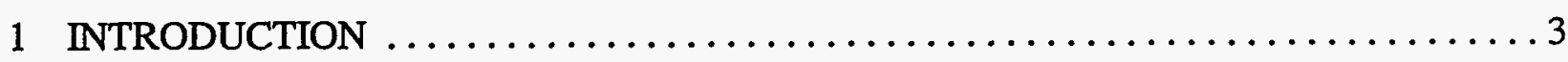

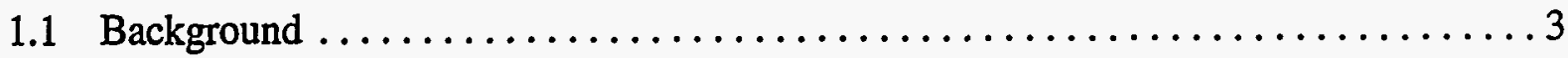

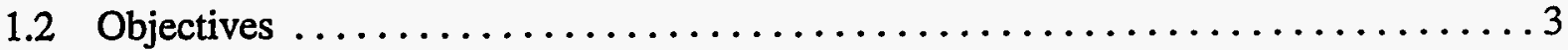

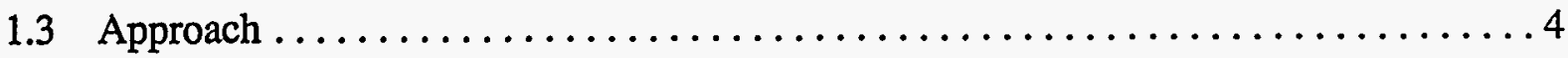

2 PRELIMINARY DATABASE REVIEWS $\ldots \ldots \ldots \ldots \ldots \ldots \ldots \ldots \ldots \ldots \ldots \ldots$

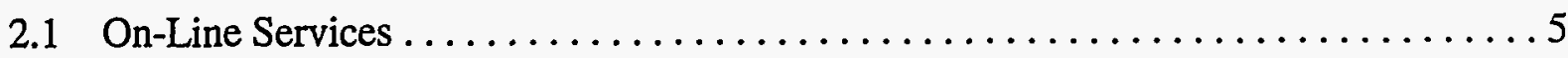

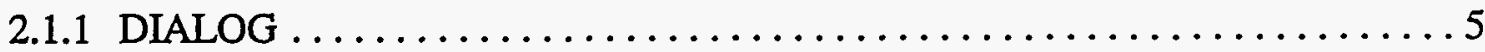

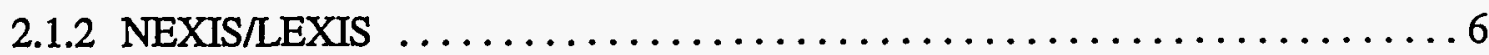

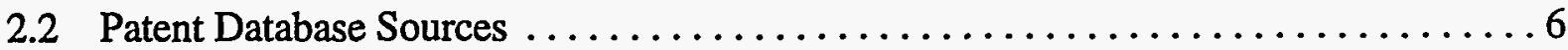

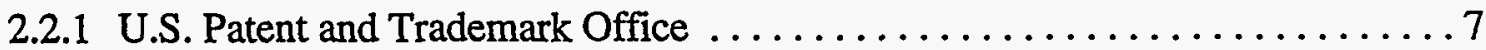

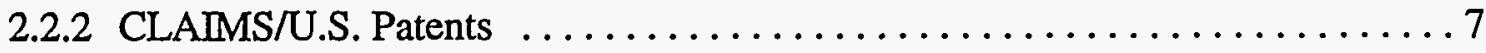

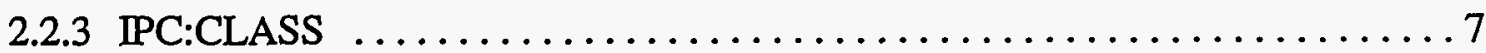

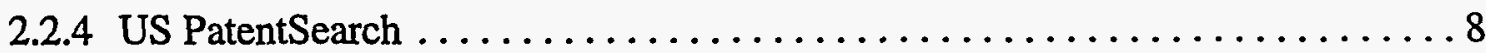

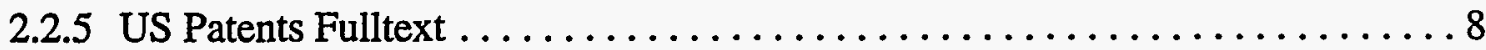

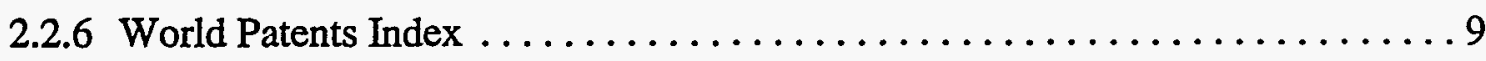

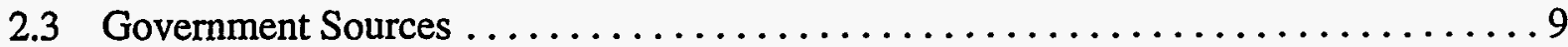

2.3.1 Office of Science and Technical Information .................

2.3 .2 National Technical Information Service $\ldots \ldots \ldots \ldots \ldots \ldots \ldots \ldots \ldots \ldots \ldots$

2.3.3 Defense Technical Information Center . . . . . . . . . . . . . . . 11

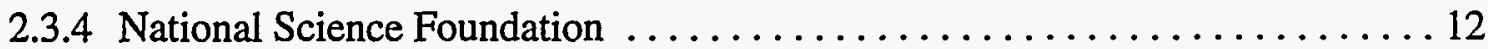

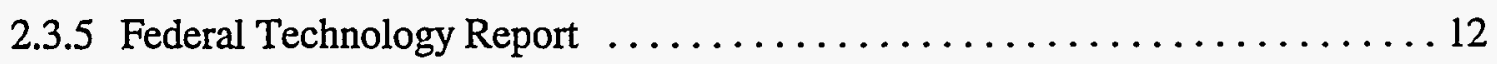

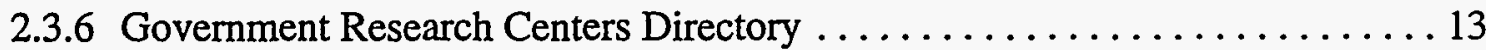

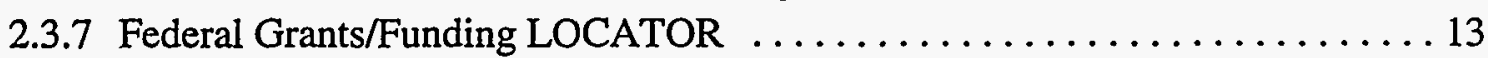

2.4 Aerospace Technology Sources $\ldots \ldots \ldots \ldots \ldots \ldots \ldots \ldots \ldots \ldots \ldots \ldots \ldots \ldots \ldots$

2.4.1 Aerospace Database ........................... 14 


\section{CONTENTS (Cont.)}

2.4.2 Aerospace/Defense Markets \& Technology .................... 14

2.4.3 NASA COSMIC Software Catalog ......................... 15

2.4.4 NASA Scientific and Technical Information Database .............. 15

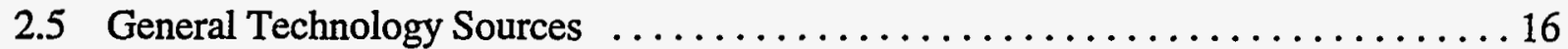

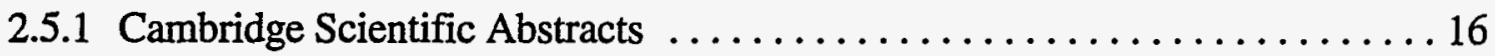

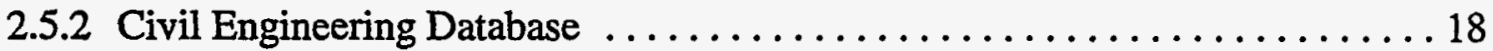

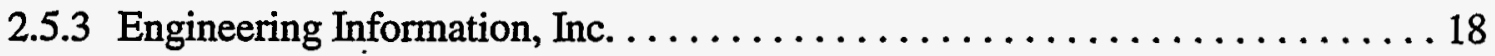

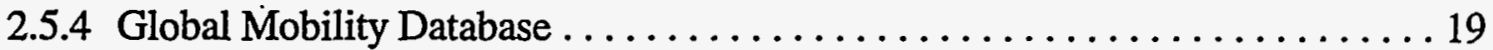

2.5.5 H.W. Wilson Databases ................................ 19

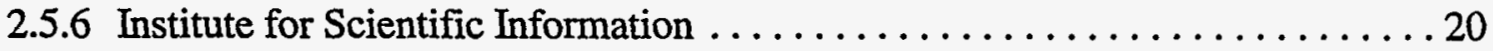

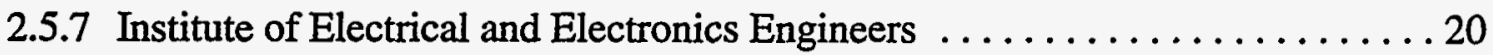

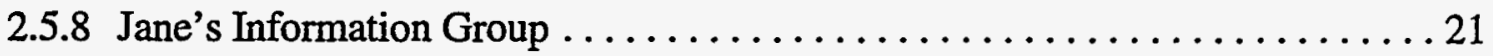

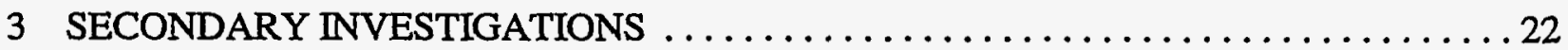

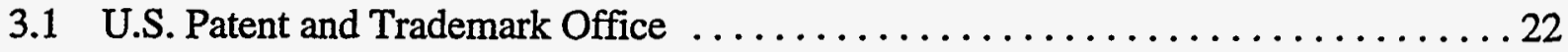

3.1.1 Data Description ...................................... 22

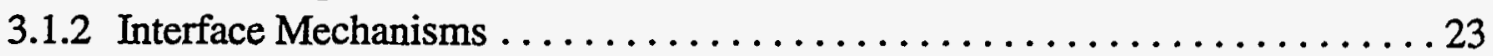

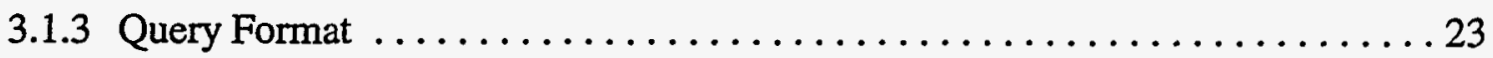

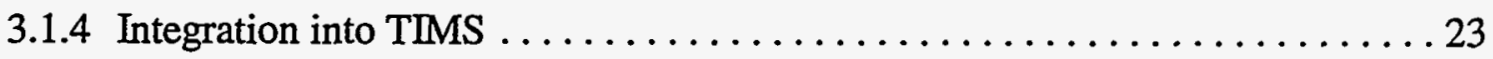

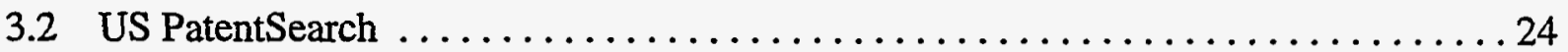

3.2.1 Data Description ..................................... 24

3.2.2 Interface Mechanisms .................................. 25

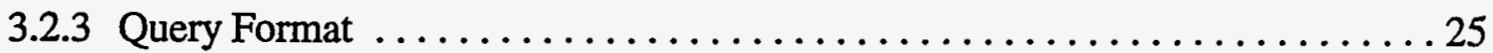

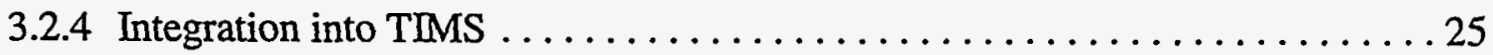

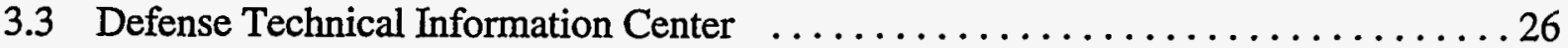

3.3:1 Data Description .................................... 26

3.3.2 Interface Mechanisms ................................. 27

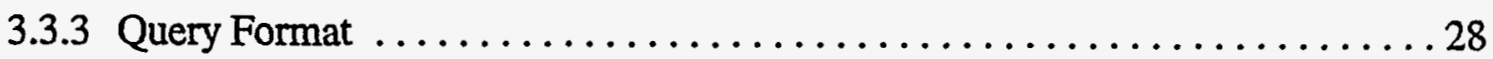

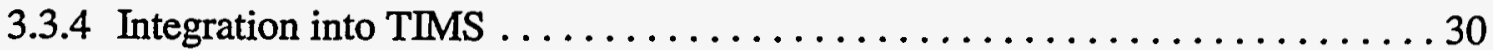

3.4 NASA Scientific and Technical Information Database $\ldots \ldots \ldots \ldots \ldots \ldots \ldots \ldots$

3.4.1 Data Description .................................... 31

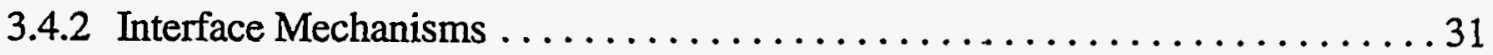

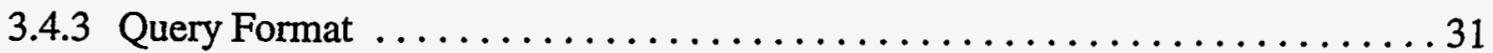

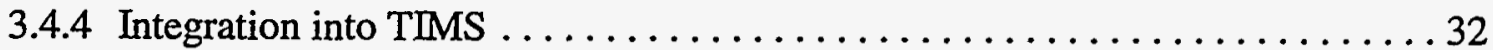

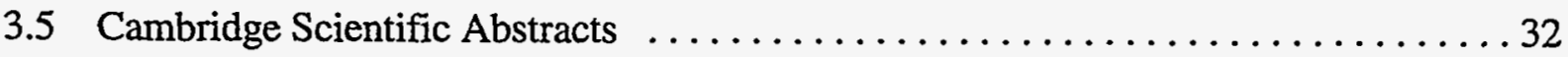

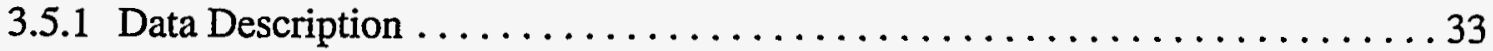

3.5.2 Interface Mechanisms ................................. 33 


\section{CONTENTS (Cont.)}

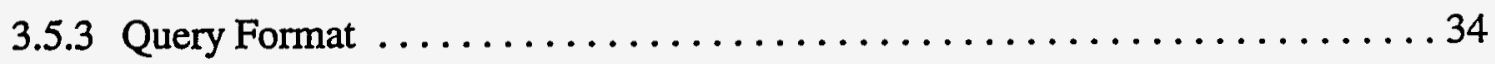

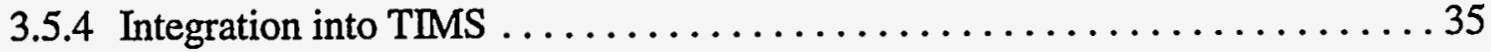

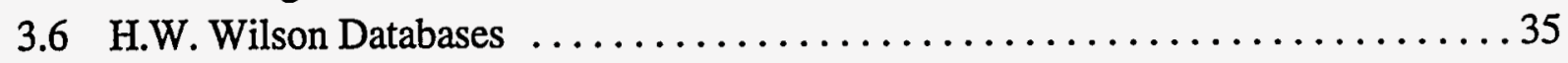

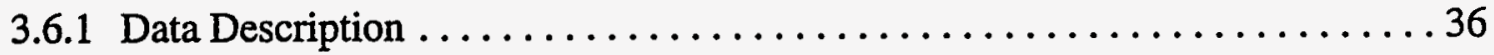

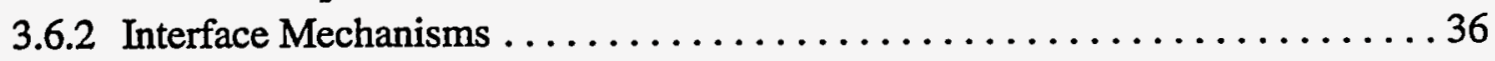

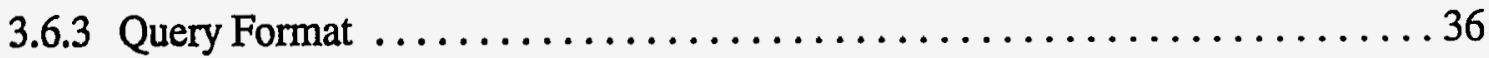

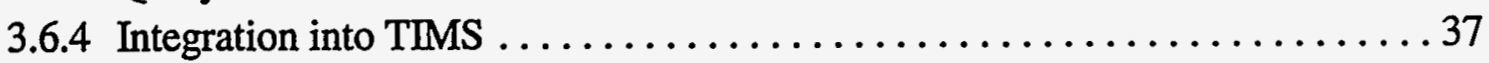

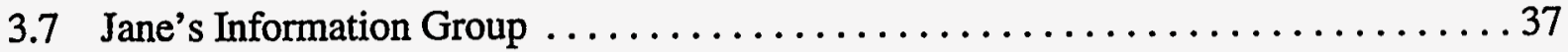

3.7.1 Data Description ...................................... 38

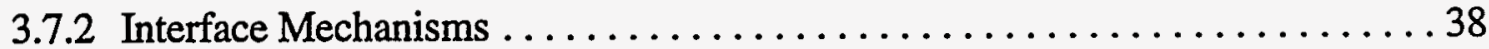

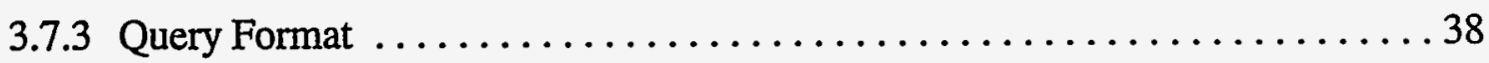

3.7.4 Integration into TIMS $\ldots \ldots \ldots \ldots \ldots \ldots \ldots \ldots \ldots \ldots \ldots \ldots \ldots \ldots \ldots \ldots \ldots$

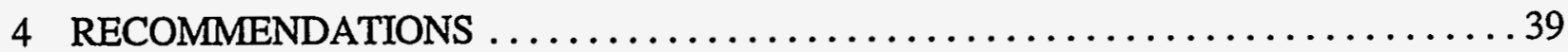

APPENDIX A: Preliminary Investigation Sheets $\ldots \ldots \ldots \ldots \ldots \ldots \ldots \ldots \ldots \ldots \ldots \ldots \ldots$

APPENDIX B: Secondary Investigation Information $\ldots \ldots \ldots \ldots \ldots \ldots \ldots \ldots \ldots \ldots \ldots \ldots \ldots$

\section{TABLE}

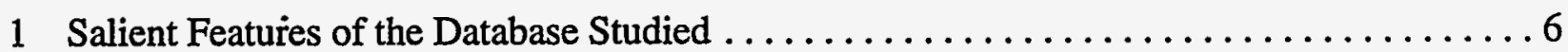




\section{ACKNOWLEDGMENTS}

The authors gratefully acknowledge the support of Robert Wall, Program Manager, Special Technologies Program, U.S. Department of Energy (DOE). We also wish to thank Robert Nine and Tripp Robertson of DOE and Frank Annecchini of Special Technologies Laboratory for their advice and assistance. Finally, the authors thank Margaret Clemmons and Marita Moniger for editorial assistance. 


\section{NOTATION}

The following is a list of the acronyms, initialisms, and abbreviations used in this document.
A/DM\&T Aerospace/Defense Markets \& Technology database
AIAA American Institute of Aeronautics and Astronautics
ANL Argonne National Laboratory
CEDB Civil Engineering DataBase
COSMIC Computer Software Management and Information Center
CSA Cambridge Scientific Abstracts
DAT digital audio tape
DGIS DoD Gateway Information System
DOC U.S. Department of Commerce
DoD U.S. Department of Defense
DOE U.S. Department of Energy
DROLS Defense Research, Development, Test, and Evaluation On-line System
DTIC Defense Technical Information Center
Ei Engineering Information, Inc.
ESA European Space Agency
ESTD Energy Science and Technology Database
FTP file transfer protocol
IAC Information Access Company
IEEE Institute of Electrical and Electronics Engineers
IPO IEEE Publications OnDisc
IR\&D Independent Research and Development database
ITIS Integrated Technical Information System

MATRIS Manpower and Training Research Information Development database

NASA National Aeronautics and Space Administration

NSF National Science Foundation

NTIS National Technical Information Service

OSTI Office of Science and Technical Information

PC personal computer 
PCT Patent Cooperation Treaty

PTO U.S. Patent and Trademark Office

R\&D research and development

R\&T research and technology

RECON REsearch CONnection

RLG Research Libraries Group

SAE Society of Automotive Engineers

SRS Science Resources Studies

STAR Scientific and Technical Aerospace Reports

STI Scientific and Technical Information

STIS Science \& Technology Information System

STN Scientific Technical Information Network

STP Special Technology Program

TIMS Technology Information Management System

TR Technical Report bibliographic database

WAIS Wide Area Information Service

WPI World Patent Index

WUIS Work Unit Information System 


\title{
DOE TECHNOLOGY INFORMATION MANAGEMENT SYSTEM DATABASE STUDY REPORT
}

\author{
by \\ M.A. Widing, D.W. Blodgett, M.D. Braun, M.J. Jusko, J.M. Keisler, \\ R.J. Love, and G.L. Robinson
}

\begin{abstract}
To support the missions of the U.S. Department of Energy (DOE) Special Technologies Program, Argonne National Laboratory is defining the requirements for an automated software system that will search electronic databases on technology. This report examines the work done and results to date. Argonne studied existing commercial and government sources of technology databases in five general areas: on-line services, patent database sources, government sources, aerospace technology sources, and general technology sources. First, it conducted a preliminary investigation of these sources to obtain information on the content, cost, frequency of updates, and other aspects of their databases. The Laboratory then performed detailed examinations of at least one source in each area. On this basis, Argonne recommended which databases should be incorporated in DOE's Technology Information Management System.
\end{abstract}

\section{SUMMARY}

\section{S.1 OVERVIEW}

In support of the missions of the U.S. Department of Energy's (DOE's) Special Technologies Program (STP), Argonne National Laboratory (ANL) is defining requirements for an automated software system to help users search technology databases. This requirements definition phase focuses on developing a Technology Information Management System (TIMS) prototype. To assist in this effort, ANL conducted a detailed examination of existing electronic sources of technology data as follows. First, discussions with DOE/STP yielded an initial list of databases. ANL then conducted a preliminary investigation of these databases, which focused on content, form, media availability, and cost. After these preliminary investigations, ANL analyzed each database to determine which candidate databases merited a secondary, more detailed examination. Through these secondary investigations, ANL obtained more precise information on the content of selected databases. 
Electronic database sources in five areas were examined: on-line service providers, patent database sources, government sources, aerospace technology sources, and general technology sources. At least one source in each area was identified for a secondary investigation. Secondary investigations determined additional details on the actions needed to implement automated interfaces to the selected databases.

\section{S.2 RECOMMENDATIONS}

Argonne performed secondary investigations of several database sources: US PatentSearch, Defense Technical Information Center, the National Aeronautics and Space Administration's (NASA's) Scientific and Technical Information database, Cambridge Scientific Abstracts, H.W. Wilson databases, and Jane's Information Group databases. Implementation approaches for these sources would include accessing data in a local search database, providing remote connection to Internet or other services, and allowing access by means of commercial software search libraries.

To demonstrate the feasibility of building a computer system with these different linkages, the TIMS prototype includes interfaces to three different data sources: a communications link to the U.S. Patent and Trademark Office Internet database, a communications link to NASA's REsearch CONnection Internet demonstration database, and. a local software link to a sample Cambridge Scientific data set.

For the complete TIMS, the STP should examine each data source to determine how the different databases fit its requirements. On the basis of STP's decisions in this area, a full TIMS design and implementation strategy could be developed. 


\section{INTRODUCTION}

\subsection{BACKGROUND}

The U.S. Department of Energy's (DOE's) Threat Assessment Division, Special Technologies Program (STP), monitors and must quickly respond to requests for information about current technological programs. To efficiently find and screen this information, the STP must rapidly access a wide variety of information sources to determine which programs apply to a specific technological area. Although some automated tools are available to search selected data sources, no unified system is available to assist users in searching databases for information on technologies (hereinafter referred to as technology data).

Automated information management systems allow users to query networked databases for textual information, such as project summaries and magazine articles. An information management system could be developed to automatically query multiple sources through one common interface. This capability would enable the user to quickly and easily conduct detailed searches across many data sources without manually accessing those systems through their native interfaces. Using an information management system of this type would allow the user to quickly perform these searches, as well as conduct a wider variety of searches, because the queries would be executed automatically.

To support the STP, Argonne National Laboratory (ANL) is defining requirements for an automated software system that would assist users in searching external technology databases. The primary focus is to develop a prototype Technology Information Management System (TIMS). To assist in this effort, ANL examined existing electronic sources of technology data in detail. These sources would be candidates for inclusion in later phases of system development.

\subsection{OBJECTIVES}

Electronic technology data are available from a variety of sources. The purpose of this study is to identify these sources, obtain information on the content and cost of using these sources, and determine the usability of these sources by a system such as TIMS. Examining these sources will result in a better understanding of the requirements needed to link to various technology databases.

In addition to gaining information on the requirements of these interfaces, this study will provide information concerning the appropriateness of including these data sources in an information management system for the STP. This information can be used to make educated selections of the databases that would most benefit the final system. 


\subsection{APPROACH}

The STP identified specific databases in an initial list. The Gale Directory of Databases (edited by K. Young Marcaccio; published by Gale Research Inc., Detroit, Michigan, in July 1994) provided additional information on those sources and other candidate sources. A Database Study Group was then formed to investigate these sources.

The sources were investigated in two stages: a preliminary and a secondary investigation of the databases. Preliminary investigation sheets ensured that the investigations were thorough and consistent. These initial investigations focused on content, form, media availability, and cost. To the extent possible, information was obtained through direct contact with the original sources of the databases. Explicit technical details were requested to help determine the feasibility of developing an automated interface to each database.

After the preliminary investigations, the Database Study Group analyzed each database to determine which candidates merited a secondary, more detailed examination. These databases were selected on the basis of a wide range of factors, including appropriateness of content, completeness, currentness, cost, media formats, and lack of interface restrictions. Section 2 summarizes the results of the preliminary investigations. Appendix A contains the preliminary investigation survey sheets for reference.

The secondary investigations allowed the Database Study Group to obtain more precise content information on the selected databases. The group also verified verbal information supplied by the sources. Wherever possible, the group queried these databases to determine their actual content, beyond the general descriptions provided by the sources in the preliminary investigations. The requirements imposed in developing an automated interface to each database were detailed so that cost could be accurately estimated later, if desired. Section 3 summarizes the results of these secondary investigations. Appendix B contains the secondary investigation searches.

Section 4 contains recommendations for future actions. These recommendations are based on the results of the preliminary and secondary investigations. 


\section{PRELIMINARY DATABASE REVIEWS}

\subsection{ON-LINE SERVICES}

An on-line service is an information provider that has a bulletin board that allows users to access numerous databases that cover topics in several areas. These services enable the user to query specific databases developed and maintained by either a separate source or a service provider. The costs of these services consist of initial fees and usage charges based on the specific database queried, as well as on the number of records downloaded or printed. In many cases, a particular database is available in multiple formats: through an on-line service, on CD-ROM, or on magnetic tape. For a particular user of a database, selecting the best access media depends on the relative costs and the anticipated frequency of searches for different records. For example, it may be appropriate to use a CD-ROM system for frequently searched data and an on-line service when very current, obscure, or detailed information is needed.

Many on-line services are commonly used: CompuServe, DataStar, DIALOG, NEXIS/LEXIS, and others. This report discusses the two main on-line services that access many of the databases discussed in this section.

\subsubsection{DIALOG}

DIALOG Information Services (DIALOG) is a well-known company that specializes in providing access to hundreds of technical data sources, mostly prepared by other parties. The content of the databases ranges from bibliographic (e.g., the aerospace database) to full text (e.g., CLAIMS/US PATENTS). Many of the databases cited in this report are available through DIALOG. Most DIALOG services are on-line, although a subset is available on CD-ROM and through other channels.

DIALOG charges a fee for each service. This fee is partially set by the original provider of the database (e.g., a per-record fee and a connect-time fee) and partly for the service provided by DIALOG (e.g., initial sign-up costs, connect time, and search costs). DIALOG services are often convenient, particularly for customers who would benefit from DIALOG's high-quality, one-stop shopping. However, DIALOG has fairly strong restrictions on the use of its services, and comparable data sources are often available at lower cost. 


\subsubsection{NEXIS/LEXIS}

NEXIS is a widely used on-line service with a vast selection of databases pertaining to fulltext news, publications, and patents. An associated service - LEXIS - provides financial, medical, and business information. The STP currently uses this service. Although NEXIS/LEXIS provides a wealth of information, its cost is high. For this reason, this study also examined alternate sources of information, particularly in the patent area.

\subsection{PATENT DATABASE SOURCES}

Because patents are public domain and largely self-contained, patent databases differ more in the way in which they package and price the information than in the information they offer. The systems studied showed some differences in content: some databases feature only U.S. patents, and some are updated more frequently than others. All databases offer similar indexes (e.g., author, numbers) but they differ in the extent of these indexes. They also differ in the extent of the actual records, which range from bibliographic information to abstracts to full text and images. Although it would be possible access most of the patent information through DIALOG, it may not be the most cost-effective choice, especially when restrictions on use and access are considered. Table 1 gives the salient features of the databases studied.

TABLE 1 Salient Features of the Databases Studied

\begin{tabular}{|c|c|c|c|c|}
\hline Database & International & Complete & Full text & Cost \\
\hline PTO & No & Yes & Full text and images & Reasonable \\
\hline $\begin{array}{l}\text { CLAIMS/U.S. } \\
\text { Patents }\end{array}$ & No & Yes & $\begin{array}{l}\text { Abstract and front } \\
\text { page }\end{array}$ & $\begin{array}{l}\text { High variable cost } \\
\text { through on-line vendors }\end{array}$ \\
\hline IPC:CLASS & Yes & $\begin{array}{l}\text { No (infrequent } \\
\text { update) }\end{array}$ & No & $\$ 360$ for CD-ROM \\
\hline US PatentSearch & No & Yes & $\begin{array}{l}\text { Abstract and front } \\
\text { page; optional full text } \\
\text { and images }\end{array}$ & $\begin{array}{l}\$ 1,400-\$ 7,500 / \text { year } \\
+\$ 3,000-\$ 5,000 \text { for } \\
\text { back files }\end{array}$ \\
\hline US Patents Fulltext & No & Yes & Full text of patents & $\begin{array}{l}\text { High variable cost } \\
\text { through on-line vendors }\end{array}$ \\
\hline $\begin{array}{l}\text { World Patents } \\
\text { Index }\end{array}$ & Yes & Yes & No & $\begin{array}{l}\text { High variable cost } \\
\text { through on-line yendors }\end{array}$ \\
\hline
\end{tabular}




\subsubsection{U.S. Patent and Trademark Office}

The U.S. Patent and Trademark Office (PTO) is responsible for registering all patents and trademarks. It offers limited services to enhance public access to patent information. One main service is USA-PAT, a CD subscription service (of two to three disks per week), featuring full images for all new patents starting in January 1994 and indexed by patent number. The full text of patents may be accessed on-line through the Wide Area Information Service (WAIS) system, the other main service offered by PTO. The services currently offered are not particularly user-friendly; however, they are timely, inexpensive, and expected to be reliable. The PTO continues to develop additional electronic services, and its MOSAIC Internet server contains references to other patent information sources. The PTO is more stable than any other provider of patent information. For these reasons, the Database Study Group conducted a secondary investigation of PTO services.

\subsubsection{CLAIMS/U.S. Patents}

CLAIMS/U.S. Patents is an on-line service that provides front-page patent information, author information, and abstracts for U.S. utility and design patents, as well as standard search fields. The advantages of this service include its extensive information on claims and its companion databases:

- CLAIMS/CITATION (reference of all patents cited by another patent and all patents cited in each patent),

- CLAIMS/REFERENCE (manual of classification),

- CLAIMS/Reassignment and Reexamination,

- ONTAP CLAIMS (on-line training and practice), and

- U.S. Patent Abstract Weekly (transferred once per month).

If the citation service or one of the other companion databases is of particular value, a secondary investigation of CLAIMS/U.S. Patents would be appropriate.

\subsubsection{IPC:CLASS}

IPC:CLASS is a CD-ROM-based, easily searched reference database that contains technical and specialized indexes (e.g., catchwords, concordance data, IPC symbols) on international patents. Although the IPC:CLASS dataset is not as comprehensive as that of other patent databases, it could 
be used in a patent investigation system. It could perform inexpensive preliminary patent searches. After locating a specific patent, a more extensive database could then be used to access detailed information. This approach would be warranted if extensive patent searching were required.

\subsubsection{US PatentSearch}

US PatentSearch is a CD-ROM subscription that provides front-page bibliographic information on all U.S. utility patents, defensive publications, design patents, reissue patents, statutory invention registrations, and plant patents granted since 1974. US PatentSearch provides 18 standard search fields and keyword-searchable abstracts. Several extensions on this database are also available. US FullText is an extension of this service that offers the complete text of the same patents. US PatentImages is another extension that provides complete text and drawings of utility patents.

Other services include PatentQuery, Patent Bulletin (bulletin of new patents) and BBS, PatentCopies, PhoneSea rch (a means of obtaining patent information mailed through a phone call rather than on-line), PatentBible (database search tools), and ESPACE ACCESS (European and Patent Cooperation Treaty [PCT] international patent applications).

Because this package offers substantial value for its cost, particularly when used frequently, the Database Study Group recommends it and its companion products for a secondary investigation.

\subsubsection{US Patents Fulltext}

US Patents Fulltext, produced by DIALOG, contains the complete text of 1.4 million U.S. patents issued from 1974-present, including partial coverage for 1971-1973, for all granted U.S. utility patents, defensive publications, design patents, reissue patents, statutory invention registrations, and plant patents.

The core information is available through US Patents Fulltext under a different pricing structure. As with other DIALOG services, this service has a low fixed cost but high variable costs that could accrue quickly. The main benefits of US Patents Fulltext are (1) the administrative information it contains beyond the text for each patent and (2) the frequent updates. On the basis of its anticipated use, it may have a lower fixed cost. 


\subsubsection{World Patents Index}

World Patents Index (WPI) is a very extensive database, updated weekly, that contains abstracts, citations, and standard reference fields on more than 6 million citations issued by 31 countries. WPI is available on-line through DIALOG. Access to WPI is fairly expensive, though not prohibitive.

The WPI is the most complete sources of current international patent information. (One advantage of international information is that certain patents are issued in other countries before they are issued in the United States). If a DIALOG interface is developed, the marginal additional effort required to include WPI would be relatively small.

\subsection{GOVERNMENT SOURCES}

Government information can be obtained through a number of sources. Several originate at government installations and contain information on technological projects initiated through DOE, the Department of Commerce (DOC), or the Department of Defense (DoD). Other sources contain government-owned and publicly available information. Although the STP currently has access to similar types of data, these databases were included in this study for reference.

\subsubsection{Office of Science and Technical Information}

The Office of Science and Technical Information (OSTI) is a DOE agency responsible for centralized planning, development, maintenance, and administration of services and facilities required to accomplish DOE's responsibilities that relate to controlling and disseminating technical information to DOE and the public. More specifically, OSTI's responsibilities include providing support and direction for managing DOE's Scientific and Technical Information Program; serving as an archive for worldwide energy research and development (R\&D) information; producing and maintaining databases of R\&D information; providing information on DOE research in progress and on energy-related environmental, safety, and health issues; issuing periodicals that announce the most recent additions to the Energy Science and Technology Database (ESTD); overseeing DOE's centralized scientific and technical information software management activity; providing customized information products and services for DOE program offices, contractors, and field organizations; and negotiating and representing the United States in bilateral and multilateral agreements for international exchange of energy-related scientific and technical information to support DOE's domestic programs.

OSTI also maintains the Integrated Technical Information System (ITIS), a DOE on-line system. ITIS provides access to DOE's scientific and technical databases, information merging for 
customized information products, and electronic mail that links OSTI to other DOE and contractor offices. Users can search various databases and review the results on-line. Users can download records to their personal computer (PC) or order printed copies.

Twelve databases are available through ITIS: ESTD, Management Information File, Report Holdings File, Research in Progress, Controlled Access File, Minority Economic Impact, Nevada Nuclear Waste, Energy Science and Technology Software, Numeric Database Directory, Foreign Research in Progress, New Technology from DOE, and Nuclear Criticality Safety.

One database housed by OSTI is the International Energy Association database, which contains more than 1 million citations in bibliographic form in the fields of nuclear science and technology. These citations are obtained from journals, research reports, monographs, conference proceedings, theses, patents, and unpublished materials. Accessible through CD-ROM, it has extensive citations in nuclear technology.

The ESTD contains bibliographies and summaries of all unlimited, unclassified information related to energy and nuclear science and technology from worldwide sources processed at OSTT. This energy research covers all scientific and technical aspects of fossil, renewable, and nuclear energy sources; energy conservation, consumption, and utilization; energy policy; and the environmental effects of energy production and utilization. Beyond energy fields, it also contains citations in, for example, basic scientific studies, computers, environment and pollution, nuclear medicine, and arms control. The records are citations to and abstracts of U.S. and foreign technical reports, journal articles, conference papers and proceedings, engineering drawings, computer software, audiovisual materials, books, patents, theses, and monographs.

\subsubsection{National Technical Information Service}

The National Technical Information Service (NTIS) bibliographic database contains summaries of scientific, technical, engineering, and business information products available from NTIS. Major areas covered include the biological, social, and physical sciences; mathematics; engineering; and business information. NTIS acquired these products from 1964-present. Included are announcements of computer-readable software and data files, U.S. government-owned inventions available for licensing, selected reprints, federally sponsored translations, videos, and some non-English-language reports. Currently, more than 1.8 million records are on file, and NTIS adds about 70,000 new products to its collection annually. In addition, these products can be ordered from NTIS.

The bibliographic database is available through a PC from a number of on-line services: BRS, CISTI (in Canada), DataStar, DIALOG, ESA/RS (in Italy), NERAC, ORBIT, and STN International. The database is also available on CD-ROM from either DIALOG or Silver-Platter. 
DIALOG's CD-ROM includes records from 1980-present. Silver-Platter includes records from 1983present.

Because the content of this database is rather restricted, the Database Study Group did not conduct a secondary investigation.

\subsubsection{Defense Technical Information Center}

The Defense Technical Information Center (DTIC) is the central point of technical information distribution within DoD. DTIC's multiple sites across the country support users in DoD and other government agencies.

DTIC's holdings include technical reports, management information summaries at the work-unit level, and independent $R \& D$ efforts. The collection includes topics associated with defense research, such as aeronautics, missile technology, space technology, navigation, and nuclear science. In addition, nondefense subjects, such as biology, chemistry, energy, environmental sciences, oceanography, computer sciences, sociology, and human factors engineering, are available. Four primary databases are managed by DTIC: Technical Report (TR) bibliographic database, Research and Technology Work Unit Information System (WUIS) database, Independent Research and Development (IR\&D) database, and Manpower and Training Research Information System (MATRIS) database. In addition, DTIC supports DoD's Gateway Information System (DGIS), which unifies interfaces to various databases and on-line services with technical information.

The TR database contains unclassified bibliographic citations and abstracts. The records are from printed and nonprinted technical reports and products submitted to DTIC, associated with completed research.

The WUIS database contains management information summaries that reflect ongoing DoD and NASA research and technology efforts at the work-unit level. The records include information about what, where, when, and how research is being conducted and who is conducting the research, at what costs, and under what sponsorship. .

The $\mathbb{R} \& D$ database contains reports of independent $R \& D$ initiated and performed by $D o D$ contractors but not wholly funded by DoD. Only DoD personnel with classified clearance can access this database.

The MATRIS database contains more than 5,600 summaries of defense-related projects in the area of human resources management. This database covers the areas of education and training, human factors engineering, personpower, and simulation systems. Project histories, contacts, budgets, and summaries are included. 
Because of the importance and relevance of these databases, the Database Study Group conducted a more detailed secondary investigation of DTIC data sources.

\subsubsection{National Science Foundation}

The goal of the National Science Foundation (NSF) is to have all printed NSF publications available electronically through the Science \& Technology Information System (STIS). Currently, available publications include the NSF Bulletin, program announcements and "Dear Colleague" letters, general publications and reports, Division of Science Resources Studies (SRS) publications, press releases, other NSF news items, NSF organization charts and alphabetical telephone directories, NSF vacancy announcements, and award abstracts. The publications likely to be of interest to the sponsor are the award abstracts and the SRS publications.

STIS is an electronic dissemination system that provides easy access to NSF publications through modem or the Internet. The on-line interface is somewhat cumbersome compared with other access methods, which perform searches easier and faster. However, STIS can search all of the electronically available NSF publications at once, whereas other access methods cannot. The publications can be searched and downloaded at no cost.

The Database Study Group did not conduct a secondary investigation because this data source is limited in size and scope.

\subsubsection{Federal Technology Report}

The Federal Technology Report database contains the full text of the biweekly newsletter Federal Technology Report. This newsletter discusses business opportunities at the U.S. federal laboratories under DoD, DOE, and DOC. Articles in the newsletter cover technology transfer laws, licensing arrangements, and cooperative $R \& D$ arrangements. Different areas covered in the database include environment and waste management, energy, materials science, manufacturing processes, computers and communications, biotechnology and medicine, and instrumentation.

The electronic database dates back to January 1990 and is available on a variety of on-line services, including DIALOG, NewsNet, and NEXIS. The standard on-line service restrictions apply to these data (see Section 2.1). The cost of this database is in the middle range for DIALOG. (DIALOG costs are discussed in detail in Appendix A.)

Although this database has some relevance to STP requirements, the Database Study Group does not recommend a secondary investigation of this source because it is limited in size. Copies of 
the Federal Technology Report can be examined to better determine the scope, completeness, and timeliness of this database.

\subsubsection{Government Research Centers Directory}

The Government Research Centers Directory is a database maintained by Gale Research Inc. (Detroit, Michigan). The directory contains information on approximately 4,000 U.S. and Canadian research centers. This directory includes contact information (e.g., names, telephone numbers, and addresses), geographic information, history, status, activities and programs, and publications.

Gale Research's primary product is a hard-copy directory. The database is updated annually and is available on diskette. This distribution includes interface and search software. Custom sets of raw data can also be obtained on diskette for a moderate price. For example, the user can purchase a subset containing only the publications data.

A license agreement restricts the data to internal use only, except for mailing labels. Because the primary market for this database appears to be industry representatives, the Database Study Group did not conduct a secondary investigation of this database.

\subsubsection{Federal Grants/Funding LOCATOR}

The Federal Grants/Funding LOCATOR is an electronic form of the federal publication Catalog of Federal Domestic Assistance. This catalog is published biannually, generally in November and July. The LOCATOR is updated soon after the catalog is available and contains only current data.

The Catalog of Federal Domestic Assistance is a directory of federal programs, projects, services, and activities that assist or benefit the American public. It contains data on financial and nonfinancial assistance programs administered by departments and establishments of the federal government. Data include the legal authority, administering office, funding, purpose, benefits, and beneficiaries for each program.

The LOCATOR is available in a DOS product on CD-ROM at minimal cost. This software is licensed, and the data can be accessed only through the provided interface. If it is determined at a later time that this database would be of interest, the diskette version would be easier to incorporate into a different interface. 


\subsection{AEROSPACE TECHNOLOGY SOURCES}

Aerospace technology often encompasses the latest advanced technological advancements in many areas of engineering, materials science, and related disciplines. Because of the importance of this specific technology, several databases from NASA and the American Institute of Aeronautics and Astronautics (AIAA) were included in this study.

\subsubsection{Aerospace Database}

The Aerospace database is maintained as a service of the AIAA. It is the electronic version of International Aerospace Abstracts, published by AIAA, plus additional references. Included are abstracts culled from the aerospace literature from 1962-present, with emphasis on aeronautics, space and planetary sciences, propulsion, rockets, commercial aircraft, airports, and related subjects. It also covers associated engineering fields, materials, chemistry, physics, medicine, geosciences, life sciences, mathematics, and computer sciences.

The Aerospace Database is available on-line through DIALOG (see Section 2.1). These on-line data are updated monthly. DIALOG also produces a CD-ROM version of the database, DIALOG OnDisc(R) Aerospace Database. This PC product has two search modes: Command Mode (the same search language used with DIALOG on-line) and Easy Menu Mode (an interface created for novice searchers). The currently available CD-ROM contains data for the current year in addition to the last four years. Prior years are available on CD-ROM at additional cost. The yearly fee for this version of the database includes an updated CD-ROM every three months. In addition, any documents referenced in the Aerospace Database are available in full on paper through AIAA's service Aeroplus Dispatch at minimal cost.

Because other aerospace databases cover a wider subject area, the Database Study Group did not conduct a secondary investigation of this database.

\subsubsection{Aerospace/Defense Markets \& Technology}

This commercial product is available from Information Access Company (Foster City, California). The Aerospace/Defense Markets \& Technology (A/DM\&T) database contains abstracts and the full text of more than 70 worldwide defense and aerospace publications. Sources include Armed Forces Journal International, ARMY, Jane's Intelligence Review (U.K.), Military Technology (Germany), Defense \& Aerospace Electronics, and Defense Daily, as well as DoD news releases. A/DM\&T also includes sources such as Air International, Air Transportation World, Aviation Week \& Space Technology, and Space News. In addition, the database includes relevant articles from 2,000 business and government sources, including DoD news releases on major defense contract awards. 
A/DM\&T topics include industrial products and technologies that apply to defense, such as chemicals, metals, plastics, electronics, computers, and telecommunications. Military topics covered in the database include weapons systems, government defense policies and goals, new orders and contracts, international military sales, defense market data, new business opportunities, and trends in military spending. A/DM\&T is available on-line from DIALOG, DataStar, European Space Agency (ESA), and M.A.I.D. at a moderate price.

\subsubsection{NASA COSMIC Software Catalog}

The Computer Software Management and Information Center (COSMIC) maintains a catalog of computer programs and software developed by NASA and its contractors. This software directory is accessible at no cost via the Internet or available in a DOS version on diskette. (Other access options also exist.)

The software referenced in the catalog covers a range of topics, including artificial intelligence, computational fluid dynamics, finite element structural analysis, scientific visualization, thermal and fluid flow analysis, and others. Between 900 and 1,000 software packages are included. Some of the software is available to U.S. government organizations only.

The COSMIC Annual Software Catalog is updated monthly. It is also included in the NASA Scientific and Technical Information (STI) database via NASA's RECON service (Section 2.4.4). Because this database is only marginally relevant to STP's needs, the Database Study Group did not conduct a secondary investigation.

\subsubsection{NASA Scientific and Technical Information Database}

The STI database is a bibliographic database consisting of more than 3 million records. Each year, 90,000 records are added. The database is divided into more than 20 "files" or topic areas. Each file covers different dates and is updated at various intervals. The records represent project records, journal articles, patents, reports, dissertations, and software. A variety of subjects are represented, with an emphasis on aerospace technology. Sources include NASA and its contractors, other government agencies, institutions, universities, and both foreign and domestic private firms.

Some of the files of potential interest are the COSMIC Annual Software Catalog; NASA Tech Briefs (includes unclassified articles on technical innovations that originate from nine NASA centers; covers 1963-present; is updated monthly); Research and Development Contract Search (includes information about R\&D contracts, grants, and work orders; covers 1979-present; is updated monthly); and Scientific and Technical Aerospace Reports (STAR) (includes references to 
unclassified documents announced in the published STAR that have significant and current value to the NASA communities; covers 1968-present; is updated weekly).

The STI database is available on-line through NASA's REsearch CONnection (RECON). It is inexpensive when compared with other on-line services. A demonstration with limited data (1990-1992) is available via the Internet. The Database Study Group examined this Internet demonstration during the secondary investigation of this database.

\subsection{GENERAL TECHNOLOGY SOURCES}

Scientific and engineering journals contain a wealth of information on current technological research and trends. The databases discussed in this section contain references to research being performed through universities, professional organizations, and other societies. Although this work may contain more detailed technical specifics than the sponsor needs for preliminary searches, these databases may have a role in later stages of the search process.

\subsubsection{Cambridge Scientific Abstracts}

Cambridge Scientific Abstracts (CSA) offers a wide range of abstract and bibliographic services in 25 databases covering environmental, aquatic, and biomedical sciences; engineering; materials and computer sciences; and market résearch. Complete on-line databases can be accessed on the Internet via several third parties such as DIALOG or the Research Libraries Group, Inc. (RLG). Discipline-specific subsets of these databases are available in electronic media, such as CD-ROM, magnetic tape, and on-line. Some of the databases will be available directly through CSA's Internet services later in 1994. CSA databases contain summaries of scientific, technical, or market research, together with information to obtain the full articles or reports. The databases vary in size, depending on the discipline and the number of years of coverage.

CitaDel is the full-service citation and document-delivery service from RLG. One search interface is available for all CitaDel files - Eureka, RLG's patron-oriented search service. The Eureka connection is through the Internet, SprintNet, or a direct-dial line. Eureka streamlines searching of RLG's on-line resources. Data on other media (e.g., magnetic tape, CD-ROMs) are subsets of the complete databases on RLG systems, generated to support specific markets. CSA's Internet Journal Service provides users with Internet access to an electronic file corresponding to a journal subscription.

CSA is open to customizing specific abstracts and to making them available for file transfer protocol (FTP) access or on other media. Magnetic nine-track tapes or digital audio tapes (DATs) are probably the most straightforward to handle; software can be easily written to access databases 
on these files. CSA's standard CD-ROMs use Silver-Platter retrieval software. The largest databases are available on a number of on-line services (such as DIALOG), and several database subsets are available on a variety of media (CD-ROM, Internet, magnetic tape, and DATs). CSA works with Engineering Information, Inc. $(\mathrm{Ei})$, to provide document delivery services.

Mechanical Engineering Abstracts is published jointly with Engineering Information. This abstract journal surveys and summarizes worldwide literature in mechanical engineering, engineering management, and production engineering. Topics covered in this journal include operations research; production development, management, and control; tribology; civil and structural engineering; military engineering; transportation engineering; energy and power; robotics; computer-aided design/computer-aided manufacturing; computer-integrated manufacturing/computer-aided engineering; and fluid mechanics. The journal reports on key developments published in journals, articles, books, patents, dissertations, and conference papers. These abstracts currently number 260,000 , date from 1973, and are updated monthly.

The Ei/CSA Computer \& Information Systems database covers computer science and information management. This database summarizes international theoretical research and practical application in software, artificial intelligence, automation, equipment manufacturing and design, system security, robotics, and logic and switching theory. The database covers all the journals scanned for Computer \& Information Systems. It includes 861 primary sources and 2,500 secondary sources, with approximately 175,000 records.

The Ei/CSA Electronics \& Communications database examines electronic systems, electronic physics, electronic circuits, electronic devices, communications, and optical engineering. Topics covered by this database include scientific, industrial, and engineering applications; semiconductors, supercondüctors, and lasers; biomedical engineering; and promising communications technologies. It includes 600 primary sources and 2,500 secondary sources, with about 106,000 records.

The Ei/CSA Solid State/Superconductivity database has covered solid-state technology since 1960. This database includes information on solid-state materials and devices as well as on new high- and low-temperature superconductivity technology. Updated bimonthly, this database includes 544 primary sources and 2,500 secondary sources, with about 100,000 records.

Because of the breadth of information covered in these databases, the Database Study Group performed a secondary investigation of CSA. 


\subsubsection{Civil Engineering Database}

The Civil Engineering DataBase (CEDB) is an on-line service that covers worldwide literature on civil engineering, including aerospace; air transport; codes and standards; cold regions; computer practices; construction; energy; forensic engineering; earthquake, environmental, geotechnical, and structural engineering; waterway, port, coastal, and ocean engineering; education; engineering mechanics; highways; hydraulics; irrigation and drainage; materials; pipelines; surveying; urban planning and development; materials; surveying and mapping; and water resources. It provides about 50,000 citations, with abstracts, to worldwide publications, including all American Society of Civil Engineers' publications: 22 journals, about 50 books per year, and conference proceedings. The Scientific \& Technical Information Network (STN) system contains about 170 databases, including this CEDB. A not-for-profit system, STN was founded by three organizations: Chemical Abstract Service, a German company, and the Japanese Information Center. The intent was to have less expensive access to bibliographic and database information.

\subsubsection{Engineering Information, Inc.}

Compendex*Plus contains 2.8 million citations, with abstracts, from more than 4,500 international journals, reports, books, and conference proceedings that cover mechanical, civil, environmental, electrical, structural, and process engineering, materials science, solid-state and superconductivity, bioengineering, energy, chemistry, optics, air and water pollution, solid waste management, hazardous waste, road transportation, and transportation safety. In addition to applied engineering, Compendex*Plus also covers manufacturing, quality control, and engineering management. Seven specialty CD-ROM disks have been derived from this master database in the following fields: chemical engineering, civil engineering, mechanical engineering, advanced materials, manufacturing, energy/environment, and computer/electrical/electronic engineering. The advanced materials disk covers international research, focusing on nonmetallic engineered materials, including polymers and plastics; ceramics and refractories; wood products, such as paper, textiles, and fibers; rubbers and elastomers; and composites intended for use in design, construction, and operation of structures, equipment, and systems.

The Ei Page One product is a table of contents disk that references Compendex*Plus. It does not include the abstracts found in Compendex*Plus. It contains more than 300,000 citations taken from tables of contents each year and is updated every two months. It claims to be the world's largest engineering citations database with fixed-price searching. The Concise Engineering and Technology Index contains 125,000 citations, with abstracts, to 425 very specific technical titles used mainly by engineers at universities. It is a subset of Compendex*Plus and is available on either CD-ROM or on-line. The Ei Reference Desk is an all-inclusive searching and document delivery system. 
CD-ROMs are updated quarterly and are available from 1985 onward. Single-unit disks are $\$ 3,450$ for one year ( $\$ 5,420$ for complete data), with specialty disks ranging from $\$ 3,850$ to $\$ 1,295$. All CD-ROMs are available for a three-day free trial. ANL-West has at least one disk. About 13,000 records are added weekly to the on-line system, starting from 1970, and are available from a number of commercial vendors for typical fees.

\subsubsection{Global Mobility Database}

The Global Mobility database contains citations with abstracts to technical papers from Society of Automotive Engineers (SAE) meetings and conferences, as well as SAE books on automotive, aerospace technology, and vehicular-related industries. Information included in this database concerns such topics as vehicle design, manufacturing, materials, fuels and lubricants, testing, aerodynamics, brakes, control systems, electronics, batteries, composites, and related technology. The data are updated monthly and are available in multiple media formats, including magnetic tape, CD-ROM, and on-line services. The fees for these data are moderate to high.

Although this database contains some areas of technology that may be of particular interest to the sponsor, it is limited in scope to automotive engineering. For this reason, the Database Study Group did not conduct a secondary investigation of this database.

\subsubsection{H.W. Wilson Databases}

H.W. Wilson's Wilson Applied Science \& Technology Abstracts contains citations with abstracts provided by various product reviews, conferences, and seminars. In bibliographic form, specific areas covered include aeronautics and space science, chemistry, computer technology, construction, data processing, energy, engineering, the environment, fire prevention, food, machinery, marine technology and oceanography, mathematics, metallurgy, meteorology, mineralogy, optics, petroleum and gas, physics, robotics, solid-state technology, telecommunications, textiles, transportation, water, and waste. Created in 1993, this database is accessible by CD-ROM, magnetic tape, and on-line services through $\mathrm{H}$.W. Wilson.

H.W. Wilson's Applied Science \& Technology Index contains citations to articles, book reviews, interviews, new product reviews, and selected editorials and letters to the editors of 390 English-language publications in science and technology. In bibliographic form, it includes citations on aeronautics and space science, chemistry, computer technology, construction, data processing, energy, engineering, the environment, fire prevention, food, geology, machinery, marine technology and oceanography, mathematics, metallurgy, meteorology, mineralogy, optics, petroleum and gas, gas physics, robotics, solid-state technology, telecommunications, textiles, transportation, water, and waste. This database originated in 1983. 
These databases cover many areas of technology research. Therefore, the Database Study Group conducted a secondary investigation of these products to obtain additional information.

\subsubsection{Institute for Scientific Information}

The Institute for Scientific Information's SciSearch database provides bibliographic data with citations from an international source of information in science and technology. This database covers the natural, physical, earth, environmental, biomedical, and life sciences. Specific fields include chemistry, agriculture, clinical medicine, engineering, technology and applied sciences, and computer and information sciences. This product is offered on magnetic tape and dates back to 1972.

The Institute for Scientific Information also offers a database titled Current Contents on Diskette/Engineering Technology \& Applied Sciences. This database lists articles from many journals in engineering, the applied sciences, and technology. In bibliographic form, it covers such areas as aerospace, chemical, electrical, environmental, marine, mechanical, nuclear, and petroleum engineering; metallurgy; optics; acoustics; computer science; electronics; laser science; operations research; polymer science; robotics; telecommunications; and transportation technology. The database is offered on diskette.

Another bibliographic database offered by the Institute for Scientific Information is the Current Contents Search database. It provides abstracts for various articles listed in the tables of contents in many journals. The main areas covered in bibliographic form include life sciences; clinical medicine; arts and humanities; engineering, technology, and applied sciences; agricultural, biological, and environmental sciences; and physical, chemical, and earth sciences. The database is available on magnetic tape and through on-line services.

Although these databases cover a broad area of information, they do not cover many years. As a result, the Database Study Group did not conduct a secondary investigation of them.

\subsubsection{Institute of Electrical and Electronics Engineers}

Several products are available from the Institute of Electrical and Electronics Engineers (IEEE). Their IEEE Publications OnDisc (IPO) contains scanned images of the full text of all (U.S.) IEEE and (U.K.) IEE journals, conference papers, and standards, totaling 80 journal titles from 1988-present. These publications are on CD-ROM. An index contains bibliographic and indexing records (relevant records from IEEE's INSPEC database). Records are added both monthly and annually. Subject areas include physics, electronics, electrical engineering, computer science, and control technology. An annual subscription to IPO ranges from $\$ 17,000$ to $\$ 30,000$. University Microfilms, Inc., offers a 60-day free trial of its CD-ROMs. 
IEEE's on-line INSPEC database is an electronic version of three printed publications: Physics Abstracts, Electrical and Electronics Abstracts, and Computer and Control Abstracts. The database is available on-line from a number of vendors, on magnetic tape, or on CD-ROM (as INSPEC OnDisc). This database provides indexing and abstracts for journals, conferences, books, reports, and dissertations in all areas of physics, electrical engineering and electronics, computing and control technology, and information technology. It is updated weekly on-line and monthly on magnetic tape and dates back to 1969. This database contains records for more than 4.5 million scientific and technical papers, and 280,000 records are added annually. These publications reference more than 4,200 journals and about 2,000 published conference proceedings, as well as numerous books, reports, and dissertations. A complete CD-ROM database costs $\$ 27,600$; specific subsets of data range from $\$ 4,400$ to $\$ 22,000$. On-line services incur typical charges.

Because of the high cost and narrow range of these products, the Database Study Group did not recommend a secondary investigation at this time.

\subsubsection{Jane's Information Group}

Jane's Information Group has a series of well-known manuals on military equipment. The content of these manuals includes defense, weaponry, civil aviation, and transportation information. Many of these manuals are available on CD-ROM, and many contain images as well as full text descriptions and inventory information. These $C D$ are available as moderately priced single $C D s$ or as volumes of related CDs. Currently, Jane's offers more than a dozen CD titles.

The electronic databases offered by Jane's include:

- Jane's Battlefield Surveillance Systems,

- Jane's C3I Systems,

- Jane's Defense Magazine Library, and

- Jane's Fighting Ships.

These CDs can be purchased in either production versions, including search software, or raw ASCII formats. Argonne is using several of these CDs on other projects, and they would be available for further investigations. The Database Study Group conducted a secondary investigation of this data source to determine the cost of automating an interface to these databases. 


\section{SECONDARY INVESTIGATIONS}

More detailed investigations were performed on several of the databases identified as a result of the preliminary investigations

\subsection{U.S. PATENT AND TRADEMARK OFFICE}

The PTO has an interest in making patent information available as widely and quickly as possible. In the past, PTO maintained a library and enabled intermediaries, such as MicroPatent, to develop database products. The PTO now has developed several services for more direct public access, and more are planned for the future. These services are:

- A bulletin board that includes new patent information,

- An electronic information center (estimated to be available in the next two years),

- An Internet server for the full text of all patents, and

- USA-PAT (January 1994-present), two to three CDs per week.

The Internet server was accessed for this study; the CD version was not.

\subsubsection{Data Description}

USA-PAT contains full-page images (text and diagrams) of all new patents since January 1994. The CD-ROM-based data (USA-PAT) are stored in a compressed graphic nonproprietary format, similar to scanned images.

The Internet server contains data in a standard text format. This data set has no significant restrictions on its use. The sample obtained through the gopher server contained extensive reference data in text format. Although this structure is not accessible as a relational database, it appears to be designed so that it can be incorporated into third-party databases.

These records contain the following types of information:

- Patent bibliographic information (14 fields), 
- Inventor information (name, city, state),

- Assignee information (name, city, state, type code),

- Classification (original U.S., cross-reference, international classification, field of search class, field of search subclass), and

- U.S. patent reference data for all referenced patents (number, date, patentee name, classification).

Other identified Internet resources for patent information include an Internet patent newsletter that describes interesting new patents and is put out by a one-person shop (at the E-mail address srctran@world.std.com) and two Usenet groups featuring news about patent-related issues (at the addresses misc.legal.computing and misc.int_property).

\subsubsection{Interface Mechanisms}

The interface used for the CD-ROM product is simple; it has not been investigated in detail.

The interface used for on-line queries depends on the user's platform for running gopher or MOSAIC. In general, it is a standard text menu system that can be accessed by any VT100-compatible display. Because the interface takes character streams as input, automated links are feasible.

\subsubsection{Query Format}

According to the PTO, USA-PAT is in a graphic format and is currently searchable only by patent number. This limitation restricts the use of this database to the later stages of patent searching.

The gopher server can be queried by keywords without Boolean functions. An on-line search for Battery, Lithium yielded a list of 39 patents with patent numbers. The results of this search and an abridged version of one of the records it yielded are included in Appendix B.

\subsubsection{Integration into TIMS}

Neither of these two database formats has restrictions on data. An automated link to the interface should be straightforward to construct. This interface would be useful in identifying 
potential patents for further investigation. One concern with the on-line service is the time needed to download a patent.

One viable approach for performing initial searches would be to use the Internet search mechanism or a patent search program available from an independent source. One of the on-line services could provide access to patents not yet on disk, although frequent updates of the disks should usually make this unnecessary. $C D$ products would provide the fastest general searching. After candidate patents are identified, an image-based product could be used to get a full patent. USA-PAT may be a quick, cost-effective way to get a full set of patent information after a particular patent number has been identified.

\subsection{US PATENTSEARCH}

MicroPatent (East Haven, Connecticut), an information company specializing in patent information, markets a broad line of self-contained products and services relating to patents. It also runs a free electronic bulletin board with news on patents. The coverage is complete, for all practical purposes. Most of its products and services are relatively inexpensive. The "user-friendliness" of its

products is limited because standard DOS interfaces are used. The primary focus of this secondary investigation is on one of MicroPatent's products - US PatentSearch.

\subsubsection{Data Description}

Front-page patent data may be sufficient for some users; others find such data detailed enough to determine whether the full text or image would be needed.

US PatentSearch provides front-page bibliographic information and 18 search fields, including keyword-searchable abstracts and exemplary claims for the current year. It contains back files to 1974. The records contain extensive reference information to related materials and other databases. The fields offered are patent number, issue date, application number/date, title/abstract/claim, inventors, assignee, state, U.S. class, international patent class, U.S. references, foreign references, other references, PCT data, related data, primary examiner, agent, priority, and status.

US FullText provides the complete text of patents (without pictures) and 18 search fields. It contains keyword-searchable text, as well as fields for title, abstract, background summary, description, and claims information.

US PatentImages contains the complete text and drawings of utility patents, ready for laser printing. It provides 12 search fields, including keyword-searchable abstracts. 
Other services include PatentQuery, Patent Bulletin (bulletin of new patents), PatentCopies, PhoneSearch (a means of getting patent information mailed through a telephone call rather than on-line); PatentBible (a proprietary set of database search tools), and ESCAPE ACCESS (European and PCT international patent applications).

The data on the disks are compressed and encrypted by using the CD-Author package manufactured by Dataware Inc. (Cambridge, Massachusetts). The precise format of these data is unknown, since it is proprietary to Dataware.

\subsubsection{Interface Mechanisms}

This section discusses the US PatentSearch interface in particular because it was the most likely candidate product. Information in this section was derived through the use of a demonstration disk. US PatentSearch is designed to be more easily and powerfully queried than the other MicroPatent products.

The standard interface is typical of Dataware products. It is DOS-based with a simple menu driven by arrow keys, not by a mouse. The user screen contains fields that could be queried independently. The interface has standard features. Users can browse the index, display partial or full records, perform queries, or access other databases, if available and compatible.

\subsubsection{Query Format}

In US PatentSearch, queries are performed by using the menu. Criteria, such as keywords, patent number, and names, can be entered in each of 16 fields. Search strategies can be saved in Dataware query files and reloaded for future use. Query tools include standard Boolean features within fields and across fields (AND, NOT, OR) as well as nesting. Output from queries can be printed directly or downloaded to a file.

Appendix B includes a sample query of this database. US PatentSearch was queried for patents containing Lithium and Battery. An approximate 10- to 15-second search yielded a list of 48 patents, sorted by patent number and followed by the records for those patents.

\subsubsection{Integration into TIMS}

To build an interface to US PatentSearch data, an agreement with Dataware will be necessary, as will one with Micropatent. Currently, it may be necessary to use Dataware developer products to access the data for use within the TIMS structure. Many other CD-ROM, database 
products (such as Dialog-on-Disk) are in the same format. This approach could be costly if only one product in the Dataware format is used. (Dataware development packages cost approximately $\$ 25,000$.)

For some applications, US PatentSearch data would probably have to be supplemented by a richer database containing full text and images. Options include services provided by Micropatent, disks from the patent office, and products from other providers identified in the primary investigation.

\subsection{DEFENSE TECHNICAL INFORMATION CENTER}

The DTIC is the central point of technical information distribution within DoD. The Center has multiple sites across the country to support users in DoD and other government agencies.

DTIC holdings include technical reports, management information summaries at the work-unit level, independent R\&D efforts, and special collections. Its collection includes areas associated with DoD research, such as aeronautics, missile technology, space technology, navigation, and nuclear science. In addition, DTIC's collection includes other subjects that reflect DoD's interests, such as biology, chemistry, energy, environmental sciences, oceanography, computer sciences, sociology, and human factors engineering.

Three primary databases are available: the TR bibliographic database, the research and technology (R\&T) WUIS database, and the IR\&D database. A separate DTIC MATRIS office manages the MATRIS database.

\subsubsection{Data Description}

The TR database contains unclassified bibliographic citations and abstracts. The records are from print and nonprint technical reports and products submitted to DTIC, associated with completed research. The raw data format of the TR database is not known. It is handled internally and is obtained through DTIC's on-line system command output.

The WUIS database contains management information summaries that reflect ongoing DoD and NASA R\&T efforts at the work-unit level. The records include information about what, where, when, and how research is conducted, and who is conducting the research, at what costs, and under what sponsorship. 
The IR\&D database contains reports of independent $R \& D$ initiated and performed by DoD contractors but not wholly funded by DoD. Only DoD personnel with classified access can access this database.

The MATRIS database contains more than 5,600 summaries of defense-related projects in the area of human resources management. This database covers the areas of education and training, human factors engineering, personpower, and simulation systems. Project histories, contacts, budgets, and summaries are included.

\subsubsection{Interface Mechanisms}

The actual TR database could not be tested without registering as a DTIC user and purchasing a DTIC TR product (the on-line connection or a CD-ROM). DTIC did supply a presentation-style instructional demo on floppy disk. This secondary investigation concentrated on the information extracted from this demo, focusing on the on-line unclassified dial-up service. (Both classified access and unclassified dedicated terminal access require special hardware.)

The demo explained how to use the Defense Research, Development, Test, and Evaluation On-line System (DROLS) to access the TR database (as well as the WUIS and IR\&D databases). The demo did not show what the DROLS interface looks like but did indicate how it feels. It is text-based and accessible only by modem. The commands are cryptic, but few DROLS can be used to interactively search the three DTIC databases and to order copies of documents.

Signing on to DROLS is a complicated process, partially because an additional telecommunication connection is required; access is routed through Tymnet. Several user inputs beyond a simple log-in and passwords are required.

Signing off of DROLS is a somewhat easier process. When the user exits DROLS, a termination message is displayed, containing the current date, the time the user connected to DROLS, and the time the user disconnected from DROLS. An example is shown below. (The first set of numbers gives the date; the second set gives the connect and disconnect times, respectively.)

$010191084522-103030$

Operators must maintain a log of all dates and times DROLS was accessed and should also include user names. 


\subsubsection{Query Format}

A DROLS query uses the following search rules:

- All search commands must be preceded and followed by a "@”.

- Search terms and phrases are limited to 60 characters.

- Dial-up users can use no more than 220 terms in any search.

- All searches have a nine-level limit.

- Search output is limited to 25,000 finds.

- Any search requires a three-minute processing time limit.

- Each search must end with the terminator "END".

Searching the TR database requires the use of the @STR@ command. It recognizes the AND and NOT Boolean operators, and the OR Boolean operator is implied between multiple terms not separated by AND or NOT. If the NOT operator is used, it must be on the last level of the search command (just before "END"). An example is given below.

@STR@

INFRARED OPTICS // OR is implied between

INFRARED EQUIPMENT // these two terms

AND

LASERS

NOT

LASER WEAPONS

END

The@STR@ command can search a record's subject, title, personal author, report data, report number, contract numbers, or corporate author. Three options can be used with the @STR@ 
command: hierarchy, truncation, and weighted term. The hierarchy option allows the search to include all narrower terms automatically. For example,

@STR@

\$TROPICAL DISEASES

END

expands the term TROPICAL DISEASES and also searches for specific tropical diseases. The truncation option allows the search to include terms that have the truncated term as a substring. For example,

\section{@STR@}

\%gastro

END

also searches for terms such as "gastrock" and "gastroenteritis." The weighted term option limits the search to output only those items in which the term is a primary subject.

The @DSR@ command is used to display one of the items identified in the search. All or part of a record's contents can be displayed, depending on the display format used. The predefined formats are listed below:

- $1 \mathrm{~F}$ Complete record;

- 2F Cataloging data and index terms;

- 3F Classification of abstract, title, report, descriptors and identifiers, IAC fields;

- 4F Corporate author, report classification, limitations, IAC fields;

- 6F Unclassified title, index terms, abstract; and

- 7F Cataloging data, limitations, change authority (custom display formats can be designed). 
Dial-up connections have two display modes: "item by item" and "continuous," designated by " $Y$ " and "C," respectively. The display mode is specified after the "END"; for example,

\section{@DSR@}

$1 F$

END

$\mathrm{Y}$

An actual sample query could not be performed for the TR database as part of this study.

\subsubsection{Integration into TIMS}

It should be possible to connect to DROLS with a modem and send and receive the characters necessary to perform search queries. The sign-on, search, and sign-off procedures could be coded into the TIMS, and the search commands could recognize the basic Boolean operators.

TIMS could use a modem for unclassified dial-up access to the TR database through DROLS. To do this, the user must register with DTIC, submit a certification application to the Defense Logistics Services Center, establish a deposit account at NTIS, complete a DROLS application, and provide a list of terminal operators who will access TR.

DROLS registration requires a $\$ 100$ annual fee and a $\$ 40$-per-hour connect charge for dial-up access. An initial $\$ 100$ is required to set up an NTIS deposit account; thereafter, the user is billed on a monthly basis for actual costs incurred.

\subsection{NASA SCIENTIFIC AND TECHNICAL INFORMATION DATABASE}

NASA's STI database consists of more than 3 million records, and 90,000 are being added annually. The database is divided into more than 20 "files" or topics. Each file has different coverage dates and update frequency. The records represent project records, journal articles, patents, reports, dissertations, and software. A variety of subjects are represented, with an emphasis on aerospace technology. Sources include NASA, NASA contractors, other government agencies, institutions, universities, and both foreign and domestic private firms. 
Some of the files of potential interest are the COSMIC Annual Software Catalog, NASA Tech Briefs, Research and Development Contract Search, and Scientific and Technical Aerospace Reports.

The STI database is available on-line through RECON. An Internet demo of NASA RECON is also available, but it includes a limited portion of the STI database (1990-1992). This demo is the main subject of this investigation.

\subsubsection{Data Description}

The STI database, both on the full NASA RECON and the Internet demo, is a bibliographic database that contains citations with abstracts to published reports, journal articles, conference papers, project records, patents, and dissertations.

The raw data are not accessible through the demo; the information that can be obtained is processed by a WAIS client and a gopher client. These Internet tools control the searching and display processes and are discussed in more detail below.

\subsubsection{Interface Mechanisms}

The Internet NASA RECON demo is implemented as a WAIS keyword search on the gopher server "gopher.sti.nasa.gov." It can be accessed through a gopher client that runs on a machine with an Internet connection. This machine can be accessed via a modem.

The gopher client (gopher) is a text-based program that emulates a terminal and displays information in a menu format. The WAIS keyword search is handled by the WAIS client (WAIS) software and is accessible as a menu option through gopher.

Gopher provides the user interface and is rather limited because it is text-based. Only a few basic command options are displayed at the bottom of the window; others must be memorized or written. Commands are provided for selecting among gopher's menu options and viewing and downloading currently selected items.

\subsubsection{Query Format}

A WAIS keyword search can be performed, but it does not contain Boolean operator recognition. Multiple search terms are treated as if an "OR" operator separates them. The WAIS keyword search also uses a weighting scheme to determine the order of the records returned. The 
number of records returned is truncated, usually to 30 , with the last record being a query report. It is believed that this version of WAIS, rather than gopher or the RECON demo, is causing the truncation.

The query lithium and battery was entered as a WAIS keyword search. The query report generated by the WAIS search is listed in Appendix B. It shows that "AND" was treated as just another search term (the same search results were obtained with lithium or battery and lithium not battery queries). Appendix B also contains a list of records that gopher returned along with the first record in the returned list.

\subsubsection{Integration into TIMS}

It should be possible to connect to a gopher client that runs on a machine connected to the Internet via modem. Because the gopher client program is text-based, it should be possible to send and receive the characters necessary to perform search queries. The log-in, search, and log-out procedures could be coded into the TIMS. One problem involves the Boolean operators; because they are not recognized, their functionality may somehow have to be reproduced in the TIMS code. One possible approach would be to perform multiple searches. Further, the TIMS code may not be able to change the number-of-records limit encountered in the RECON demo.

TIMS could use a modem to access a gopher client running on a machine connected to the Internet. It may also be possible to use a WAIS client that runs on a machine connected to the Internet, thereby bypassing gopher to directly access the demo database. The latter option may allow more control over the search, but such control depends on how the demo has been set up.

The gopher client and the Internet can be used at no cost, but any costs related to having a machine connected to the Internet may need to be considered. An interface could be developed for the portion of the STI database accessible through the NASA RECON Internet demo at a reasonable cost.

\subsection{CAMBRIDGE SCIENTIFIC ABSTRACTS}

Cambridge Scientific Abstracts offers more than 25 databases that cover environmental sciences, biomedical sciences, aquatic sciences, engineering, materials and computer sciences, and market research. Complete on-line databases can be accessed on the Internet via several third parties, such as DIALOG Information Services or the RLG. Discipline-specific subsets of these databases are available in various electronic media, such as CD-ROM, magnetic tape, and on-line. Some of the databases are available directly through CSA's Internet services. 


\subsubsection{Data Description}

CSA databases contain summaries of scientific, technical, or market research, together with full-source information to obtain the full articles or reports. The databases vary in size depending on the discipline and number of years of coverage. For example, 10 years of the primary database Environmental Sciences and Pollution Management has more than 600,000 records, whereas the more specialized database Safety Sciences \& Risk Assessment has 190,000 records. The average CSA record has 1,600 characters.

CSA contains data on a wide range of media in a variety of formats (some accessible through the use of proprietary search software, others in plain ASCII text files) for several different platforms. This variety of formats makes it very easy to customize CSA data for use in TIMS.

Access to CSA is limited to the contracting person (or organization) only. Data cannot be distributed, sold, commercially exploited, or transferred to others.

\subsubsection{Interface Mechanisms}

CSA's standard CD-ROMs use Silver-Platter retrieval software. CSA's Internet "remoteaccess" WAIS interface provides format-independent access to data. Its Internet Journal Service allows access to an electronic file that contains the current-year journal contents and five years of back issues.

CitaDel is the full-service citation and document-delivery service from RLG. Eureka, RLG's patron-oriented search service, is the one search interface for all CitaDel files. A user can connect to Eureka through the Internet, SprintNet, or direct-dial line. Eureka streamlines searching of RLG's on-line resources. It gives users straightforward access to a wide variety of on-line information, including the Research Libraries Information Network (RLIN) bibliographic database of library, archives, and museum library holdings and the CitaDel article-citation and documentdelivery service. Eureka uses a common-command language and allows users to download results so that they can create bibliographies on their PCs. It is accessible from any terminal or PC that uses VT100 emulation. Data on other media (magnetic tape, CD-ROMs) are subsets of the complete databases on RLG systems, generated to support specific markets.

CSA's Internet Journal Service provides users with Internet access to an electronic file corresponding to a journal subscription. The electronic contains up-to-date contents of the journal (updated even before the print version of the journal goes to press), as well as five years of backfile data. It allows a user to search for keywords and specific topics through five years of journal contents and to download citations and abstracts. 
CSA is open to customizing specific abstracts and to making them available for FTP access or on other media of choice. Magentic nine-track tapes or DATs are probably simplest to handle; software can be easily written to access databases on these files. CSA's standard CD-ROMs use Silver-Platter retrieval software. Some services are available on DIALOG Information Services.

The Internet Journal Service (see comments below) requires Transport Control Protocol/Interface Program and WAIS client software. MOSAIC support is being planned. MS Windows 3.1 and the Winsocket Library (winsock.dll) are required.

CSA's abstracts can be accessed in many ways. Some interface methods may be faster, more efficient, or less expensive than others. The trade-offs among these access methods should be evaluated.

\subsubsection{Query Format}

This section describes access methods available to CSA's Internet Journal Service by using WAIS in MS Windows. It illustrates (1) the flexibility of the query mechanisms available through the use of CSA software and (2) mechanisms that would be possible by using customized TIMS software. Searchable fields are:

$\begin{array}{llll}\text { abstract } & \text { accession number } & \text { author } & \text { author affiliation } \\ \text { classification code } & \text { conference } & \text { corporate author } & \text { descriptors } \\ \text { environmental regime } & \text { identifiers } & \text { ISBN } & \text { ISSN } \\ \text { language } & \text { notes } & \text { original title } & \text { other number } \\ \text { publication type } & \text { publication year } & \text { publisher } & \text { source } \\ \text { subfile name } & \text { summary language } & \text { title } & \text { Transaction Input } \\ & & & \text { Center Number }\end{array}$

Users can mix and match fields by using Boolean operators. These operators must be input in uppercase letters to distinguish them from keywords. In a search, the WAIS software provided by CSA searches all documents relevant to the query, ranks them, and provides only the top 100 . Other WAIS clients (not provided by CSA) may have different maximum values.

Phase or proximity searching is available, as are searches by root word.

The search $a b=$ battery $A N D$ ab=lithium $A N D$ ( $p y=1993$ OR $p y=1994$ ) retrieves documents with abstracts containing the word battery and the word lithium and with a publication year of either 1993 or 1994. 
The search lithium ADJ battery retrieves lithium followed by battery within eight characters of lithium.

The search batter* retrieves words with a common root, in this case battery and batteries.

\subsubsection{Integration into TIMS}

The graphic interface available with the standard WAIS access to CSA's Internet Journal Service would be difficult to incorporate into TIMS. Automating title and document downloads is possible (or at least most straightforward) only if the user interface is text-based. The availability of CSA's data and CAS's willingness to provide data in various formats on various media make these abstracts very good candidates to include in TIMS. The most flexible way to incorporate CSA databases into TIMS, which would provide users with very quick response times, would be either via regular updates on magnetic tapes or via regular Internet downloads. The sample data provided by CSA contain a file with many fields, delimited by codes that make it simple to identify fields (see example in Appendix B).

It is recommended that an interface be developed for portions of CSA's databases. Access to these data would probably be most flexible if magnetic tapes were used or if up-to-date, on-line access were available so that all relevant files could be downloaded and then searched by TIMS software.

\subsection{H.W. WILSON DATABASES}

The H.W. Wilson Company markets a wide range of electronic information products in a variety of formats. Wilson is similar to the DIALOG company. Of particular interest are its science and technology products.

H.W. Wilson's Wilson Applied Science \& Technology Abstracts contains citations with abstracts provided by various product reviews, conferences, and seminars. Specific areas covered in bibliographic form include aeronautics and space science, chemistry, computer technology, construction, data processing, energy, engineering, the environment, fire prevention, food, machinery, marine technology and oceanography, mathematics, metallurgy, meteorology, mineralogy, optics, petroleum and gas, physics, robotics, solid-state technology, telecommunications, textiles, transportation, water, and waste. This database originated in 1993 and is accessible by CD-ROM, magnetic tape, and on-line services through H.W. Wilson.

H.W. Wilson's Applied Science \& Technology Index contains citations to articles, book reviews, interviews, new product reviews, and selected editorials and letters to the editors of 
390 English-language publications in the fields of science and technology. Specific areas covered in bibliographic form include aeronautics and space science, chemistry, computer technology, construction, data processing, energy, engineering, the environment, fire prevention, food, geology, machinery, marine technology and oceanography, mathematics, metallurgy, meteorology, mineralogy, optics, petroleum and gas, gas physics, robotics, solid-state technology, telecommunications, textiles, transportation, water, and waste. This database originated in 1983.

\subsubsection{Data Description}

The citations contain searchable bibliographic data.(e.g., author, journal, date). The abstracts are approximately 50-100 words in length. Disks are issued every two weeks, and the most recent data can be accessed on-line. Abstracts for approximately the last year are on the current disk.

Information on WilsonDisc is compressed through a proprietary system. However, Wilson also offers data on tapes and will customize the format. This option would be good for a full TIMS.

\subsubsection{Interface Mechanisms}

This section discusses the interface for WilsonDisc. On-line services offered by H.W. Wilson are not discussed; however, those services can be accessed through the same interface or through third parties. Magnetic tape would contain the same data.

The interface for WilsonDisc is a traditional DOS-based menu system. The user navigates the interface by means of arrow keys and a small menu and selects a search mode: single or multiple subjects, on disk or on-line. The user types query parameters on one line for each subject and selects the form in which query results are displayed. Displayed results range from summary statistics (e.g., 10 records found), to a list of the search results, to a list of the complete abstracts for all hits.

Within the default interface, it is possible to search and/or browse the database, save search parameters to a file, and print search results or download them to a file.

\subsubsection{Query Format}

This section describes the queries supported by WilsonDisc. WilsonDisc contains the following query features:

- Browsing features that allow users to look at a record related or close to those identified in a search (i.e., get, find, neighbor, expand, up, down). 
- Relation descriptors that facilitate more powerful searches: Use (substitute word), Used for (substitute word), BT (broader than), NT (narrower than), and RT (related to).

- Standard Boolean features: AND, OR, NOT, as well as nesting with parentheses.

- Standard String functions, such as wildcard characters and truncation.

In addition to text, records contain fields for author, basic index, corporate name author, corporate name subject, description string, full periodical title abbreviation, language, personal name subject, subject heading, title, and year. Searches can be limited to any of these fields. For example, a search for lithium limited to title only would not identify all articles by National Lithium Corporation employees.

WilsonDisc can be used to access Wilson's on-line services when data are not available on disk, either because the data are too new or because the user has not purchased the disks that contain the desired data.

A sample query was performed on WilsonDisc and is included in Appendix B. The query for Lithium and Battery produced 33 records under lithium batteries, as well as several hundred records under related topics. The query took approximately 15 seconds.

When the lithium batteries line is selected, it expands to a list of 33 citations. The first two citations (one of which has an abstract) are shown in Appendix B.

\subsubsection{Integration into TIMS}

The data on these Wilson products can be obtained on tape in a format customized for the desired interface. According to the provider, libraries have used this approach. Tape data could be installed on a hard drive. If this approach is used, maintenance will be necessary to ensure that current data are available. It is also possible that Wilson would allow users to press their own CDs of their data for internal use.

\subsection{JANE'S INFORMATION GROUP}

Jane's Information Group has a series of well-known manuals on military equipment. These manuals include defense, weaponry, civil aviation, and transportation information. Currently, Jane's offers more than a dozen $\mathrm{CD}$ titles. 
The electronic databases offered by Jane's include:

- Jane's Battlefield Surveillance Systems,

- Jane's C3I Systems,

- Jane's Defense Magazine Library, and

- Jane's Fighting Ships.

\subsubsection{Data Description}

Jane's has many military manuals available on CD-ROM. Many contain images as well as full-text descriptions and inventory information. These CDs are available either as moderately priced single CDs or as volumes of related CDs.

Jane's data pertain to existing equipment, not proposed equipment, and would be useful for determining if existing technology fits a requirement. Jane's standard data format is an encrypted binary format; however, Jane's has provided ANL with CDs in simple ASCII format upon request. This ASCII format is straightforward.

\subsubsection{Interface Mechanisms}

The standard interface on Jane's CDs is a traditional DOS-style menu system. Records can be searched, and images and text of a document can be displayed. Reports can be generated, and documents can be exported to files.

\subsubsection{Query Format}

Using the RomWare software that accompanies the standard CDs enables the user to perform the usual Boolean searches on keywords on fields in the documents. A sample query was not performed on this database.

\subsubsection{Integration into TIMS}

Jane's data could be easily integrated into TIMS. General search software would have to be developed or procured to query and display these data. However, this task should be straightforward. Limited searches of these data have been successfully performed during other ANL efforts, so the risk of this effort is minimal. 


\section{RECOMMENDATIONS}

For TIMS, a wide variety of databases are available in many different areas. Several data sources for each category of data have been identified. Some of the most promising electronic data sources are as follows:

- U.S. Patent and Trademark Office,

- US PatentSearch,

- DTIC,

- NASA STI,

- Cambridge Scientific,

- H.W. Wilson, and

- Jane's Information Group.

Secondary investigations determined that it is feasible to develop interfaces to these data sources. Implementation approaches for the sources would be to directly include data in a local search database, remotely connect to the Internet or other services, and access these sources through commercial software search libraries.

To demonstrate the feasibility of building a computer system with these different linkages, the TIMS prototype includes several interfaces to three different data sources. The first interface consists of a communications link to the PTO Internet database. The second interface consists of a communications link to the NASA RECON Internet demonstration database. The third interface consists of a local software link to a sample Cambridge Scientific data set. To reduce the cost of prototype development, ANL used preexisting government-owned software developed by ANL. By including three different linkages, the TIMS prototype demonstrates how these linkages can be combined under one common user interface.

For the complete TIMS, the STP should examine each data source to determine how the different databases fit their requirements. On the basis of STP's decisions in this area, a full TIMS design and implementation strategy could be developed. 
APPENDIX A:

PRELIMINARY INVESTIGATION SHEETS 


\section{Technology Information Management System Database Study \\ Preliminary Investigation}

Database Title: Aerospace Database

Point of Contact:

Richard Miller

American Institute of Aeronautics and Astronautics (AIAA)

Technical Information Division

555 W. 57th St., Suite 1200

New York, NY 10019

212-349-1289

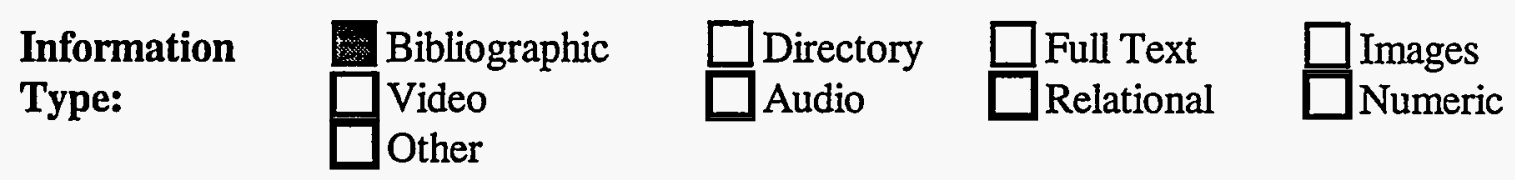

$\begin{array}{llll}\text { Media } & \text { CD-ROM } & \square \text { Magnetic Tape } & \square \text { Diskette } \\ \text { Format: } & \text { On-line Service }_{\text {Internet }} & \square \text { BBS }\end{array}$

Restrictions: $\square_{\text {Other }}$ Classified $\square$ Government Only $\square$ U.S. Only

\section{Content:}

Literature citations with abstracts from 76 subject areas, including aeronautics; astronautics; chemistry and materials; engineering; geosciences; life sciences; mathematics and computer sciences; physics; and relevant social, economic, and legal issues.

\section{Update Date, Frequency:}

For on-line (DIALOG): first of each month

For new CD-ROM: every three months

\section{Sources, Number of Records:}

Worldwide published and unpublished literature from books, conference papers, journals, monographs, patents, reports, and theses. Includes International Aerospace Abstracts (IAA) and Scientific and Technical Aerospace Reports (STAR)(see NASA database).

1.9 million records

Restrictions on Distribution of Derived Data:

Unknown 
Database Title: Aerospace Database

Hardware/Operating System:

CD-ROM: PC, XT, AT, or PS/2; 3-MB storage, 512-K memory (640-K recommended); MS-DOS 3.1 or higher; Microsoft CD-ROM extensions 2.0 or higher

Special Hardware Requirements:

CD-ROM drive or modem

Special Software Requirements:

None

Restrictions on Interface Mechanisms:

None

Initial Costs:

CD-ROM: $\$ 4,890 /$ year (includes current year and four previous years)

Subsequent Costs:

CD-ROM: $\$ 4,890 /$ year (includes current year and four previous years)

DIALOG File 108: $\$ 90 /$ connect hour, $\$ 0.60 /$ full record on- or off-line

Availability of Demonstration Copies or Demonstration Licenses:

No demo copies of the $C D$ are available.

Comments:

CD-ROM: each new CD includes the last four years plus the current year to date. Other CDS available cover 1962-1972 (citations only) and 1972-present (citations and abstracts). 


\title{
Technology Information Management System Database Study
}

Preliminary Investigation

Database Title: Aerospace/Defense Markets \& Technology (A/DM\&T)

\author{
Point of Contact: \\ Information Access Company (IAC) \\ 362 Lakeside Drive \\ Foster City, CA 94404 \\ 415-358-4643 \\ 800-321-6388
}

Fax: 415-358-4759

Information

Bibliographic
$\square$ Video
$\square$ Other

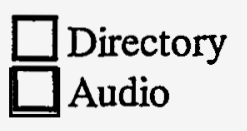

Full Text
$\square$ Relational

$\square$ Images
$\square$ Numeric

Type:

Media

Format:

$\square_{\text {BBS }}^{\text {Diskette }}$ $\square$ Magnetic Tape
$\square$ Internet

On-line Service

Other

Restrictions:

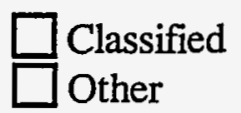

$\square$ Government Only

$\square$ U.S. Only

\section{Content:}

Citations have abstracts, and some have full text. Worldwide literature on the aerospace and defense industries, covering companies, technologies, products, and shipments; land, sea, and air defense systems; defense budgets and weapons systems appropriations; military and sales trends; new technologies; aerospace and airline products; government regulations; and market data. Data include indicators for the presence of various types of illustrations.

\section{Update Date, Frequency:}

DIALOG: updated daily

Data Star: updated weekly

\section{Sources, Number of Records:}

More than 90 military journals, aerospace and civil aviation publications, defense agency reports, and defense-related material contained in the business and trade publications covered by PROMT and reports contained in PTS Annual Reports Abstracts. Also, DoD news releases on major defense contract awards.

381,000 records 
Database Title: Aerospace/Defense Markets \& Technology (A/DM\&T)

Restrictions on Distribution of Derived Data:

Hardware/Operating System:

Special Hardware Requirements:

Modem

Special Software Requirements:

Restrictions on Interface Mechanisms:

Initial Costs:

DIALOG File 980 for subscribers to the print publication; File 80 for nonsubscribers

Subsequent Costs:

Data Star: $\$ 122 /$ connect hour, $\$ 0.72 /$ full record on-line, $\$ 0.87 /$ full record off-line.

DIALOG File 980: $\$ 111 /$ hour, $\$ 0.58 /$ full record on-line, $\$ 0.68$ /full record off-line.

DIALOG File 80: $\$ 150 /$ hour, $\$ 0.80 /$ full record on-line, $\$ 1.00 /$ full record off-line.

Availability of Demonstration Copies or Demonstration Licenses:

Trial licenses of DIALOG can be obtained.

Comments:

On-line services: Data Star, ESA (European), DIALOG, MAID 


\section{Technology Information Management System Database Study}

Preliminary Investigation

Database Title: Cambridge Scientific Abstracts (CSA); Conference Papers Index and Database

\section{Point of Contact:}

Mark Hyer

Cambridge Scientific Abstracts (CSA)

7200 Wisconsin Avenue, Suite 601

Bethesda, MD 20814
(POC for federal accounts)

301-961-6753

Fax: $301-961-6720$

mark@csa.com

800-843-7751, ext. 6741, Howard McCullah (POC for CD-ROM information)

800-843-7751, ext. 6734, Suzanne Langen (POC for magnetic tape information)

Information

Type:

Media

Format:

Restrictions:

\author{
Bibliographic \\ Video \\ Other
}

Directory
$\square$ Audio

$\square$ Images

$\square_{\text {Biss }}$

Magnetic Tape

Internet

Government Only $\square$ U.S. Only

\section{Content:}

The database provides access to significant research papers, up to a year before publication. This database represents the scientific community's sole source of citations from unpublished conference proceedings in the life sciences, engineering, and physical sciences. Covered disciplines include animal and plant science, biochemistry and chemistry, clinical and experimental medicine, materials science and engineering, and nuclear power and engineering.

The index contains more than 1.5 million citations to scientific and technical papers presented at regional, national, and international meetings. It covers current research and development activities, primarily in the life sciences, medicine, chemistry, physical sciences, and engineering. For each paper, it provides names and addresses of authors, conference titles, location, date, sponsors, and the information required to order available proceedings, preprints, reprints, and abstracts. Separate references are included for conferences held from 1982 to date.

Update Date, Frequency:

Index and database: updated bimonthly, 72,000 records/year 
Database Title: Cambridge Scientific Abstracts (CSA); Conference Papers Index and Database

Sources, Number of Records:

The index (1973-date) contains more than 1.5 million citations to scientific and technical papers presented at regional, national, and international meetings.

The database: Current +5 years: 362,500 records

Current +10 years: 671,500 records

The Internet Journal Service (see comments below) for Electronics and Communications Abstracts references 384,000 records.

Restrictions on Distribution of Derived Data:

Users must conform to standard research-only and copyright laws.

Hardware/Operating System:

Some aspects of CSA database and abstract services require VT100 emulation.

Special Hardware Requirements:

None

Special Software Requirements:

The Internet Journal Service (see comments below) requires TCP/IP and WAIS client software. MOSAIC support is being planned. MS Windows 3.1 and the Winsocket Library (winsock.dll) are required.

\section{Restrictions on Interface Mechanisms:}

Initial Costs:

Some CSA services are available by DIALOG Information Services, Inc.: $\$ 90 /$ hour, $\$ 0.75 /$ record) An annual subscription to the Internet Journal Service for Conference Papers Index is $\$ 985$.

Most other Internet Journal Service journal subscriptions cost about $\$ 800$ (range: $\$ 275$ to $\$ 2,145$ ).

Subsequent Costs:

Some CSA services available by DIALOG charge $\$ 0.75 /$ record.

Availability of Demonstration Copies or Demonstration Licenses:

A free 60-day trial to the Internet Journal Service is available.

Comments:

(See CSA's Mechanical Engineering Abstracts.) 


\section{Technology Information Management System Database Study \\ Preliminary Investigation}

Database Title: Cambridge Scientific Abstracts (CSA); Electronics and Communications Abstracts

Point of Contact:

Mark Hyer

Cambridge Scientific Abstracts (CSA)

(POC for federal accounts)

7200 Wisconsin Avenue, Suite 601

Bethesda, MD 20814

301-961-6753

Fax: 301-961-6720

mark@csa.com

800-843-7751, ext. 6741, Howard McCullah (POC for CD-ROM information)

800-843-7751, ext. 6734, Suzanne Langen (POC for magnetic tape information)

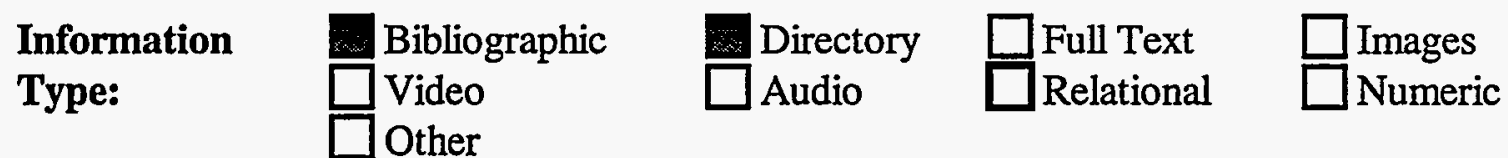

\begin{tabular}{|c|c|c|c|}
\hline $\begin{array}{l}\text { Media } \\
\text { Format: }\end{array}$ & $\begin{array}{l}\square \text { CD-ROM } \\
\text { On-line Service }\end{array}$ & $\begin{array}{l}\text { Magnetic Tape } \\
\text { Internet }\end{array}$ & $\begin{array}{l}\square \text { Diskette } \\
\square \text { BBS }\end{array}$ \\
\hline
\end{tabular}

Restrictions: $\square$ Classified $\square$ Government Only $\quad \square$ U.S. Only

\section{Content:}

The journal covers both theoretical and applied research for specialists working in the following areas: medical, scientific, and industrial applications; semiconductors, superconductors, lasers, and other electronic devices; or promising technologies in communications. New developments in business practice, marketing, leading-edge research, and practical deployment of new technical advances are also covered.

Specific subject areas include electronic systems (power, instrumentation and measurements, automatic control, reliability, and applications); electronic physics (electromagnetics, physical electronics); electronic circuits (amplifiers, oscillators and waveform generators, switches, modulators, pulse circuits, and filters); electronic devices (from cryogenic devices to solid state); communications (covering the field from audio systems to fiber optics).

Contents include electromagnetics; energy/power sources; instrumentation/measurements; automatic control; aerospace electronics; military, medical, geoscience, safety, computer, and transportation electronics; electronics in education; circuit theory; circuit aspects of devices; specific circuits; electronic devices; discrete components; linear beam tubes; photodevices; lasers and masers; magnetic devices; communication theory/information theory; audio systems; positioning systems. 
Database Title: Cambridge Scientific Abstracts (CSA); Electronics and Communications Abstracts

Update Date, Frequency:

11,000 abstracts/year; updated monthly

Sources, Number of Records:

Contains more than 120,000 citations, with abstracts, to the world's literature on electronics and communications; 1982 to date; 600 primary sources in the database, with 2,500 secondary sources. The Internet Journal Service for Electronics and Communications Abstracts (see comments below) references 60,400 records.

Restrictions on Distribution of Derived Data:

Users must conform to standard research-only and copyright laws.

Hardware/Operating System:

Some aspects of CSA database and abstract services require VT100 emulation.

Special Hardware Requirements:

None

Special Software Requirements:

The Internet Journal Service (see comments below) requires TCP/IP and WAIS client software. MOSAIC support is planned. MS Windows 3.1 and Winsocket Library (winsock.dll) are required.

\section{Restrictions on Interface Mechanisms:}

Unknown

\section{Initial Costs:}

Some CSA services are available by DIALOG Information Services, Inc.: $\$ 90 /$ hour, $\$ 0.75 /$ record. Annual subscription to Internet Journal Service for Electronics and Communications Abstracts is $\$ 975$.

Most other Internet Journal Service journal abstracts subscriptions are about $\$ 800$ (range: $\$ 275$ to $\$ 2,145$ ).

\section{Subsequent Costs:}

Some CSA services available by DIALOG charge $\$ 0.75 /$ record.

Availability of Demonstration Copies or Demonstration Licenses:

Free 60-day trial to the Internet Journal Service is available.

\section{Comments:}

This database is now jointly published with Engineering Information. (See CSA's Mechanical Engineering Abstracts.) 


\section{Technology Information Management System Database Study \\ Preliminary Investigation}

Database Title: Cambridge Scientific Abstracts (CSA); Information Engineering, Inc. (Ei) Databases

\section{Point of Contact:}

Mark Hyer

Cambridge Scientific Abstracts (CSA)

7200 Wisconsin Avenue, Suite 601

Bethesda, MD 20814
(POC for federal accounts)

301-961-6753

Fax: 301-961-6720

mark@csa.com

800-843-7751, ext. 6741, Howard McCullah (POC for CD-ROM information)

800-843-7751, ext. 6734, Suzanne Langen (POC for magnetic tape information)

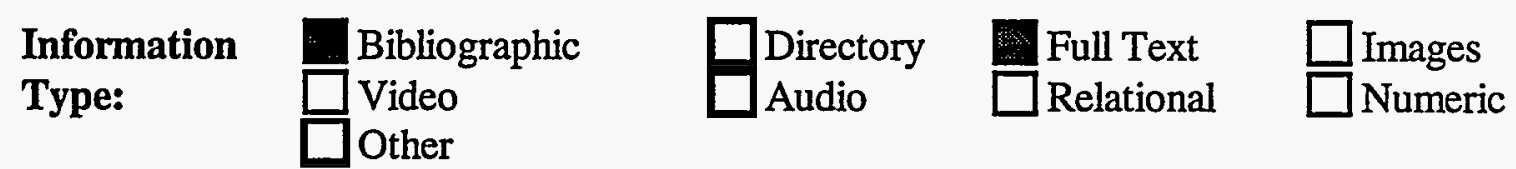

$\begin{array}{llll}\text { Media } & \text { CD-ROM } & \text { Magnetic Tape } & \square \text { Diskette } \\ \text { Format: } & & \square \text { On-line Service } & \text { Internet }\end{array}$

Restrictions: $\square_{\text {Cther }}^{\text {Classified }} \square$ Government Only $\square$ U.S. Only

\section{Content:}

These databases were formerly included in CSA's Hard Science database. The databases include the Ei/CSA Computer \& Information Systems Database, the Ei/CSA Electronics \& Communications Database, and the Ei/CSA Solid State/Superconductivity Database. These databases are compiled from Compendex, the world's largest engineering database.

The Ei/CSA Computer \& Information Systems Database is designed for the practicing professional and academic researcher. Covering the fields of computer science and information management, this database summarizes current theoretical research and practical applications from around the world. Topics include software, artificial intelligence, automation, equipment manufacturing and design; system security, robotics, logic and switching theory, and applications for specific fields. The database covers all the journals scanned for Computer \& Information Systems. 
Database Title: Cambridge Scientific Abstracts (CSA); Information Engineering, Inc.

(Ei) Databases

\section{Content (Cont.):}

The Ei/CSA Electronics \& Communications Database is designed for the practicing professional and academic researcher to offer in-depth coverage of electronics and communications. This database examines electronic systems, electronic physics, electronic circuits, electronic devices, communications, and optical engineering. Topics span scientific, industrial, and engineering applications; semiconductors, superconductors, and lasers; biomedical engineering; and promising communications technologies.

The Ei/CSA Solid State/Superconductivity Database is designed for the practicing professional and academic researcher. Published under the editorial guidance of Nobel Laureate Philip W. Anderson of Princeton and Millie Dresselhaus of MIT, this database has covered the field of solid-state technology since 1960 . Now highlighting new findings in superconductivity, the database presents unparalleled global coverage on all aspects of theory, production, and application of solid-state materials and devices, as well as the new high- and low-temperature superconductivity technology.

(See CSA's Mechanical Engineering Abstracts.)

\section{Update Date, Frequency:}

Ei/CSA Computer \& Information Systems Database: updated monthly: 17,600 records/year.

Ei/CSA Electronics \& Communications Database: updated monthly: 11,000 records/year.

Ej/CSA Solid State/Superconductivity Database: updated bimonthly: 8,000 records/year.

\section{Sources, Number of Records:}

Ei/CSA Computer \& Information Systems Database:

861 primary sources; 2,500 secondary sources

Includes journals, books, and conference proceedings

File size: current +5 years: 96,165 records

current +10 years: 174,730 records

Ei/CSA Electronics \& Communications Database 600 primary sources; 2,500 secondary sources Includes journals, books, and conference proceedings

File size: current +5 years: 60,000 records current +10 years: 106,000 records

Ei/CSA Solid State/Superconductivity Database:

544 primary sources; 2,500 secondary sources

Includes journals, books, and conference proceedings

File size: current +5 years: 53,000 records;

current +10 years: 99,200 records 
Database Title: Cambridge Scientific Abstracts (CSA);Information Engineering, Inc.

(Ei) Databases

Restrictions on Distribution of Derived Data:

Users must conform to standard research-only and copyright laws.

Hardware/Operating System:

Some aspects of CSA database and abstract services require VT100 emulation.

Special Hardware Requirements:

None

Special Software Requirements:

The Internet Journal Service (see comments below) requires TCP/IP and WAIS client software. MOSAIC support is planned. MS Windows 3.1 and Winsocket Library (winsock.dll) are required.

Restrictions on Interface Mechanisms:

Unknown

Initial Costs:

Some CSA services are available by DIALOG Information Services, Inc.: \$90/hour, $\$ 0.75 /$ record. Annual subscription to Internet Journal Service for Solid State/Superconductivity Abstracts is $\$ 985$. Annual subscription to Internet Journal Service for Electronics \& Communications Abstracts is $\$ 975$. Annual subscription to Internet Journal Service for Computer \& Information Systems Abstracts is $\$ 1,150$.

Most other Internet Journal Service journal abstracts subscriptions are about $\$ 800$ (range: $\$ 275$ to $\$ 2,145$ ).

\section{Subsequent Costs:}

Some CSA services available by DIALOG charge $\$ 0.75 /$ record.

Availability of Demonstration Copies or Demonstration Licenses:

Free 60-day trial to the Internet Journal Service is available.

\section{Comments:}

(See CSA's Mechanical Engineering Abstracts.)

Date: $8 / 25 / 94$ 


\section{Technology Information Management System Database Study}

Preliminary Investigation

Database Title: Cambridge Scientific Abstracts (CSA); Mechanical Engineering Abstracts

\section{Point of Contact:}

Mark Hyer

(POC for federal accounts)

Cambridge Scientific Abstracts (CSA)

301-961-6753

7200 Wisconsin Avenue, Suite 601

Fax: 301-961-6720

Bethesda, MD 20814

mark@csa.com

800-843-7751, ext. 6741, Howard McCullah (POC for CD-ROM information)

800-843-7751, ext. 6734, Suzanne Langen (POC for magnetic tape information)

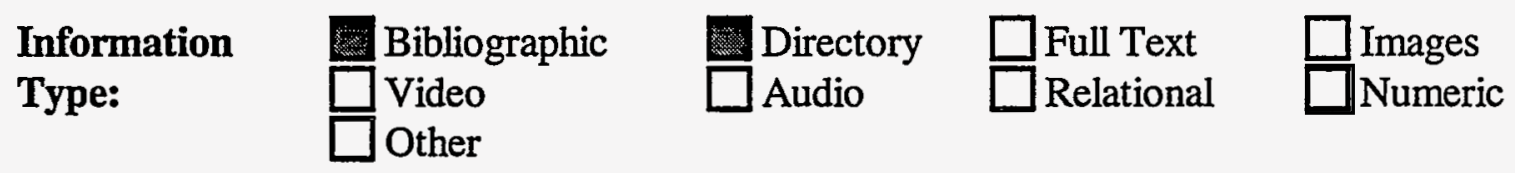

Media

Format:

CD-ROM
Magnetic Tape
Onthe Service

$\square$ Diskette

$\square$ Government Only

$\square$ U.S. Only

\section{Content:}

Mechanical Engineering Abstracts is published with Engineering Information, Inc. This abstracts journal surveys and summarizes worldwide literature in mechanical engineering, engineering management, and production engineering.

Presenting theoretical perspectives as well as concrete applications, the journal reports on important developments published in journals, articles, books, patents, dissertations, and conference papers. The database contains information in operations research; production development, management, and control; tribology; civil and structural engineering; military engineering; transportation engineering; energy and power; robotics; CAD/CAM and CIM/CAE; and fluid mechanics.

The contents of Mechanical Engineering Abstracts include management and production; measurement and control; mechanics, materials, and devices; production processes, tools, and equipment; energy and power; transport and handling; mechanical engineering and natural resources; mechanical engineering in science and industry; and other applications of mechanical engineering.

Full-text document delivery is available from Engineering Information, Inc. 
Database Title: Cambridge Scientific Abstracts (CSA); Mechanical Engineering Abstracts

Update Date, Frequency:

Mechanical Engineering Abstracts: 9,600/year, monthly updates

Sources, Number of Records:

Contains more than 260,000 citations (from 1973 [some references say from 1967]) with abstracts (from 1982), to the literature in mechanical engineering, production engineering, engineering management, and related areas.

The Internet Journal Service for Mechanical Engineering Abstracts (see comments below) references 60,400 records.

\section{Restrictions on Distribution of Derived Data:}

Users must conform to standard research-only and copyright laws. Customized media and databases are not for resale.

\section{Hardware/Operating System:}

PC-based. Some aspects of CSA database and abstract services require VT100 emulation.

\section{Special Hardware Requirements:}

Nine-track tape drives or DAT drive is required if those types of media are used.

\section{Special Software Requirements:}

The Internet Journal Service (see comments below) requires TCP/IP and WAIS client software. MOSAIC support is planned. MS Windows 3.1 and Winsocket Library (winsock.dll) are required.

\section{Restrictions on Interface Mechanisms:}

\section{Initial Costs:}

Some CSA services are available by DIALOG Information Services, Inc.: $\$ 90 /$ hour, $\$ 0.75 /$ record. Annual subscription to Internet Journal Service for Mechanical Engineering Abstracts is $\$ 895$.

Most other Internet Journal Service journal abstracts subscriptions are about $\$ 800$ (range: $\$ 275$ to $\$ 2,145$ ).

Customized services on user-specified media are also available.

\section{Subsequent Costs:}

Some CSA services available by DIALOG charge $\$ 0.75 /$ record.

Availability of Demonstration Copies or Demonstration Licenses:

A free 60-day trial to the Internet Journal Service is available. 
Database Title: Cambridge Scientific Abstracts (CSA); Mechanical Engineering Abstracts

\section{Comments:}

This database includes Mechanical Engineering Abstracts, which was formerly ISMEC: Mechanical Engineering Abstracts. It is now jointly published with Engineering Information, Inc.

Cambridge Scientific Abstracts offers more than 25 databases, covering environmental sciences, biomedical sciences, aquatic sciences, engineering, materials and computer sciences, and market research. The complete on-line databases can be accessed on the Internet via several third parties, such as DIALOG Information Services, Inc., or the Research Libraries Group (RLG). Discipline-specific subsets of databases are available in a variety of electronic media, such as CD-ROM, magnetic tape, and on-line. Some of the databases will be available directly through CSA's Internet services in late 1994.

CSA databases provide summaries of scientific, technical, or market research, together with full source information to obtain the full articles or reports. The databases vary in size depending on the discipline and the number of years of coverage. For example, 10 years of the primary database Environmental Sciences and Pollution Management has more than 600,000 records, whereas the more specialized databàse Safety Sciences \& Risk Assessment has 190,000 records. The average CSA record has 1,600 characters.

CitaDel is the full-service citation and document-delivery service from RLG. One search interface is used for all CitaDel files - Eureka, RLG's patron-oriented search service. One can connect to Eureka through the Internet, SprintNet, or direct-dial line. Eureka streamlines searching of RLG's on-line resources. It gives users straightforward access to a wide variety of on-line information, including the RLIN bibliographic database of library, archives, and museum library holdings, and the CitaDel article-citation and document-delivery service. Eureka uses a common-command language and allows users to download results so that they can create bibliographies on their PCs. It is accessible from any terminal or PC that uses VT100 emulation. Data on other media (magnetic tape, CD-ROMs) are subsets of the complete databases on RLG systems, generated to support specific markets.

CSA's Internet Journal Service provides users with Internet access to an electronic file that corresponds to a journal subscription. The electronic file contains up-to-date contents of the journal (updated even before the print version of the journal goes to press), as well as five years of back-file data. It allows the user to search for keywords and specific topics through five years of journal contents and to download citations and abstracts.

CSA is open to customizing specific abstracts and placing them on the Internet (for FTP access) or on the media of choice.

Magnetic nine-track or DAT tapes are probably easiest to handle; the software can be easily written to access databases on these files. CAS's standard CD-ROMs have built-in Silver-Platter software.

Some services are available on DIALOG Information Services, Inc. 
Database Title: Cambridge Scientific Abstracts (CSA); Mechanical Engineering Abstracts

Comments (Cont.):

Yvette N. Woell at 708-252-4275 at Argonne National Laboratory has additional information. More information is available at gopher.csa.com.

WAIS can also be used from the Internet. 


\section{Technology Information Management System Database Study \\ Preliminary Investigation}

Database Title: Civil Engineering DataBase (CEDB)

Point of Contact:

Carol Reese, Manager

American Society of Civil Engineers (ASCE) 212-705-7520

Information Products

800-548-2723

345 E. 47 th St.

Fax: 212-705-7712

New York, NY 10017-2398

creese@ny.asce.org

Science Technical Network, International (STN)

P.O. Box 3012

Columbus, OH 43210

800-753-4227

stnc.cas.org for Internet

Information

Bibliographic
$\square$ Video
$\square$ Other
$\square$ Directory Audio

$\square$ Full Text
$\square$ Relational

$\square_{\text {Images }}$

Type:

Media

Format:

$\square$ CD-ROM
On-line Se
$\square$ Other
$\square$ Classified
Other

$\square$ Magnetic Tape
Internet

$\square$ Diskette

$\square$ BBS

Restrictions: $\square$ Government Only

$\square$ U.S. Only

Standard Copyright notices.

\section{Content:}

Bibliographic service is available through STN services by modem or Internet (stnc.cas.org). The STN system (see comments below) contains about 170 other databases. A 40-page catalog lists the titles referenced by CEDB, which references all ASCE publications. It has U.S. coverage, with some international coverage.

CEDB covers worldwide literature on civil engineering, including topics on aerospace; air transport; codes and standards; cold regions; computer practices; construction; energy; forensic engineering; earthquake, environmental, geotechnical and structural engineering; waterway, port, coastal, and ocean engineering; education; engineering mechanics; highways; hydraulics; irrigation and drainage; materials; pipelines; surveying; urban planning and development; materials; surveying and mapping; and water resources.

Update Date, Frequency:

Dates from 1975. About 4,500 records are added per year. References to about 50 books are added each year. 
Database Title: Civil Engineering DataBase (CEDB)

Sources, Number of Records:

This database offers 50,000 citations, with abstracts, to the worldwide literature on civil engineering. It references all ASCE publications: 22 journals, about 50 books per year, conference proceedings, and Civil Engineering magazine. It corresponds in part to ASCE Publications Information and ASCE Annual Combined Index.

\section{Restrictions on Distribution of Derived Data:}

\section{Hardware/Operating System:}

$\mathrm{PC}$-based system for the $\mathrm{CD}$ version

\section{Special Hardware Requirements:}

CD-ROM for upcoming CD version

Modem for on-line service

\section{Special Software Requirements:}

\section{Restrictions on Interface Mechanisms:}

ASCE does not recommend writing customized software to access the databases on the CD version.

\section{Initial Costs:}

$\$ 25$ application fee

\section{Subsequent Costs:}

No yearly fees.

$\$ 85 /$ hour charged by CEDB (other STN databases charge their own rates).

Internet charges about $\$ 5 /$ hour to STN, which bills users.

Phone networks typically charge about $\$ 9-\$ 12 /$ hour to STN, which bills users.

\section{Availability of Demonstration Copies or Demonstration Licenses:}

A $\$ 20$ simulation disk for the CEDB is available as one of the demonstration disks for use with the $\$ 40-\$ 50$ training disk offered by STN. The STN system also offers free introductory courses nationwide on its retrieval systems.

\section{Comments:}

STN, a not-for-profit system, was founded by three organizations: Chemical Abstract Service (CAS), a German company, and the Japanese Information Center. The intent was to allow less expensive access to bibliographic and database information. The STN system contains about 170 databases, including this CEDB. CEDB was designed to be used by engineers: it is supposedly simple to use. CEDB is developing a CD-ROM system for its journals and will offer 1995 publications next year. 
Technology Information Management System Database Study

Preliminary Investigation

Database Title: CLAIMS/U.S. Patents

Point of Contact:

Harry M. Allcock

Vice President, IFI/Plenum Data Corporation

102 Eastwood Road, Suite D6F

Wilmington, NC 28405

800-368-3093; 919-392-0068 or -0240

Manager, Technical Operations

3202 Kirkwood Highway, Suite 203

Wilmington, DE 19808

302-998-0478

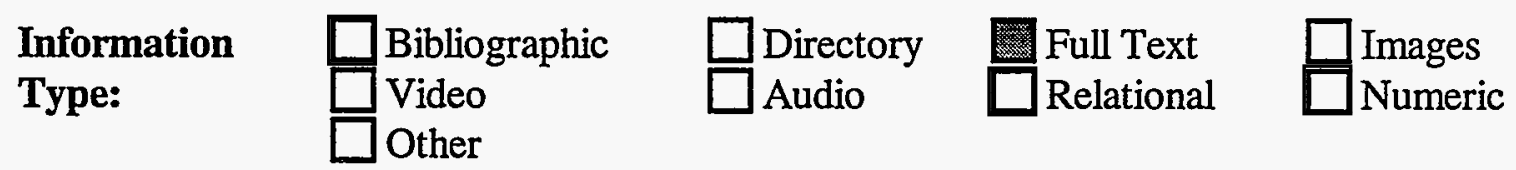

Media

Format:

$\square$ CD-ROM
On-line Service
$\square$ Other

$\square$ Magnetic Tape
$\square$ Internet

$\square$ Diskette
$\square$ BBS

Restrictions:

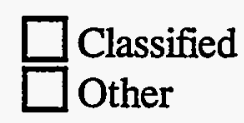

$\square$ Government Only

$\square$ U.S. Only

\section{Content:}

CLAIMS/U.S. Patents: Front-page patent information, claims, author abstract.

Utility and design patents.

The specific fields provided are abstract; broad claim; text of claim; other claims; title; priority application country code; application country, date, and number; reissue application number; art unit; inventor name and country; class codes searched by examiner; U.S. class codes; CA reference number; and DIALOG access number.

In addition to the U.S. Patents service, CLAIMS offers several companion services:

CLAIMS/CITATION: all patents cited by and citing each patent

CLAIMS/REFERENCE: manual of classification

CLAIMS/Reassignment and Reexamination

ONTAP CLAIMS: on-line training and practice

U.S. Patent Abstract Weekly: transferred once per month

Update Date, Frequency:

Weekly 
Database Title: CLAIMS/U.S. Patents

Sources, Number of Records:

All granted U.S. utility patents, reissue patents, defensive publications, statutory invention registrations, and design patents (since 1980) are announced in the U.S. Patent and Trademark Office Official Gazette.

$2,259,000$ records as of June 1992; 2,000 new records per week; 1981: 771,000 records

Restrictions on Distribution of Derived Data:

Data may not be duplicated without written authorization from IFI/Plenum, except for up to 25 printed copies for distribution within the subscriber organization. No resale.

Hardware/Operating System:

Runs on DIALOG and Orbit/Questal on-line services. Requirements are similar for each.

Special Hardware Requirements:

(See general discussion of DIALOG.)

Special Software Requirements:

(See general discussion of DIALOG.)

Restrictions on Interface Mechanisms:

(See general discussion of DIALOG.)

Initial Costs:

(See general discussion of DIALOG.)

\section{Subsequent Costs:}

DIALOG: $\$ 2.50 /$ connect minute, $\$ 1.60 /$ full-format on-line type or off-line print; $\$ 0.30 /$ report element; $\$ 9.75 /$ monthly DIALOG Alert plus prints.

Also available through QUESTEL-ORBIT. Subscriber rate: $\$ 125 /$ connect hour, $\$ 0.25 /$ full record on-line or $\$ 0.50 /$ full record off-line. Nonsubscriber rate: $\$ 140 /$ connect hour, $\$ 0.50 /$ full record on-line, $\$ 0.75 /$ full record off-line.

Also available through STN International: $\$ 125 /$ connect hour, $\$ 0.12$ /full record on-line, $\$ 0.15 /$ full record off-line.

Availability of Demonstration Copies or Demonstration Licenses:

(See general discussion of DIALOG.)

Comments:

ANL Investigator Name: Jeff Keisler

Date: $8 / 24 / 94$ 


\section{Technology Information Management System Database Study}

Preliminary Investigation

Database Title: Compendex*Plus (and associated databases)

Point of Contact:

Wendy Rand

Engineering Information, Inc. (Ei)

Castle Point on the Hudson

Hoboken, NJ 07030
201-216-8500

800-221-1044, ext. 551

Fax: 201-216-8532

E-mail: ei@einet.ei.org

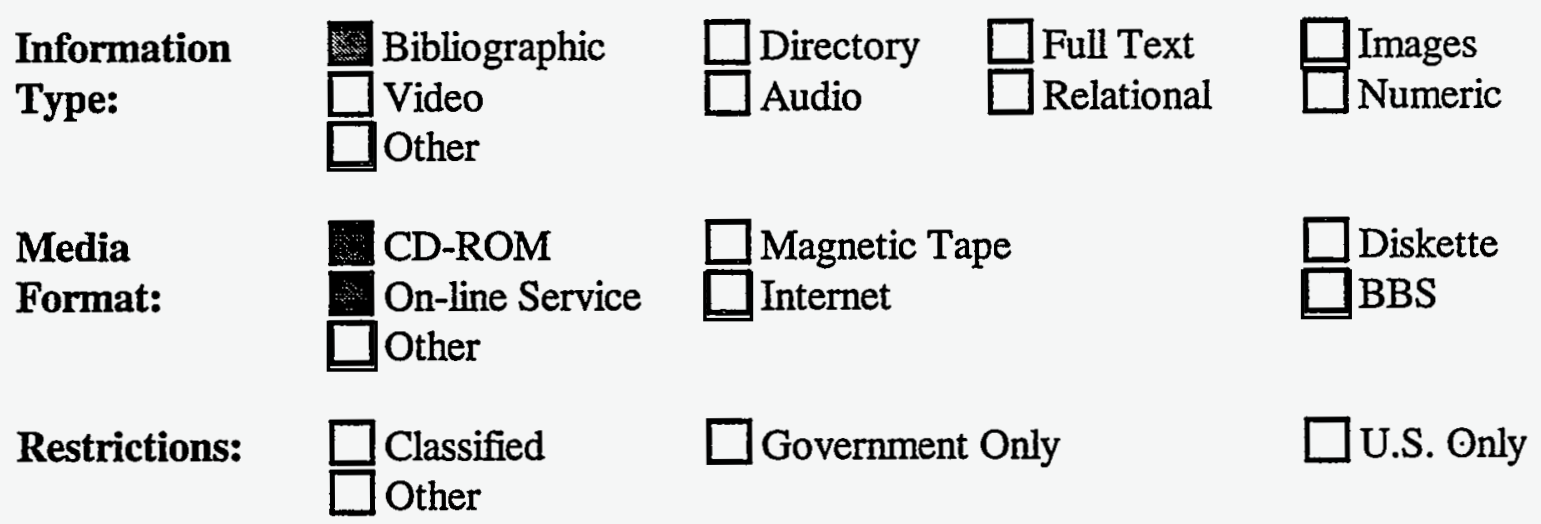

\section{Content:}

This database contains 2.8 million citations, with abstracts, from more than 4,500 international journals, reports, books, and conference proceedings, covering the mechanical, civil, environmental, electrical, structural, and process fields; materials science; solid state and superconductivity; bioengineering; energy; chemical; optics; air and water pollution; solid waste management; hazardous waste; and road transportation and transportation safety. The coverage also extends to manufacturing, quality control, and engineering management issues.

Compendex*Plus is the "master database," with seven specialty CD-ROM disks for chemical engineering, civil engineering, mechanical engineering, advanced materials, manufacturing, energy/environment, and computer/electrical/electronic engineering. The Advanced Materials Disc covers international research. It focuses on nonmetallic engineered materials, including polymers and plastics; ceramics and refractories; wood products, such as paper, textiles, and fibers; rubbers and elastomers; and composites intended for use in design, construction, and operation of structures, equipment, and systems.

The Ei Page One product is a table of contents disk and references Compendex*Plus. It does not include abstracts found in Compendex*Plus. It contains more than 300,000 citations taken from tables of contents each year and is updated every two months. It is the world's largest engineering citations database with fixed-price searching. 
Database Title: Compendex*Plus (and associated databases)

\section{Content (Cont.):}

The Concise Engineering and Technology Index contains 125,000 citations, with abstracts, to 425 very specific technical titles used mainly by engineers at universities. It is a subset of Compendex*Plus. It is available either on CD-ROM or on-line.

The Ei Reference Desk is an all-inclusive searching and document delivery system. At this work station, the following functions can be performed: search $\mathrm{Ei}$ Page One, the table of contents database that is twice as large as Compendex*Plus; capture the citations; order the full-text document (via Internet); or receive, view, and print the document at a workstation.

\section{Update Date, Frequency:}

On-line system: 13,000 records added weekly (from 1970).

Applied physics: 10,000 new entries recently added.

CD-ROM: updated quarterly (from 1985).

\section{Sources, Number of Records:}

2.8 million citations, with abstracts, from more than 4,500 journals, reports, books, and conference proceedings

\section{Restrictions on Distribution of Derived Data:}

\section{Hardware/Operating System:}

IBM compatible under DOS or Mac

\section{Special Hardware Requirements:}

Modem or CD-ROM drive

\section{Special Software Requirements:}

Software supplied with CD-ROM databases

\section{Restrictions on Interface Mechanisms:}

The representative of Engineering Information, Inc., stated that "you cannot write your own software to access data on the disk" but could not provide more details. 
Database Title: Compendex*Plus (and associated databases)

\section{Initial Costs:}

Single-unit disks:

$\$ 3,450$

Compendex*Plus current data (1994/1993)

$\$ 5,420$

Compendex*Plus complete (1994/1990-1993)

$\$ 3,850$

ChemDisc (chemical engineering) offers 10 years of abstracts

$\$ 3,850$ EEDisc (electronic, electrical, and computer engineering) offers 10 years of abstracts

$\$ 2,500$

$\$ 2,995$

Energy/Environment Disc includes 10 years of abstracts

$\$ 1,295 \quad$ Manufacturing Disc MechDisc (mechanical engineering) offers 10 years of abstracts

$\$ 2,495 \quad$ CivilDisc (civil and structural engineering) offers 20 years of data (update frequency not stated)

$\$ 3,450 \quad$ Advanced Materials Disc (materials engineering and related fields) covers nine years of research

$\$ 995$ Ei Page One contains two years worth of citations

Other prices are available for various simultaneous LAN users.

\section{Subsequent Costs:}

Various on-line access providers charge about $\$ 100 /$ hour and about $\$ 0.50 /$ record.

Compuserve charges about $\$ 24 /$ hour.

Availability of Demonstration Copies or Demonstration Licenses:

All CD-ROM disks are available for a 30-day free trial. ANL-West has at least one disk.

\section{Comments:}

Ei is currently testing a new on-line end-user service called Ei Connexion that provides technical and engineering information as well as access to other pertinent databases that engineers may need. This service is primarily for end users and will allow them to search Compendex*Plus, plus more than 140 DIALOG files. It is menu-driven, which makes it a very user-friendly system. During an eight-week test, Ei will provide $\$ 1,500$ of free usage of Compendex*Plus via the on-line service. The other files will be available on a paid basis at charges comparable to DIALOG rates. The only equipment needed to access the service is a terminal, a modem, and access to SprintNet or Internet.

Information about on-line services can be requested from DIALOG Information Services at 800-334-2564. Compendex*Plus is File 8 on DIALOG. 


\section{Technology Information Management System Database Study \\ Preliminary Investigation}

Database Title: COSMIC Annual Software Catalog

Point of Contact:

Richard Saunders

Computer Software Management and Information Center (COSMIC)

382 E. Broad St.

University of Georgia

Athens, GA 30602-4272

706-542-3265

Information

Type:

Media

Format:

Restrictions:

\author{
$\square$ Bibliographic \\ $\square$ Video
}

$\square$ Full Text

$\square_{\text {Images }}$

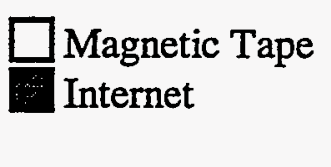

Government Only Other

$\square$ CD-ROM
$\square$ On-line Se
$\square$ Other
$\square$ Classified
Other

International version is available.

\section{Content:}

Computer programs and software developed by NASA and NASA contractors in artificial intelligence, computational fluid dynamics, finite element structural analysis, scientific visualization, thermal and fluid flow analysis, and others.

Update Date, Frequency:

Monthly update (usually the first of the month)

Sources, Number of Records:

NASA programs and contractor work; 900 to 1,000 records

Restrictions on Distribution of Derived Data:

No restrictions on records in database; actual software referenced: some licenses and some U.S. only

Hardware/Operating System:

MS-DOS: 5-MB hard disk

Special Hardware Requirements:

On-line: modem 
Database Title: COSMIC Annual Software Catalog

Special Software Requirements:

Restrictions on Interface Mechanisms:

\section{Initial Costs:}

None

\section{Subsequent Costs:}

None (actually, acquiring software costs between $\$ 50$ and $\$ 7,000$ )

Availability of Demonstration Copies or Demonstration Licenses:

Comments:

Diskette: MS-DOS catalog: precompiled system with data, uses CLIPPER, full-screen application. Available on 5-1/4-in. and 3-1/2-in. diskettes. 
Technology Information Management System Database Study

Preliminary Investigation

Database Title: CURRENT CONTENTS on DISKETTE/ENGINEERING and APPLIED SCIENCES

Point of Contact:

Donna Del Reaux

Institute for Scientific Information

3501 Market Street

Philadelphia, PA 19104

800-336-4474, ext. 1330

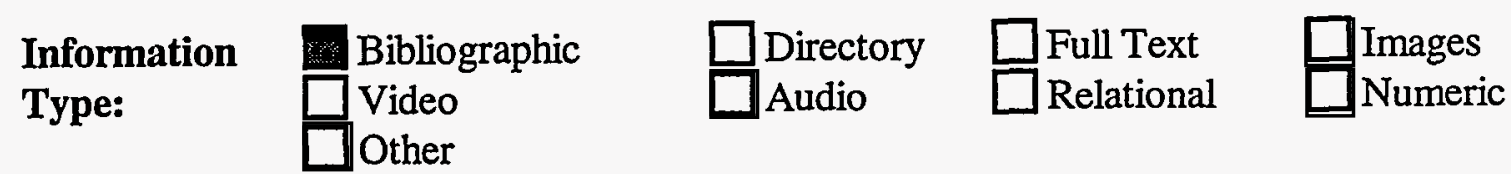

\begin{tabular}{|c|c|c|c|}
\hline $\begin{array}{l}\text { Media } \\
\text { Format: }\end{array}$ & $\begin{array}{l}\text { CD-ROM } \\
\text { On-line Service } \\
\text { Other }\end{array}$ & 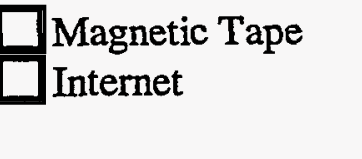 & $\begin{array}{l}\text { Diskette } \\
\square \text { BBS }\end{array}$ \\
\hline Restrictions: & $\begin{array}{l}\text { JClassified } \\
\text { JOther }\end{array}$ & $\square$ Government Only & $\square$ U.S. Only \\
\hline
\end{tabular}

Content:

Provides tables of contents for articles listed in approximately 820 journals in engineering, applied sciences, and technology

Update Date, Frequency:

Weekly

Sources, Number of Records:

Wide range of scientific and technological disciplines from conferences and seminars

1,927 records.

Restrictions on Distribution of Derived Data:

If ANL purchases a network license, distribution is possible; otherwise, it depends on the type and number of queries.

Hardware/Operating System:

PC-based

Special Hardware Requirements: 
Database Title: CURRENT CONTENTS on DISKETTE/ENGINEERING and APPLIED SCIENCES

Special Software Requirements:

Restrictions on Interface Mechanisms:

No known legal problems with writing our own interface to these products

\section{Initial Costs:}

On a stand-alone PC, for the printed version, the fee is $\$ 442$ annually.

On diskette, the fee is $\$ 457$ annually.

For a network implementation, in a single institution, the cost is $\$ 11,465$ per year.

Subsequent Costs:

Annual license must be renewed.

Availability of Demonstration Copies or Demonstration Licenses:

ANL has a demonstration copy on diskette.

Comments: 


\section{Technology Information Management System Database Study \\ Preliminary Investigation}

\section{Database Title: CURRENT CONTENTS SEARCH}

\section{Point of Contact:}

Donna Del Reaux

Institute for Scientific Information

3501 Market Street

Philadelphia, PA 19104

800-336-4474, ext. 1330

\begin{tabular}{|c|c|c|c|}
\hline $\begin{array}{l}\text { Information } \\
\text { Type: }\end{array}$ & $\begin{array}{l}\text { Bibliographic } \\
\text { Video }\end{array}$ & 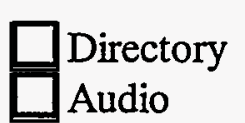 & $\begin{array}{l}\square \text { Full Text } \\
\text { Relational }\end{array}$ \\
\hline
\end{tabular}

\begin{tabular}{|c|c|c|c|}
\hline Media & 口CD-ROM & Magnetic Tape & Diskette \\
\hline Format: & $\begin{array}{l}\text { On-line Service } \\
\square \text { Other }\end{array}$ & $\square$ Internet & BBS \\
\hline
\end{tabular}

Restrictions: $\square_{\text {Classified }}^{\text {Oother }} \square$ Government Only $\square$ U.S. Only

\section{Content:}

Provides complete bibliographic coverage, with abstracts, to articles listed in the tables of contents of approximately 6,900 leading journals in the sciences, social sciences, arts, and humanities.

Three areas may be of particular interest to DOE:

1. ENGI: engineering, technology, and applied sciences;

2. AGRI: agriculture, biology, and environmental sciences;

3. PHYS: physical, chemical, and earth sciences.

\section{Update Date, Frequency:}

$18,000 \mathrm{records} / \mathrm{week}$

Sources, Number of Records:

6,900 leading journals in sciences, social sciences, arts, and humanities

\section{Restrictions on Distribution of Derived Data:}

If ANL purchases a network license, distribution will be possible; otherwise, it depends on the type and number of queries.

\section{Hardware/Operating System:}

PC-based 
Database Title: CURRENT CONTENTS SEARCH

Special Hardware Requirements:

On-line: modem

Special Software Requirements:

Restrictions on Interface Mechanisms:

No known legal problems with writing our own interface to these products

Initial Costs:

For ISI magnetic tape: $\$ 29,185$ annual fee for all groups, but $\$ 22,800$ annual fee for just the ENGI, AGRI, PHYS groups. These costs include networking for a single institution.

Subsequent Costs:

For tape: annual license costs.

On-line services:

CDP On Line costs $\$ 95 /$ connect hour, $\$ 0.59 /$ full record on-line, and $\$ 0.65 /$ full record off-line.

CDP after Dark costs $\$ 39 /$ connect hour and $\$ 1.08$ /full record on-line.

CDP Colleague costs $\$ 100 /$ connect hour (prime time), $\$ 90 /$ connect hour (nonprime time), and $\$ 1.18 /$ full record both on- and off-line.

DIALOG costs $\$ 102 /$ connect hour, $\$ 0.80$ cents/full record on-line, and $\$ 0.80 /$ full record off-line.

Availability of Demonstration Copies or Demonstration Licenses:

Comments:

ANL has a demonstration copy on diskette. 


\section{Technology Information Management System Database Study \\ Preliminary Investigation}

Database Title: Defense Technical Information Center

\section{Point of Contact:}

Defense Technical Information Center

DTIC Product Management Branch

Building 5, Cameron Station

Alexandria, VA 22304-6145

703-274-6434

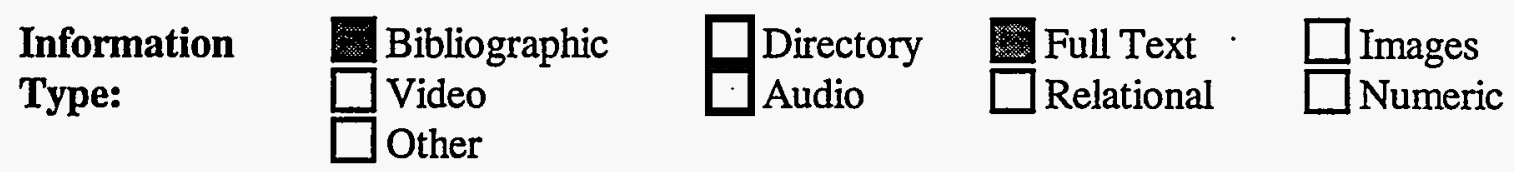

$\begin{array}{llll}\text { Media } & \text { CD-ROM } & \text { Magnetic Tape } & \square \text { Diskette } \\ \text { Format: } & \text { On-line Service } & \text { Internet } & \square \text { BBS }\end{array}$

Restrictions:

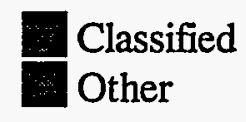

Government Only

U.S. Only

\section{Described below.}

DTIC access is limited to DoD, DoD contractors, and U.S. government agencies and their contractors. Other organizations may become eligible for access on the basis of several support programs. Access is limited to unclassified titles, abstracts, reports, and support information unless the agency/contractor has an approved security access and STU III capabilities. (See discussion in comments.) The highest classified information level is Secret.

\section{Content:}

DTIC holdings include technical reports, management information summaries at the work unit level, and independent research \& development (IR\&D) efforts. The collection includes topics associated with defense research, such as aeronautics missile technology, space technology, navigation, and nuclear science. In addition, subjects such as biology, chemistry, energy, environmental sciences, oceanography, computer sciences, sociology, and human factors engineering are available. Four primary databases make up DTIC: (1) Technical Report (TR) bibliographic database, (2) R\&T Work Unit Information System (WUIS) database, (3) IR\&D database, and (4) Manpower and Training Research Information System (MATRIS) database.

\section{Update Date, Frequency:}

On-line databases: updated daily.

CD-ROM: updated quarterly.

Tape on demand. 
Database Title: Defense Technical Information Center

\section{Sources, Number of Records:}

The sources are DoD organizations and their contractors. In addition, foreign governments and other U.S. government agencies and their contractors can also submit material to be included in the DTIC databases. The TR bibliographic database contains nearly 2 million citations. The R\&T WUIS database contains more than 208,000 summaries of work unit projects. The MATRIS database contains approximately 5,600 summaries. The size of the IR\&D database is not identified.

\section{Restrictions on Distribution of Derived Data:}

Restrictions on distribution of classified data follow standard security guidelines. The IR\&D database is proprietary and is provided to DoD personnel with classified access.

\section{Hardware/Operating System:}

Unclassified access requires no specific hardware platform or operating system. If CD-ROM distribution of TR is being used, hardware requirements are any IBM PC-compatible, version 3.0 or a later of version DOS, 640-K RAM, 500-K hard disk, CD-ROM reader, and 5.25-in. floppy disk drive.

\section{Special Hardware Requirements:}

Classified access requires a STU III encryption capability and secure facility for storing retrieved classified information.

Modem or Internet access capabilities are required for unclassified access.

\section{Special Software Requirements:}

Standard modem communications software is required for basic access.

\section{Restrictions on Interface Mechanisms:}

Must use either DoD's RDT\&E On-line System (DROLS) for search access from modem or DoD's Gateway Information Service (DGIS) for either modem or Internet access. CD-ROM requires DROLS software (supplied) on PC.

\section{Initial Costs:}

Access can be set up through an NTIS deposit account. An initial $\$ 100$ is required to establish an account. Following initial account setup, the user (agency/office) will be billed for actual costs. Access through DGIS requires a $\$ 100$ annual fee plus the standard retrieval costs. This new fee structure was effective October 1,1994 , and is not shown on the current price sheet.

CD-ROM costs are $\$ 600$ per year subscription (quarterly distribution; currently three CDS per distribution). 
Database Title: Defense Technical Information Center

Subsequent Costs:

Actual usage costs. DGIS requires an annual $\$ 100$ fee. CDS require a $\$ 600$ annual subscription.

Availability of Demonstration Copies or Demonstration Licenses:

Demonstration copies/licenses are not available, however, ANL has access to DTIC through the library system.

\section{Comments:}

Classified data access is not available through DGIS. However, DGIS provides a gateway to DTIC databases as well as more than 850 commercial and government databases. Access to items such as DIALOG and STN are available through the DGIS gateway. The user must have a DIALOG, STN, or other access setup, but the search can be coordinated through DGIS. DGIS provides a single interface command language (Common Command Language [CCL]) that can be used to query all database access systems available through DGIS. The user can access DGIS through the Internet; however, if the user only has modem access, the user can access Internet through the DGIS gateway. Output from DTIC can be provided as text file or distributed on magnetic tape or in printed (hardcopy) form. 


\section{Technology Information Management System Database Study Preliminary Investigation}

Database Title: DIALOG Information Retrieval Service

Point of Contact:

DIALOG Information Services Inc.

3460 Hillview Ave.

P.O. Box 10010

Palo Alto, CA 94303

Sales Desk: 800-334-3785

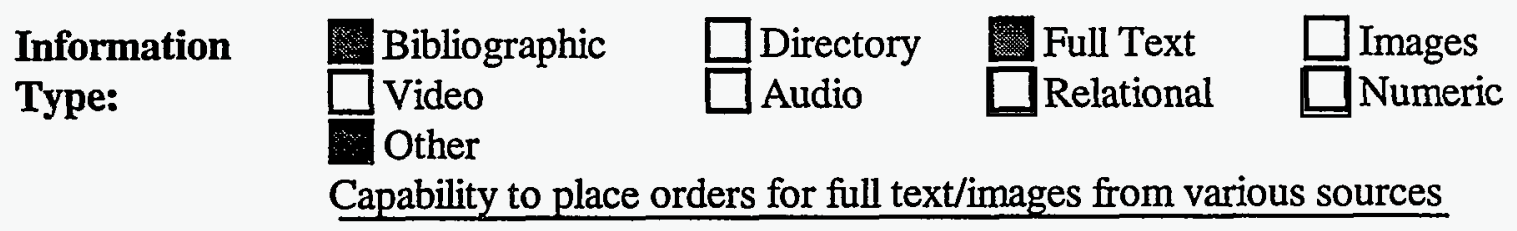

Media

Format:

CD-ROM
On-line Service
Other

$\square$ Magnetic Tape
Internet

$\square$ Diskette

Other

Fax, E-mail, U.S.

$\begin{array}{ccc}\text { Restrictions: } & \square \text { Classified } \square \text { Government Only } \\ & \square \text { Other } \underline{\text { Various restrictions of source databases }}\end{array}$

\section{Content:}

DIALOG has access to more than 450 databases from various disciplines. DIALOG has bibliographic or full access to documents, including scientific and technical literature, full-text trade journals, newspapers, and newswires. Patent, demographic, financial, medicine, and energy are other topics for which information is available.

Update Date, Frequency:

Variable, depending on source database

Sources, Number of Records:

Government databases, such as NTIS, U.S. Geological Survey, U.S. Patent Office, etc.; foreign governments; trade journals; news services; and various commercial information database sources 
Database Title: DIALOG Information Retrieval Service

\section{Restrictions on Distribution of Derived Data:}

DIALOG ERA (Electronic Redistribution and Archiving) allows DIALOG customers to purchase the right to redistribute search results within their organization (REDIST) or to retain search results in a local database (ARCHIVE). Additional costs are based on a multiplier determined by the number of copies and/or the number of users of the local database.

\begin{tabular}{|c|c|c|c|c|}
\hline & \multicolumn{2}{|c|}{ REDIST } & \multicolumn{2}{|c|}{ ARCHIVE } \\
\hline & Multiplier & $\begin{array}{l}\text { No. of Copies } \\
\text { Allowed }\end{array}$ & Multiplier & $\begin{array}{l}\text { No. of Copies } \\
\text { Allowed }\end{array}$ \\
\hline & 1 & 2 & 3 & $1-25$ \\
\hline Cost of & 3 & $3-15$ & 6 & $26-200$ \\
\hline \multirow[t]{6}{*}{ Original } & 4 & $16-50$ & 10 & $201-500$ \\
\hline & 5 & $51-100$ & 12 & $501-1,000$ \\
\hline & 6 & $101-200$ & 14 & $1,000+$ \\
\hline & 10 & $201-500$ & & \\
\hline & 12 & $501-1,000$ & & \\
\hline & 14 & $1,001+$ & & \\
\hline
\end{tabular}

\section{Hardware/Operating System:}

Access requires no specific hardware platform or operating system.

\section{Special Hardware Requirements:}

Modem capabilities are required for on-line access. The user has the option of Internet access.

\section{Special Software Requirements:}

Standard modem communications software is required for basic access.

\section{Restrictions on Interface Mechanisms:}

Access is through DIALOG's command language. Alternate interfaces are available, such as DIALOG Menus, DIALMAIL, and DIALINDEX. DIALOG Menus, for example, is a menu-driven interface for keywords, authors, etc., to simplify searching for newer users. However, only about 220 databases are accessible through this interface, not the full $450+$. 
Database Title: DIALOG Information Retrieval Service

\section{Initial Costs:}

Initial sign-up costs for DIALOG: $\$ 295$.

Basic connection cost examples: Internet connection $\$ 6 /$ hour, SprintNet $\$ 12 /$ hour.

Actual search costs depend on connect time and number of records retrieved.

Examples of some of these costs are shown below.

Database

Ceramic Abstracts

CLAIMS/U.S. Patents Abstracts

Foundation Grants Index

Reuters
HR/connect Per-Record Cost

$\$ 60$

$\$ 0.65$

$\$ 120$

$\$ 1.70$

$\$ 30$

$\$ 0.55$

$\$ 90$

$\$ 0.75$

Per-record costs can vary, depending on whether the record was typed (displayed to the screen) or printed (user local hard copy). These costs are frequently the same, but sometimes prints are more costly.

\section{Subsequent Costs:}

DIALOG annual service fee: $\$ 75$.

Basic connection cost examples: Internet connection $\$ 6.00 /$ hour, SprintNet $\$ 12.00 /$ hour.

Specific databases: actual costs.

Additional costs are specific to E-mail distribution ALERT notices, paper printout, and distribution.

\section{Availability of Demonstration Copies or Demonstration Licenses:}

ANL has a DIALOG account through ANL's Information and Publishing Division (library). It is possible that the library may be able to provide access for testing. Thirty-day demonstration licenses may also be set up.

\section{Comments:}

A variety of databases are available under the DIALOG OnDisc capability. Additional information can be requested for this option, but very little was available in the DIALOG documentation received. ALERT services can be set up for automatic notification and forwarding of new records that meet specified search criteria. (This item is expensive.)

Access costs through services such as DIALOG can be extremely high and can accumulate very quickly. A variety of hidden costs would require significant amounts of time to anticipate all the detail costs.
ANL Investigator Name: Greg Robinson
Date: $8 / 30 / 94$ 
Technology Information Management System Database Study

Preliminary Investigation

Database Title: Federal Grants/Funding LOCATOR

Point of Contact:

Lou Bossi

Staff Directories, Ltd.

P.O. Box 62

Mount Vernon, VA 22121-0062

703-739-0900

Information

Type:

$\begin{array}{lll}\square_{\text {Bibliographic }} & \square \text { Directory } & \square_{\text {Audio }} \\ \square \text { Relational } & \square \text { Images }\end{array}$

Media

Format:

CD-ROM
On-line Service
Other

$\square$ Magnetic Tape

Internet

$\square$ Diskette
$\square$ BBS

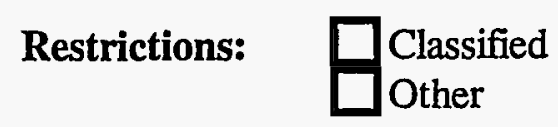

$\square$ Government Only

$\square$ U.S. Only

Content:

Copy of federal publication: Catalog of Federal Domestic Assistance

Update Date, Frequency:

Twice a year (when catalog is published), usually November and July

Sources, Number of Records:

Sources are listed in the content section.

Restrictions on Distribution of Derived Data:

None

Hardware/Operating System:

$\mathrm{PC}, \mathrm{DOS}$

Special Hardware Requirements:

CD-ROM drive

Special Software Requirements:

None 
Database Title: Federal Grants/Funding LOCATOR

Restrictions on Interface Mechanisms:

Yes, data are compiled; uses Dataware. Must use provided user interface.

\section{Initial Costs:}

For a single user: $\$ 295 /$ year.

Includes two CDs: current and next distribution.

For 2-5 users: $\$ 590$; for $6-10$ users: $\$ 738$; for $11-25$ users: $\$ 1,770$.

Subsequent Costs:

Same cost yearly

Availability of Demonstration Copies or Demonstration Licenses:

No

Comments:

ANL Investigator Name: Mary Braun Date: 8/24/94 


\section{Technology Information Management System Database Study \\ Preliminary Investigation}

Database Title: Federal Technology Report

Point of Contact:

Andrea Broadbent, General Manager

McGraw-Hill Publications On-line

Princeton-Hightstown Road

North Building - 1

Hightstown, NJ 08520

609-426-7352

Fax: 609-426-5523

\begin{tabular}{|c|c|c|c|c|}
\hline $\begin{array}{l}\text { Information } \\
\text { Type: }\end{array}$ & $\begin{array}{l}\square \text { Bibliographic } \\
\square \text { Video }\end{array}$ & $\begin{array}{l}\square \text { Directory } \\
\square \text { Audio }\end{array}$ & $\begin{array}{l}\text { Full Text } \\
\text { Relational }\end{array}$ & $\begin{array}{l}\square_{\text {Images }} \\
\square \text { Numeric }\end{array}$ \\
\hline
\end{tabular}

Media

Format:

$\square$ CD-ROM
On-line Service
$\square$ Other

$\square$ Magnetic Tape

$\square_{\text {Biss }}$

Restrictions:

$\square$ Classified

$\square$ Government Only

$\square$ U.S. Only

\section{Content:}

This database contains the full text of Federal Technology Report, a newsletter that covers business opportunities at U.S. federal laboratories under DoD, DOE, and DOC. It covers technology transfer laws, licensing arrangements, and cooperative research and development arrangements. Areas covered in this database include environment and waste management, energy, materials science, manufacturing processes, computers and communications, biotechnology and medicine, analysis, and instrumentation.

The database dates to January 1990 and is available on various on-line services, including DIALOG, NewsNet, and NEXIS.

\section{Update Date, Frequency:}

Biweekly

Sources, Number of Records:

Federal Technology Report newsletter (formerly Tech Transfer Report)

Restrictions on Distribution of Derived Data:

(See DIALOG references.) 
Database Title: Federal Technology Report

Hardware/Operating System:

PC platform

Special Hardware Requirements:

Modem for communications

Special Software Requirements:

Communications software

Restrictions on Interface Mechanisms:

No known restrictions on interface mechanisms. One should be able to write an interface on top of DIALOG that uses the command language.

Initial Costs:

Initial on-line service license charges

Subsequent Costs:

Annual on-line service charges plus additional hourly telecommunication charges and printing charges

Availability of Demonstration Copies or Demonstration Licenses:

Trial DIALOG licenses are available.

Comments:

The scope of this database may not be large enough. Other databases contain similar information. 


\section{Technology Information Management System Database Study \\ Preliminary Investigation}

Database Title: Global Mobility Database

\section{Point of Contact:}

Society of Automotive Engineers/Electronic Publishing Division

400 Commonwealth Drive

Warrendale, PA 15096

412-776-4841

Fax: 412-776-5760

\begin{tabular}{|c|c|c|c|}
\hline Information & Bibliographic & $D$ Directory & $\square$ Full Text \\
\hline Type: & $\begin{array}{l}\text { JVideo } \\
\text { Jother }\end{array}$ & $\square$ Audio & $\square$ Relational \\
\hline
\end{tabular}

Media

Format:

CD-ROM
On-line Service
$\square$ Other

Magnetic Tape
$\square$ Internet

$\square_{\text {Diskette }}$

Restrictions:

$\square$ Classified

$\square$ Government Only

$\square$ U.S. Only

\section{Content:}

Citations with abstracts to technical papers from SAE meetings and conferences, as well as SAE books on automotive, aerospace technology, and vehicular-related industries. Information includes topics such as vehicle design, manufacturing, materials, fuels and lubricants, testing, aerodynamics, brakes, control systems, electronics, batteries, composites, and related technology.

\section{Update Date, Frequency:}

Monthly

\section{Sources, Number of Records:}

58,000 citations of technical papers and 7,000 citations on SAE books, reports, etc.

Source includes SAE as well as comparable international societies.

\section{Restrictions on Distribution of Derived Data:}

None identified

\section{Hardware/Operating System:}

Access requires no specific hardware platform or operating system.

Special Hardware Requirements:

Modem capabilities are required for on-line access. 
Database Title: Global Mobility Database

\section{Special Software Requirements:}

Standard modem communications software is required for basic access.

\section{Restrictions on Interface Mechanisms:}

Users must use either their interface software or access through the various database service agencies, such as STN. A user who can receive data on magnetic tape can structure his/her software for access and search.

\section{Initial Costs:}

Costs vary depending on distribution form. Magnetic tapes depend on specific data sets selected. CD-ROM distribution (annual only) varies from a single-user license for $\$ 1,795$ to a network license for $\$ 5,000$. SAE member or university fees are $\$ 900$ and $\$ 3,350$, respectively. On-line access service varies by supplying agency.

\section{Subsequent Costs:}

Tape costs vary by the specific data set requested. CD-ROM annual renewals are $\$ 900$ for a single user and $\$ 3,000$ for network users. The renewals for SAE/university are $\$ 600$ and $\$ 1,800$, respectively.

\section{Availability of Demonstration Copies or Demonstration Licenses: \\ Demonstration disks for the tape ASCII format and the CD-ROM distribution format are available and were requested. ANL received the disks for both formats on August 18, 1994.}

\section{Comments:}

The point of contact for tape distribution is Jim Berardone (412-776-4841, ext. 271). 


\section{Technology Information Management System Database Study \\ Preliminary Investigation}

Database Title: Government Research Centers Directory

Point of Contact:

Gale Research Inc.

835 Penobscot Bldg.

Detroit, MI 48226-4094

313-961-2242

$800-347-4253$

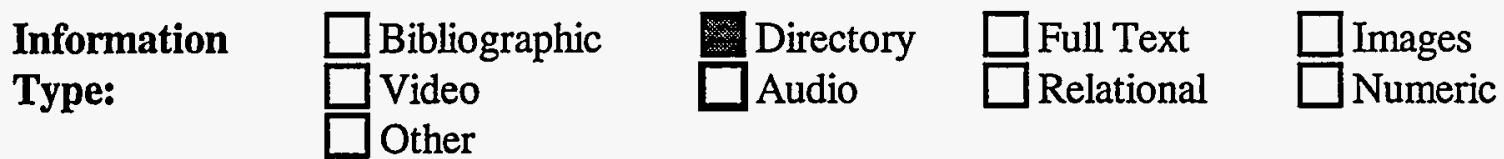

$\begin{array}{llll}\text { Media } & \square \text { CD-ROM } & \square \text { Magnetic Tape } & \\ \text { Format: } & \square \text { On-line Service } & \square \text { Internet } \\ \text { Other } & & \\ \text { Restrictions: } & \square \text { Classified } & \square \text { Government Only } & \begin{array}{l}\text { Diskette } \\ \text { BBS }\end{array}\end{array}$

\section{Content:}

Information is given on all U.S. and Canadian research centers, including contact information, geographic information, history, status, some activities, and programs and publications.

Update Date, Frequency:

Annual

Sources, Number of Records:

4,000 centers

Restrictions on Distribution of Derived Data:

Internal research needs and mailing labels only. Cannot reproduce, publish, or loan data or program to a third party.

Hardware/Operating System:

IBM-compatible PC

Special Hardware Requirements:

Special Software Requirements:

Distribution includes interface/search software. 
Database Title: Government Research Centers Directory

Restrictions on Interface Mechanisms:

Uncertain

Initial Costs:

$\$ 2 ; 000$

\section{Subsequent Costs:}

$\$ 2,000$ each new disk (annually)

Availability of Demonstration Copies or Demonstration Licenses:

No

\section{Comments:}

Hard copy seems to be the main product. Can purchase hard copy to determine whether data are appropriate.

Can get custom data sets (for example, just publication information) as raw data (ASCII). 


\section{Technology Information Management System Database Study}

Preliminary Investigation

Database Title: IEEE/IEE Publications Ondisc (IPO)

Point of Contact:

Michele A. Day

Manager, INSPEC US Office

IEEE Service Center

IEE/INSPEC Department

445 Hoes Lane

P.O. Box 1331

Piscataway, NJ 08855-1331

908-562-5549
Subscriptions available from:

University Microfilms International 300 N. Zeeb Road

Ann Arbor, MI 48106

313-761-4700

800-521-0600

Fax: 313-761-1203

\section{$\begin{array}{llll}\text { Information } & \square_{\text {Bibliographic }} & \square \text { Directory } & \square_{\text {Full Text }}\end{array}$}

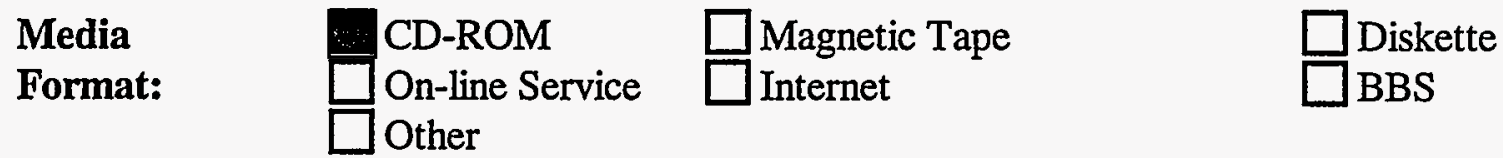

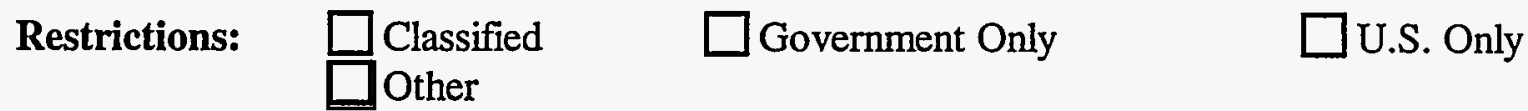

\section{Content:}

Scanned images of the full-text of all (U.S.) IEEE and (U.K.) IEE journals, conference papers, and standards, plus an index disk that contains bibliographic and indexing records (relevant records from IEE's INSPEC database). Subjects include physics, electronics, electrical engineering, computer science, and control technology.

\section{Update Date, Frequency:}

Text images: updated monthly

Sources, Number of Records:

Contains about 80 IEEE and IEE journal titles from 1988. Monthly updates add about 15,000 pages. New subscribers receive a multiple disk set with four back years, plus the current year; 25,000 index records are added annually.

\section{Restrictions on Distribution of Derived Data:}

None stated 
Database Title: IEEE/IEE Publications Ondisc (IPO)

Hardware/Operating System:

Standard CD-ROM on IBM-compatible workstations

Special Hardware Requirements:

Information on special configuration requirements can be provided by University Microfilms International (UMI).

Special Software Requirements:

Restrictions on Interface Mechanisms:

Initial Costs:

$\$ 30,750$

1994 full subscription price

$\$ 22,000$

1994 subscription price for subscribers to all IEEE/IEE journals

$\$ 17,000$

1994 subscription price to IEEE/IEE journals and conference proceedings

$\$ 10,000$

1988 and 1989 back files

\section{Subsequent Costs:}

Availability of Demonstration Copies or Demonstration Licenses:

None available, but UMI offers a 60-day free trial on its CD-ROMs.

Comments:

Publications are images, not text. 


\section{Technology Information Management System Database Study \\ Preliminary Investigation}

Database Title: INSPEC Database (see also INSPEC Ondisc)

Point of Contact:

Michele A. Day

Manager, INSPEC U.S. Office

IEEE Service Center

IEE/INSPEC Department

445 Hoes Lane

P.O. Box 1331

Piscataway, NJ 08855-1331

908-562-5549

Information

Type:

Bibliographic
$\square$ Video
Other
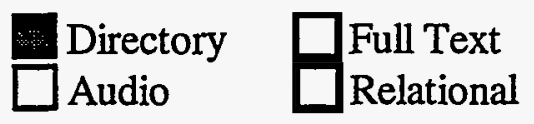

$\square_{\text {Numeric }}$

Indexing and abstracts

\begin{tabular}{|c|c|c|c|}
\hline Media & $\square$ CD-ROM & Magnetic Tape & $\square$ Diskette \\
\hline Format: & $\begin{array}{l}\text { On-line Service } \\
\square \text { Other }\end{array}$ & Internet & $\mathrm{BBS}$ \\
\hline Restrictions: & $\begin{array}{l}\square \text { Classified } \\
\square \text { other }\end{array}$ & $\square$ Government Only & $\square$ U.S. Only \\
\hline
\end{tabular}

\section{Content:}

This database is an electronic version of three printed publications: Physics Abstracts, Electrical and Electronics Abstracts, and Computer and Control Abstracts. It provides indexing and abstracts for journals, conferences, books, reports, and dissertations in all areas of physics, electrical engineering and electronics, computing and control technology, and information technology. "It covers material from all worldwide publishers" and dates back to 1969 .

The physics section covers mechanics; heat; optics; acoustics; magnetism; electricity; physics of solids, liquids, gases, plasmas, molecules, atoms, nuclei and elementary particles; applied physics, including instrumentation, lasers, nuclear power, semiconductors, and superconductors; astronomy; astrophysics; biophysics; energy research; environmental science; geophysics; materials science; physical metallurgy; relativity; and gravitation. 


\section{Database Title: INSPEC Database}

\section{Content (Cont.):}

The electrical engineering and electronics section covers electronic components and technology; telecommunications; power engineering and instrumentation; aerospace electronics; antennas and propagation; biomedical engineering; electric machines; electron tubes; electronic circuits; energy conservation; image processing; insulation; lasers; magnetic devices; measurements; microelectronics; microwave technology; military electronics; nuclear instrumentation; optical and optoelectronic devices; power generation and supply; printed circuits; radar; radio communications; radio and television; semiconductor technology; signal processing; speech processing; and superconducting devices.

The computers/computing and control technology section covers artificial intelligence; computer theory; software and computing applications; optical computing; neurocomputing; hardware topics such as circuitry, storage, peripheral equipment, and networking; software topics such as application programs, software engineering, systems, and techniques; expert systems; data, signal, and word processing; desktop publishing; computer-aided analysis and design; computer communications; computerized control and instrumentation; control technology such as communications, industrial production, instrumentation, materials handling, manufacturing processes, and transportation.

The information technology section covers materials of interest to managers and technologists in business, banking, insurance, leisure, the media, marketing, and retailing and office automation topics such as electronic mail, facsimile, teleconferencing, computer terminals, communications, and word processing.

\section{Update Date, Frequency:}

On-line service is updated weekly. Tapes are updated weekly or monthly. Back issues of tapes are available from January 1969 to December 1993.

\section{Sources, Number of Records:}

This database is an electronic version of three printed publications: Physics Abstracts, Electrical and Electronics Abstracts, and Computer and Control Abstracts. Currently it contains records for more than 4.5 million scientific and technical papers, and 280,000 records are added annually. These publications reference more than 4,200 journals and 2,000 published conference proceedings, as well as numerous books, reports, and dissertations.

\section{Restrictions on Distribution of Derived Data:}

None

\section{Hardware/Operating System:}

On-line service requires a modem.

\section{Special Hardware Requirements:}

None 
Database Title: INSPEC Database

\section{Special Software Requirements:}

None

Restrictions on Interface Mechanisms:

Initial Costs:

Tape lease fees:

$\$ 27,600$ Complete database

$\$ 22,000$ Physics Section

$\$ 17,200$ Electrical and Electronics Section

$\$ 16,600$ Computers and Control Section

$\$ 4,400 \quad$ Information Technology Section

$\$ 41,400$ Special Academic Package with a complete database with two back years and single-site unlimited usage

Costs for other data subsets are open for negotiation.

\section{Subsequent Costs:}

"You only pay when they use the system - most searches cost from $\$ 20-\$ 50 . "$

Various on-line access providers charge about $\$ 100 /$ hour and about $\$ 0.70 /$ record.

Availability of Demonstration Copies or Demonstration Licenses:

Michelle A. Day stated she "can provide us with a demonstration password to one of the on-line systems for a limited time for demo purposes only." She is also willing to provide us with a sample magnetic tape.

\section{Comments:}

INSPEC may be accessed on-line via DIALOG (Palo Alto, CA), STN (Columbus, OH), BRS (McLean, VA), Orbit (McLean, VA), DataStar (Philadelphia, PA), EPIC, and FirstSearch on-line systems. INSPEC Ondisc is the CD-ROM version of the INSPEC database, produced by University Microfilms International (UMI), covering from 1988 forward.

Each record contains an English-language title and descriptive abstract, together with full bibliographic details, including the journal title, author's name and affiliation, and the language of the original document. To supplement natural-language searching, INSPEC provides an extensive range of search elements, including classification codes from the INSPEC Classification, controlled index terms from the INSPEC Thesaurus, structured numerical data indexing, controlled chemical substance indexing, free language "keywords" pinpointing significant concepts, treatment codes that indicate the author's approach to the subject, and language and country of publication.

For additional information or help in obtaining passwords, contact the INSPEC Help Desk at 908-562-5549 from 8:00-16:00 Eastern Standard Time. 


\section{Technology Information Management System Database Study \\ Preliminary Investigation}

Database Title: INSPEC Ondisc (see technical descriptions for INSPEC database)

Point of Contact:

Michele A. Day

Manager, INSPEC U.S. Office

IEEE Service Center

IEE/INSPEC Department

445 Hoes Lane

P.O. Box 1331

Piscataway, NJ 08855-1331

908-562-5549

Information

Type:

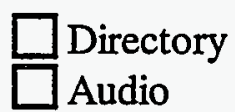

$\square$ Full Text

$\square$ Images

Audio $\square$ Magnetic Tape
$\square$ Internet

$\square$ Government Only $\square$ Diskette

BBS

$\square$ U.S. Only

Restrictions:

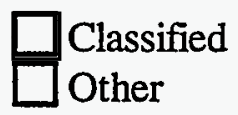
然

\section{Content:}

(See the description for INSPEC database.) This database is available on CD-ROM from 1989 onward and can be searched by University Microfilms International's (UMI's) ProQuest software.

\section{Update Date, Frequency:}

Each year, the database is published on one disk; new subscribers receive a multiple-disk set comprising two years of back files and the current year, which is updated quarterly.

\section{Sources, Number of Records:}

(See the description for INSPEC database.)

\section{Restrictions on Distribution of Derived Data:}

None

Hardware/Operating System:

Any IBM-compatible system (AT, 386, PS/2) 
Database Title: INSPEC Ondisc

Special Hardware Requirements:

640-K RAM, 4-MB free disk space, MS DOS version 3.1 or higher, CD-ROM that uses MS CDROM extensions ( 2.1 or higher), color monitor preferable but not essential

Special Software Requirements:

Software supplied

Restrictions on Interface Mechanisms:

Initial Costs:

$\$ 8 ; 100$

Complete database for nonsubscribers to Physics Abstracts, Electrical and Electronics Abstracts, and Computer and Control Abstracts

$\$ 3,785$

$\$ 1,875$

Complete database for subscribers to the three abstracts journals

$\$ 1,950$

1989 disk

$\$ 2,025$

1990 disk

$\$ 4,995$

1991 disk

1989, 1990, and 1991 disks as a pack

Two subsets of the disks are also available, containing only records for Physics Abstracts, or Electrical and Electronics Abstracts, or Computer and Control Abstracts, and the information technology section of the database:

$\$ 4,865$

$\$ 2,275$

$\$ 1,175$

$\$ 1,200$

$\$ 2,250$

1994 subscription price for abstracts nonsubscribers

$\$ 3,000$ 1994 subscription price for abstract subscribers

1989 disk

1990 disk

1991 disk

1989, 1990, and 1991 disks as a pack

Networking prices and discounts for multiple subscriptions are available on request.

\section{Subsequent Costs:}

Availability of Demonstration Copies or Demonstration Licenses:

(See the description for INSPEC database.)

\section{Comments:}

(See the description for INSPEC database.)

ProQuest user interface written by UMI is a critical part of the CD-ROM.
ANL Investigator Name: Mark Jusko
Date: $8 / 25 / 94$ 


\title{
Technology Information Management System Database Study
}

Database Title: IPC: CLASS

Preliminary Investigation

\author{
Point of Contact: \\ Mr. Hansen \\ World Intellectual Property Organization \\ 34 Chemin des Colombettes, $\mathrm{CH}-1211$ \\ Geneva, 20 Switzerland \\ 011-41-22-7309111
}

$\begin{array}{llll}\text { Information } & & \begin{array}{l}\text { Bibliographic } \\ \text { Type: }\end{array} & \square \text { Dideo } \\ \text { Other } & \square \text { Audio } & \square_{\text {Relational }} & \square \text { Images } \\ \text { Media } & \square_{\text {Numeric }}^{\text {CD-ROM }} & \square \text { Magnetic Tape } & \square \text { Diskette } \\ \text { Format: } & \square_{\text {On-line Service }} & \square \text { Internet } & \square \text { BBS } \\ \text { Restrictions: } & \square_{\text {Other }}^{\text {Classified }} & \square \text { Government Only } & \square \text { U.S. Only }\end{array}$

\section{Content:}

This database contains electronic versions of the International Patent Classification (IPC), a directory published in five-year intervals. On disk are 1980, 1985, 1990, and 1995 (to be released in September 1994). The IPC does not contain actual patents but is indexed by the technical information contained in patents to facilitate searches. In addition to the index by patent classification, IPC-CLASS has catchword indexing, concordance data, and IPC symbols data. Two of the main stated benefits of IPC are that it is available in five languages and it is international.

\section{Update Date, Frequency:}

Every five years (September 1994)

Sources, Number of Records:

World Intellectual Property Organization classification system

\section{Restrictions on Distribution of Derived Data:}

No internal restriction

Hardware/Operating System:

PC, Windows 
Database Title: IPC: CLASS

Special Hardware Requirements:

CD-ROM reader

Special Software Requirements:

Restrictions on Interface Mechanisms:

Initial Costs:

SwFr 500 (approximately $\$ 360$ in 1994 U.S. dollars)

Subsequent Costs:

Availability of Demonstration Copies or Demonstration Licenses:

The 1990 version was sent to ANL.

Comments:

IPC is inexpensive (compared with on-line services) and may be useful as a first-stage screen for patent searches. However, the documentation is awkward, and the data are not as current or as extensive as those from other sources. 


\section{Technology Information Management System Database Study \\ Preliminary Investigation}

Database Title: Jane's Information Group, Inc.

Point of Contact:

Deborah A. Boyd

TeleServicing Representative

Jane's Information Group, Inc.

1340 Braddock Pl., Suite 300

Alexandria, VA 22314

703-683-3700

Fax: 703-836-1699

\begin{tabular}{|c|c|c|c|}
\hline $\begin{array}{l}\text { Information } \\
\text { Type: }\end{array}$ & $\begin{array}{l}\text { Bibliographic } \\
\square \text { Video } \\
\square \text { Other }\end{array}$ & $\begin{array}{ll}\square \text { Directory } & \text { Full Text } \\
\square \text { Audio } & \square \text { Relational }\end{array}$ & $\begin{array}{l}\text { Images } \\
\text { Numeric }\end{array}$ \\
\hline $\begin{array}{l}\text { Media } \\
\text { Format: }\end{array}$ & $\begin{array}{l}\text { CD-ROM } \\
\square \text { On-line Service } \\
\square \text { Other }\end{array}$ & $\begin{array}{l}\square \text { Magnetic Tape } \\
\square \text { Internet }\end{array}$ & $\begin{array}{l}\text { Diskette } \\
\text { BBS }\end{array}$ \\
\hline Restrictions: & $\begin{array}{l}\square \text { Classified } \\
\square \text { Other }\end{array}$ & $\square$ Government Only & Ju.S. Only \\
\hline
\end{tabular}

\section{Content:}

Jane's Information Group has a series of well-known manuals on military equipment. These manuals include information on defense, weaponry, civil aviation, and transportation. Many of these manuals are available on CD-ROM; many contain images as well as full textual descriptions and inventory information. These CDs are available as single CDs or as volumes of related CDs. Currently, more than a dozen CD titles are offered. These include Jane's Battlefield Surveillance Systems, Jane's C3I Systems, Jane's Defense Magazine Library, and Jane's Fighting Ships.

\section{Update Date, Frequency:}

Annually, some monthly

\section{Sources, Number of Records:}

Each $\mathrm{CD}$ c ontains the equivalent of hundreds of pages from the Jane's manuals.

Restrictions on Distribution of Derived Data:

No known restrictions 
Database Title: Jane's Information Group, Inc.

Hardware/Operating System:

IBM PC

Special Hardware Requirements:

CD-ROM reader

Special Software Requirements:

For using the default searching mechanisms, a program called ROMW can be used but is not required.

Restrictions on Interface Mechanisms:

Jane's will distribute the CDs in ASCII format so that users can develop their own programs. Some work is ongoing at ANL in this area.

\section{Initial Costs:}

The general cost is approximately $\$ 800 /$ disk. Discounts are offered for buying volumes of multiple CDs. Network and multiuser licenses cost more. For example, it costs $\$ 200$ per user to add one to four additional concurrent users.

\section{Subsequent Costs:}

Annual updates to the products can be ordered.

Availability of Demonstration Copies or Demonstration Licenses:

Copies are available at ANL for performing additional evaluations.

\section{Comments:}

This data source is widely used in the defense community and holds a wealth of information. Whether or not these data are of relevance to the sponsor needs to be determined.

\section{ANL Investigator Name: Mary Ann Widing Date: 9/7/94}

Technology Information Management System Database Study 
Preliminary Investigation

Database Title: NASA Scientific and Technical (STI) Database

\section{Point of Contact:}

Gail Herbig

NASA

Center for AeroSpace Information

800 Elkridge Landing Rd.

Linthicum Heights, MD 21090-2934

301-621-0153

\begin{tabular}{|c|c|c|c|}
\hline $\begin{array}{l}\text { Information } \\
\text { Type: }\end{array}$ & $\begin{array}{l}\text { Bibliographic } \\
\square \text { Video } \\
\square \text { Other }\end{array}$ & $\begin{array}{l}\square \text { Full Text } \\
\square \text { Relational }\end{array}$ & $\begin{array}{l}\square \text { Images } \\
\square \text { Numeric }\end{array}$ \\
\hline $\begin{array}{l}\text { Media } \\
\text { Format: }\end{array}$ & $\begin{array}{l}\square \text { CD-ROM } \\
\text { Online Service } \\
\square \text { Other }\end{array}$ & $\begin{array}{l}\square \text { Magnetic Tape } \\
\square \text { Internet }\end{array}$ & $\begin{array}{l}\square \text { Diskette } \\
\square \text { BBS }\end{array}$ \\
\hline Restrictions: & $\begin{array}{l}\square \text { Classified } \\
\square \text { Other }\end{array}$ & Government Only & U.S. Only \\
\hline
\end{tabular}

\section{Content:}

Citations with abstracts to published reports, journal articles, conference papers, project records, patents, and dissertations dealing with aerospace science and technology and other fields, including but not limited to the following:

1. STAR: Scientific and Technical Aerospace Reports: primarily NASA technical reports.

2. IAA: International Aerospace Abstracts: journal and monograph literature relating to aerospace (updated semimonthly).

3. Aerospace Medicine and Biology.

4. NASA Research and Development Contracts Search File: information about research and development contracts, grants, and work orders (not documents); updated monthly.

5. COSMIC Software Catalog (current year only, updated annually).

6. AERONET Data Locator: directory of numerical, factual, and image databases.

7. NASA Tech Briefs: 13,000 unclassified articles on technical innovations originating at NASA centers; topics include electronics, physics, mathematics, life sciences, manufacturing, and information sciences; updated monthly.

\section{Update Date, Frequency:}

Every two weeks

\section{Sources, Number of Records:}

Sources are listed in the content section. Three million records are included. 
Database Title: NASA Scientific and Technical (STI) Database

Restrictions on Distribution of Derived Data:

None

Hardware/Operating System:

Special Hardware Requirements:

Special Software Requirements:

Restrictions on Interface Mechanisms:

Initial Costs:

Registration: $\$ 60$

Subsequent Costs:

Yearly maintenance: $\$ 60$.

Usage fee: $\$ 24 /$ hour.

Availability of Demonstration Copies or Demonstration Licenses:

Demo via Internet exists: instructions for WAIS access to an experimental portion of the NASA STI Database: RECON.

http://www.sti.nasa.gov/STI-homepage.html

Comments: 


\section{Technology Information Management System Database Study \\ Preliminary Investigation}

Database Title: National Technical Information Service (NTIS)

Point of Contact:

U.S. Department of Commerce

Technology Administration

National Technical Information Service

5285 Port Royal Rd.

Springfield, VA 22161

708-487-4929

Fax: 708-487-4134

Sales: $703-487-4650$

Information

Type:

Media

Format:

Restrictions:

Bibliographic
$\square$ Video
$\square$ Other

CD-ROM
Online Service
$\square$ Other

$\square$ Classified

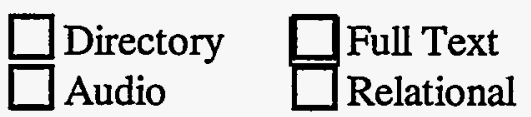

$\square$ Images

$\square$ Magnetic Tape
$\square$ Internet

$\square$ Diskette
$\square$ BBS

$\square$ Government Only $\square$ U.S. Only

\section{- Content:}

The bibliographic database contains summaries of scientific, technical, engineering, and business information products available from NTIS. Major areas covered include the biological, social, and physical sciences; mathematics; engineering; and business information. These products were acquired by NTIS from 1964 to the present and include announcements of computer-readable software and data files, U.S. government-owned inventions available for licensing, selected reprints, federally sponsored translations, videos, and some non-English-language reports. These products can be ordered from NTIS.

The bibliographic database is available, through a PC, from a number of on-line services: BRS, CISTI (in Canada), DataStar, DIALOG, ESA/IRS (in Italy), NERAC, ORBIT, STN International, or on CD-ROM from either DIALOG or Silver-Platter. DIALOG's CD-ROM includes records from 1980 to the present. SilverPlatter's CD-ROM includes records from 1983 to the present.

\section{Update Date, Frequency:}

On-line: Twice monthly

CD-ROM: quarterly 
Database Title: National Technical Information Service (NTIS)

Sources, Number of Records:

Sources are U.S. government agencies, foreign governments and agencies, and the private sector. Currently, more than 1.8 million records are on file. NTIS adds an estimated 70,000 new works to its collection annually.

Restrictions on Distribution of Derived Data:

None.

Hardware/Operating System:

On-line services: contact service providers.

DIALOG CD-ROM: IBM PC or compatible with 640-K RAM minimum, 3-MB hard disk space, DOS 3.1 or later version.

Silver-Platter CD-ROM: IBM PC or compatible with 640-K RAM minimum, 3-MB hard disk space, DOS 2.1 or later version; or an Apple Macintosh Plus, SE, or II series computer with 1-MB RAM minimum, System 6.02 or later version.

Special Hardware Requirements:

On-line services: Modem.

DIALOG CD-ROM: CD-ROM drive.

Silver-Platter CD-ROM: CD-ROM drive.

Special Software Requirements:

DIALOG CD-ROM: MS CD-ROM extensions and DIALOG's OnDisc Manager Software.

SilverPlatter CD-ROM: MS CD-ROM extensions and PC SPIRS (both for IBM PC and compatibles or MacSPIRS (for Apple).

Standard modem communications software is required for basic access.

\section{Restrictions on Interface Mechanisms:}

On-line service providers should be contacted individually to determine their restrictions.

CD-ROMs have their own interfaces (see Special Software Requirements).

\section{Initial Costs:}

The costs shown here are based on DIALOG access to NTIS.

Initial sign-up costs for DIALOG: \$295.

NTIS costs under DIALOG are $\$ 60$ per connect hour plus $\$ 0.80$ per full record of retrieval. Documents can be ordered from NTIS through the DIALOG access. If you ordered material, you could be charged out to an NTIS account.

DIALOG CD-ROM: $\$ 2,350$ for an annual subscription (current and four previous years of coverage) or $\$ 3,600$ for an annual subscription (current and eight previous years coverage).

Silver-Platter CD-ROM: $\$ 2,850$ for an annual subscription. 
Database Title: National Technical Information Service (NTIS)

\section{Subsequent Costs:}

DIALOG annual service fee: $\$ 75$.

NTIS: Actual costs.

\section{Availability of Demonstration Copies or Demonstration Licenses:}

Not determined at this time. ANL has an NTIS account through its Information and Publishing Division.

\section{Comments:}

A CD-ROM index of the NTIS bibliographic database is available from DIALOG and Silver-Platter. The cost for the CD-ROM index is not known at this time. CD-ROM access requires a PC with a CD-ROM reader.

If you do not have a PC, check either your company library or a public or academic library, since most have access to the bibliographic database.

The following are telephone numbers for commercial on-line services that can provide more information on getting started:

BRS

CISTI

DATA-STAR

DIALOG

ESA/IRS

NERAC, Inc.

ORBIT

STN International
800-456-7248 or 800-289-4377

613-993-1210 (in Canada)

800-221-7754

800-334-2564

Fax: $39 / 694180361$ (in Italy)

203-872-7000

$800-456-7248 ; 800-442-0900$ (in Virginia)

800-848-6533; 800-848-6538 (in Ohio and Canada)

For the CD-ROM providers, use these numbers:

DIALOG

800-334-2564

Silver-Platter

800-343-0064

A CD-ROM index of the database is available from DIALOG and Silver-Platter.

NTIS has a Help Desk that answers questions on searching the database and its content. It is available from 8:30 a.m. to 5 p.m. Eastern time at 703-487-4929.

NTIS also offers on-line and CD-ROM training. For more information, call the NTIS On-Line Training Coordinator at (703) 487-4078.

ANL Investigator Name: Rick Love, Greg Robinson Date: 8/30/94 
Technology Information Management System Database Study

Preliminary Investigation

\section{Database Title: NEXIS/LEXIS}

Point of Contact:

NEXIS/LEXIS: Karen Welch, 202-785-3550

DOE: Ann Edwards, 301-903-2361

\begin{tabular}{|c|c|c|c|}
\hline $\begin{array}{l}\text { Information } \\
\text { Type: }\end{array}$ & $\begin{array}{l}\square \text { Bibliographic } \\
\square \text { Video } \\
\square \text { Other }\end{array}$ & $\begin{array}{ll}\square \text { Directory } & \text { Full Text } \\
\square \text { Audio } & \square \text { Relational }\end{array}$ & $\begin{array}{l}\square \text { Images } \\
\square \text { Numeric }\end{array}$ \\
\hline $\begin{array}{l}\text { Media } \\
\text { Format: }\end{array}$ & $\begin{array}{l}\square \text { CD-ROM } \\
\text { On-line Service } \\
\square \text { Other }\end{array}$ & $\square_{\text {Internet }}^{\text {Magnetic Tape }}$ & $\begin{array}{l}\square \text { Diskette } \\
\square \text { BBS }\end{array}$ \\
\hline Restrictions: & $\begin{array}{l}\square \text { Classified } \\
\square \text { Other }\end{array}$ & $\square$ Government Only & $\square$ u.s. Only \\
\hline
\end{tabular}

\section{Content:}

Business and financial news, government news, international news, industry and technology news, general news, general information, news and information on individuals, U.S. patents, computer and communications information, company data and annual reports, and medical and health care library.

Update Date, Frequency:

Daily

\section{Sources, Number of Records:}

International, national, and regional newspapers, magazines, newsletters, wire services, journals and files, Encyclopedia Britannica, U.S. Patent Library. LEXIS includes company and industry research reports, company filings from the Securities and Exchange Commission (SEC), abstracts of proxy statements and other filings. These databases have billions of records.

\section{Restrictions on Distribution of Derived Data:}

None

Hardware/Operating System:

PC with DOS or Windows 
Database Title: NEXIS/LEXIS

Special Hardware Requirements:

Special Software Requirements:

Restrictions on Interface Mechanisms:

NEXIS/LEXIS interface software is required.

Initial Costs:

DOE discount cost is monthly fee; no per-use fee is available.

Subsequent Costs:

None

Availability of Demonstration Copies or Demonstration Licenses:

Both ANL and DOE have contracts that should allow ANL to get an ID to try the system.

Comments: 


\section{Technology Information Management System Database Study \\ Preliminary Investigation}

Database Title: Office of Science and Technical Information (OSTI); Energy Science and Technology Database (ESTD)

\section{Point of Contact:}

ITIS Access

U.S. Department of Energy

Office of Scientific and Technical Information

P.O. Box 62

Oak Ridge, TN 37831

(615) 576-8401 or

Kim Buckner: (615) 576-5363 (ITIS)

Robert W. Rutkowski: (615) 576-9362 (ESTD)

\begin{tabular}{|c|c|c|c|}
\hline $\begin{array}{l}\text { Information } \\
\text { Type: }\end{array}$ & $\begin{array}{l}\text { Bibliographic } \\
\square \text { Video } \\
\square \text { Other }\end{array}$ & $\begin{array}{l}\square \text { Full Text } \\
\square \text { Relational }\end{array}$ & $\begin{array}{l}\square \text { Images } \\
\square \text { Numeric }\end{array}$ \\
\hline $\begin{array}{l}\text { Media } \\
\text { Format: }\end{array}$ & $\begin{array}{l}\square \text { CD-ROM } \\
\text { On-line Service } \\
\square \text { Other }\end{array}$ & $\begin{array}{l}\square \text { Magnetic Tape } \\
\square \text { Internet }\end{array}$ & $\begin{array}{l}\square \text { Diskette } \\
\square \text { BBS }\end{array}$ \\
\hline Restrictions: & \begin{tabular}{|l}
$\square$ \\
Classified \\
Other
\end{tabular} & $\square$ Government Only & $\square$ U.S. Only \\
\hline
\end{tabular}

Limited to DOE and its contractors

\section{Content:}

OSTI is a U.S. Department of Energy (DOE) agency responsible for centralized planning, development, maintenance, and administration of services and facilities required to accomplish DOE responsibilities related to the control of technical information and its dissemination to DOE and the public. More specifically, the responsibilities include providing support and direction for the management of DOE's Scientific and Technical Information Program; serving as an archive facility for worldwide energy research and development information; producing and maintaining databases of research and development (R\&D) information and information on DOE research in progress; examining energy-related environmental, safety, and health issues; issuing periodicals announcing the most recent additions to the ESTD; overseeing DOE's centralized scientific and technical information software management activity; providing customized information products and services for DOE program offices, contractors, and field organizations; and negotiating and representing the United States in bilateral and multilateral agreements for international exchange of energy-related scientific and technical information to support DOE's domestic programs. 
Database Title: Office of Science and Technical Information (OSTI); Energy Science and Technology Database (ESTD)

Contents (Cont.):

The Integrated Technical Information System (ITIS) is a DOE on-line system maintained by OSTI. It provides access to DOE scientific and technical databases, information merging for customized information products, and electronic mail that links OSTI to other DOE and contractor offices. Users can search various databases and review the results on-line. Records can be downloaded to the user's personal computer, or a printed copy can be ordered.

There are 12 databases available through ITIS: ESTD, Management Information File, Report Holdings File, Research in Progress, Controlled Access File, Minority Economic Impact, Nevada Nuclear Waste, Energy Science and Technology Software, Numeric Database Directory, Foreign Research in Progress, New Technology from DOE, and Nuclear Criticality Safety.

The Energy Science and Technology Database (ESTD) contains bibliographic information for and summaries of all unlimited, unclassified information related to energy and nuclear science and technology from worldwide sources processed at OSTI. This energy research covers all scientific and technical aspects of fossil, renewable, and nuclear energy sources; energy conservation, consumption, and utilization; energy policy; and the environmental effects of energy production and utilization. Beyond energy fields, it also contains citations in, for example, basic scientific studies, computers, environment and pollution, nuclear medicine, and arms control.

The records are citations to and abstracts of U.S. and foreign technical reports, journal articles, conference papers and proceedings, engineering drawings, computer software, audio-visual materials, books, patents, theses, and monographs.

Update date, frequency:

Nightly

\section{Sources, Number of Records:}

A minimum of the current 14 months of DOE's Energy Science and Technology database - more than 200,000 records.

Also, more than a million citations in subject areas extending beyond energy fields.

\section{Restrictions on Distribution of Derived Data:}

Unknown

\section{Hardware/Operating System:}

IBM PC, Macintosh computer, DEC VT-100 compatible computer terminal, or any terminal that adheres to ANSI x3.4-1977, x3.41-1974, or 3.674-1979 
Database Title: Office of Science and Technical Information (OSTI); Energy Science and Technology Database (ESTD)

\section{Special Hardware Requirements:}

Asynchronous modem operating at $1,200,2,400$, or 9,600 bits per second, in conformance with CCITT Recommendation V.22 and V.32 or Bell Specification 212A. Alternatively, Hayes AT command set and MNP error-correcting protocol are also recommended.

\section{Special Software Requirements:}

Appropriate communications software that can emulate a VT-100 terminal. OSTI provides a software package. Commercial packages known to work with ITIS include SmartTerm 240, 4014, 100 (v.3.0), EM100, EM220 (v.3.3), PC102 (v.6.0), Hayes Smartcom III, and Procom (v.2.4.2).

\section{Restrictions on Interface Mechanisms: \\ None}

\section{Initial Costs:}

None, but see Subsequent Costs.

\section{Subsequent Costs:}

Annual fee, based on the number of password holders:

\begin{tabular}{ll}
$\begin{array}{c}\text { No. of Password } \\
\text { Holders }\end{array}$ & \multicolumn{1}{c}{$\begin{array}{c}\text { Annual Fee } \\
(\$)\end{array}$} \\
\hline 1 & 100 \\
$2-7$ & 75 each \\
$8-13$ & 50 each \\
$14-25$ & 900 total \\
More than 25 & 35 each additional \\
\hline
\end{tabular}

Fee for downloading, printing, or transferring records: $\$ 0.25$ per record, with a minimum charge of $\$ 5.00$ for off-line prints on OSTI printers.

Availability of Demonstration Copies or Demonstration Licenses:

Unknown 
Database Title: Office of Science and Technical Information (OSTI); Energy Science and Technology Database (ESTD)

\section{Comments:}

ITIS contains a subset of DOE's ESTD available through DIALOG Information Services. This database is updated semi-monthly.

Annual fees are based on the number of password holders per account at the beginning of the fiscal year. Those added to the account later are assessed at the same rate. Credit to the accounts will not be made if the number of password holders decreases during the year, but for each user dropped from the account, a replacement user may be added at no additional charge. 


\section{Technology Information Management System Database Study}

Preliminary Investigation

Database Title: The Science \& Technology Information System (STIS)

\section{Point of Contact:}

The National Science Foundation (NSF)

E-mail: stis@nsf.com

VoiceMail: 703-306-0214

TDD: 703-306-0090

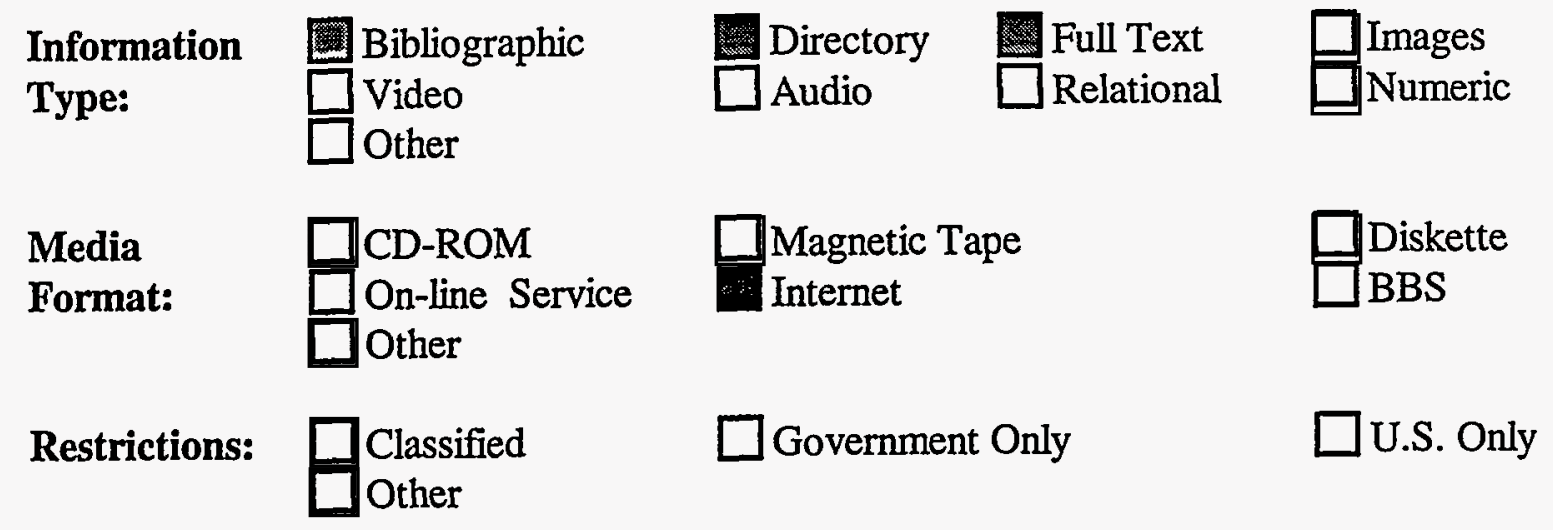

\section{Content:}

NSF's goal is for all printed NSF publications to be available electronically. The publications can be searched or downloaded via a number of Internet access methods. The NSF publications currently available on the Internet include:

The NSF Bulletin,

Program announcements and "Dear Colleague" letters,

General publications and reports,

NSF's Division of Science Resources Studies (SRS) publications,

Press releases and other NSF news items,

NSF organization charts and alphabetical telephone directories,

NSF vacancy announcements, and

Award abstracts (1989-present).

Indexes of all STIS documents are also available. File retrieval instructions are included in the index files. The award abstracts are available for searching or downloading, but there are no publications concerning the results of the projects receiving awards.

Update Date, Frequency:

Weekly

Sources, Number of Records:

Award abstracts and SRS publications: 722 records 
Database Title: The Science \& Technology Information System (STIS)

Restrictions on Distribution of Derived Data:

None

Hardware/Operating System:

Any with Internet access

Special Hardware Requirements:

Internet connection or, for on-line use, a modem

Special Software Requirements:

Internet interface program, such as gopher

Restrictions on Interface Mechanisms:

Unknown

Initial Costs:

None

Subsequent Costs:

None

Availability of Demonstration Copies or Demonstration Licenses:

The database may be used freely on Internet.

\section{Comments:}

Several methods allow the user to retrieve the indexes of STIS electronic documents through the Internet: E-mail, anonymous FTP, on-line STIS, direct E-mail, gopher, and WAIS.

To retrieve the general index through E-mail, send the message "get index" to stisserv@nsf.gov (Internet address). You will receive the list of NSF's general STIS documents, with retrieval instructions.

To retrieve the indexes through anonymous FTP, use the address stis.nsf.gov to log onto NSF's FTP server, enter "anonymous" for the username, and enter your E-mail address for the password. Use the "get" command to retrieve the files "index" and "srsindex." These files contain the lists of NSF's general and SRS publications.

To retrieve the general index through STIS's on-line system, with an Internet connection, use Telnet. Telnet to stis.nsf.gov and enter "public" at the log-in prompt and then follow the on-line system's instructions.

To receive instructions for using the direct E-mail service, send the message "get stisdirm" to stisserv@nsf.gov (Internet address). 
Database Title: The Science \& Technology Information System (STIS)

Comments (Cont.):

To access NSF's gopher server, gopher to stis.nsf.gov, port 70. You will have access to both the general NSF and SRS publications. You can also perform searches directly through gopher.

To access NSF's WAIS server, use stis.nsf.gov.

Alternatively, electronic documents can be retrieved through a modem connection to STIS's on-line system. 


\section{Technology Information Management System Database Study \\ Preliminary Investigation}

Database Title: SciSearch

Point of Contact:

Donna Del Reaux

Institute for Scientific Information

3501 Market Street

Philadelphia, PA 19104

800-336-4474 , ext. 1330

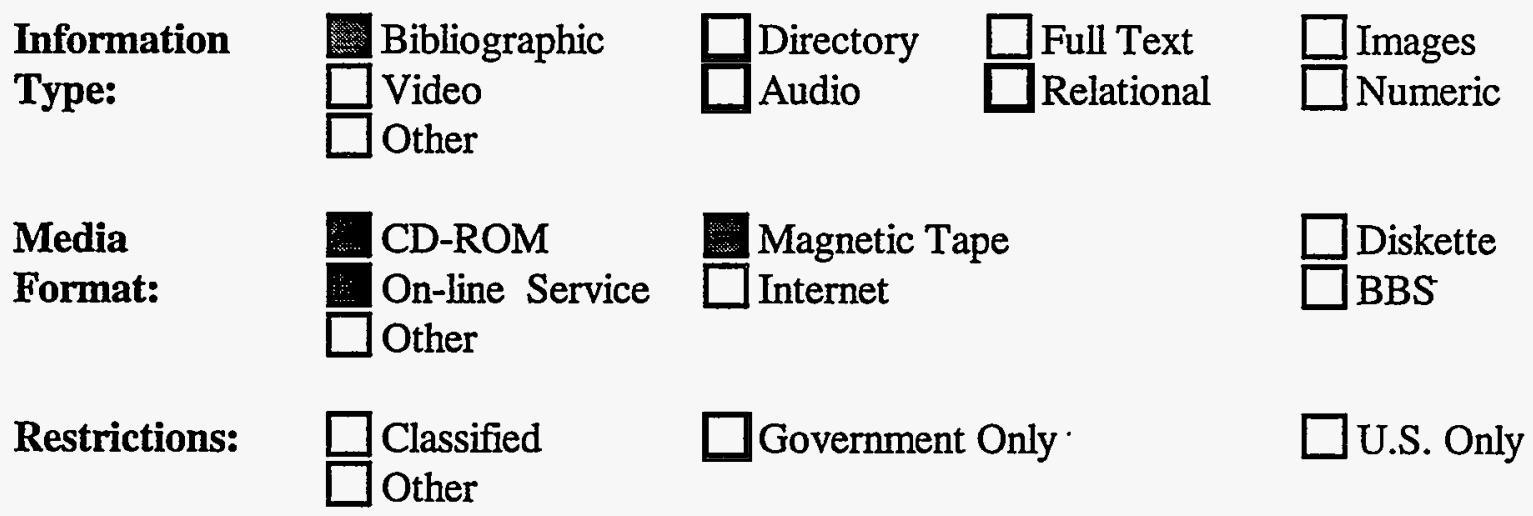

Content:

Provides complete bibliographic data plus citations and abstracts to worldwide journal literature across a wide range of scientific and technological disciplines.

Update Date, Frequency:

Weekly

Sources, Number of Records:

A SciSearch database with $C D$, magnetic tape, and on-line services has 4,500 journals in science and technology. Another SciSearch database with just $\mathrm{CD}$ and magnetic tape services has 3,200 journals. 26,300 records

\section{Restrictions on Distribution of Derived Data:}

If ANL purchases a network license, distribution will be possible; otherwise, it depends on the type and number of queries.

Hardware/Operating System:

PC-based 
Database Title: SciSearch

Special Hardware Requirements:

On-line: modem

Special Software Requirements:

CD-ROM reader for $C D$ version

Restrictions on Interface Mechanisms:

No known legal problems with writing our own interface to these products.

\section{Initial Costs:}

For ISI magnetic tape: $\$ 29,185$ annual fee for all groups, but $\$ 22,800$ annual for just the ENGI, AGRI, PHYS groups. These costs include networking for a single institution.

\section{Subsequent Costs:}

For ISI magnetic tape: $\$ 41,290$ annual fee without abstracts and an additional $\$ 11,295$ for abstracts. All these costs include networking for a single institution.

For ISI CD-ROM: $\$ 12,560$ annual fee; for 6-10 people, $\$ 25,300$ annual fee. For unlimited access, there is a $\$ 27,830$ fee. Again, these costs include networking for a single institution.

On-line services include:

DataStar, which costs $\$ 72 /$ connect hour for subscribers to the print publication, $\$ 142 /$ connect hour for nonsubscribers, $\$ 0.47 /$ full record on-line, and $\$ 0.53 /$ full record off-line.

DIALOG Information Services, Inc., which costs $\$ 63 /$ connect hour for subscribers to the print publication, $\$ 159 /$ connect hour for nonsubscribers, and $\$ 0.62 /$ full record both on- and off-line.

\section{Availability of Demonstration Copies or Demonstration Licenses:}

\section{Comments:}

ANL has a demonstration copy on diskette. 
Technology Information Management System Database Study

Preliminary Investigation

Database Title: U.S. Patent and Trademark Office (PTO)

\section{Point of Contact:}

Myra J. Best, Sales Representative

MicroPatent

250 Dodge Avenue

East Haven, CT 06512-3358

800-648-6787, 203-466-5055

Fax: 203-466-5054

Other products: $800-984-9800$

\begin{tabular}{|c|c|c|c|}
\hline $\begin{array}{l}\text { Information } \\
\text { Type: }\end{array}$ & $\begin{array}{l}\square \text { Bibliographic } \\
\square \text { Video } \\
\square \text { Other }\end{array}$ & $\begin{array}{l}\text { Full Text } \\
\square \text { Relational }\end{array}$ & $\begin{array}{l}\text { Images } \\
\square \text { Numeric }\end{array}$ \\
\hline $\begin{array}{l}\text { Media } \\
\text { Format: }\end{array}$ & $\begin{array}{l}\text { CD-ROM } \\
\text { On-line Service } \\
\text { Other }\end{array}$ & $\begin{array}{l}\square \text { Magnetic Tape } \\
\square \text { Internet }\end{array}$ & $\begin{array}{l}\square \text { Diskette } \\
\square \text { BBS }\end{array}$ \\
\hline Restrictions: & \begin{tabular}{|l} 
Classified \\
Other
\end{tabular} & $\square$ Government Only & $\square$ U.S. Only \\
\hline
\end{tabular}

\section{Content:}

The CD-ROM product USA-PAT contains full images of all new patents, indexed by patent number, starting January 1, 1994. On-line Internet services accessible through the PTO Web server include:

Information contacts subject index

Patent and trademark fees

Patent attorneys and agents registered to practice before the PTO

Patent and trademark depository libraries

Patent and trademark resources on the Internet

Legal information institute (Cornell Law School)

Carl Malamud's 1994 patent database

Patent Resources Institute, Inc.

Source Translation and Optimization

Orbit-Questel

U.S. Patent and patent title databases

Patent and Trademark Resources Page

Virtual Reading Room

Patent Information User's Group

Intellectual Property Bookshelf at UCI Bookstore

Telnet to Orbit/Questel Databases

Resource page for examiners 
Database Title: U.S. Patent and Trademark Office (PTO)

Update Date, Frequency:

USA-PAT is updated weekly through two to three new disks.

Sources, Number of Records:

U.S. Patent and Trademark Office

Restrictions on Distribution of Derived Data:

None

Hardware/Operating System:

IBM PC/DOS

Special Hardware Requirements:

CD-ROM drive for USA-PAT.

Internet access for other services.

Special Software Requirements:

A MOSAIC interface is necessary to fully utilize the PTO MOSAIC server.

Restrictions on Interface Mechanisms:

None

Initial Costs:

None for Internet access.

Annual fees for USA-PAT.

Subsequent Costs:

Internet services are free.

USA-PAT costs approximately $\$ 2,000 /$ year.

Availability of Demonstration Copies or Demonstration Licenses:

Internet services can be accessed freely.

No demonstration available for USA-PAT.

\section{Comments:}

Internet services can be accessed freely.

Internet access is slow.

No demonstration available for USA-PAT.

ANL Investigator Name: Jeff Keisler Date: 9/8/94 


\section{Technology Information Management System Database Study \\ Preliminary Investigation}

Database Title: US PatentSearch

Point of Contact:

Myra J. Best, Sales Representative

MicroPatent

250 Dodge Avenue

East Haven, CT 06512-3358

800-648-6787, 203-466-5055

Fax: 203-466-5054

Other products: $800-984-9800$

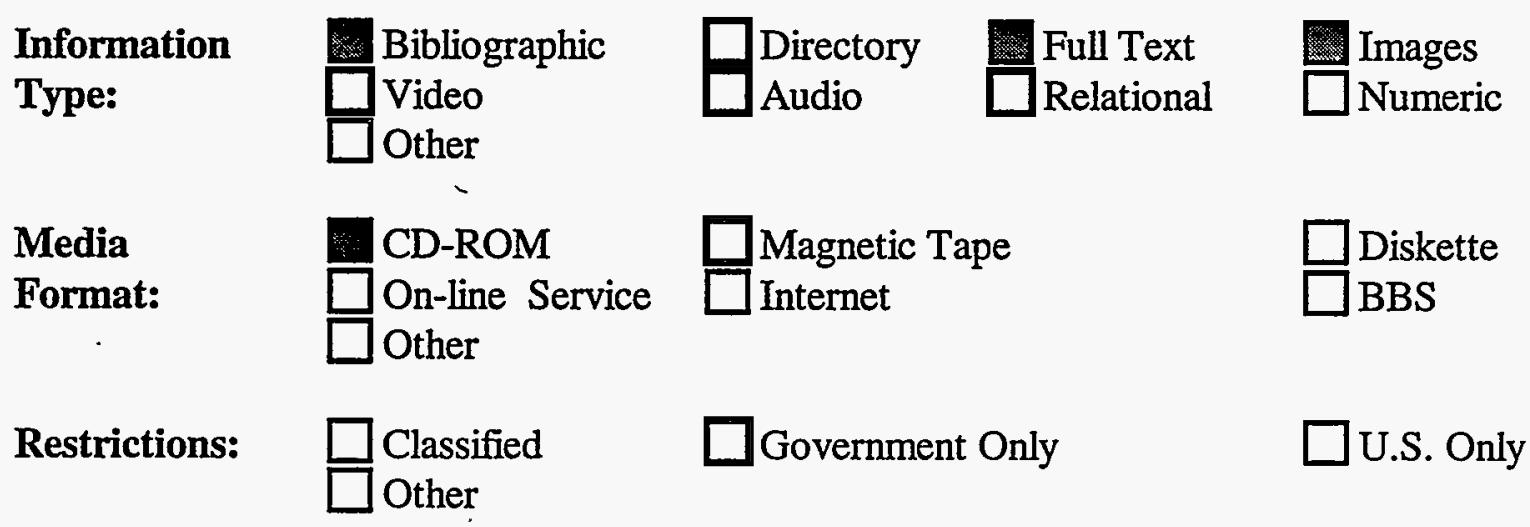

\section{Content:}

US PatentSearch provides front-page bibliographic information and 18 search fields, including keyword-searchable abstracts and exemplary claims for the current year. It contains back files to 1974. The fields offered are patent number, issue date, application number/date, title/abstract/claim, inventors, assignee, state, U.S. class, International Patent Class, U.S. references, foreign references, other references, PCT data, related data, primary examiner, agent, priority, and status.

US FullText provides complete character data (without pictures) and 18 search fields, including keyword-searchable text, title abstract, background and summary, description, and claims.

US PatentImages contains the complete text and drawings of utility patents, ready for laser printing, and 12 search fields, including keyword-searchable abstracts. It includes index and image printing software.

Other services: PatentQuery, PatentBulletin, PatentCopies, PhoneSearch, PatentBible search tools.

Update Date, Frequency:

US PatentSearch: monthly

US FullText: monthly (one disk)

US PatentImages: two disks/week

PatentBible Index updated semiannually 
Database Title: US PatentSearch

Sources, Number of Records:

US PatentImages: approximately 1,000 patents/disk.

Claims to contain "Complete library of active U.S. patents."

\section{Restrictions on Distribution of Derived Data:}

None on internal distribution

\section{Hardware/Operating System:}

AT Class or higher PC CD-ROM drive (ISO 9660), fixed disk drive with 3-MB available, HD floppy drive, VGA monitor (color or monochrome); HP laser printer with 1-MB RAM, MS-DOS 3.0 or later version

\section{Special Hardware Requirements:}

None

Special Software Requirements:

Microsoft extensions

Restrictions on Interface Mechanisms:

None (CD-ROM based)

\section{Initial Costs:}

\section{Subsequent Costs:}

US PatentSearch: $\$ 1,400 /$ year; back files to 1975 : Abstracts, $\$ 3,000$; Claims, $\$ 3,000$; both, $\$ 5,000$. US FullText: \$1,450/year; back files 1991-1993: \$1,500/year.

US PatentImages: $\$ 6,100 /$ year.

Phone Search: $\$ 50-\$ 250$.

PatentBulletin and PatentBBS: Free.

\section{Availability of Demonstration Copies or Demonstration Licenses:}

ANL has a demo copy of the July 1994 disk (1993-present). It works for 30 days after start-up. ANL also has disks for ESCAPE ACCESS (European patent database).

The bulletin board system is free to subscribers.

\section{Comments:}

Good value for high-volume users.
ANL Investigator Name: Jeff Keisler
Date: $8 / 24 / 94$ 


\section{Technology Information Management System Database Study}

Preliminary Investigation

Database Title: US Patents Fulltext

\section{Point of Contact:}

DIALOG (Files 652, 653, 654)

DIALOG Information Services, Inc.

3460 Hillview Avenue

P.O. Box 10010

Palo Alto, CA 94303

Sales Desk: 800-334-3785

\begin{tabular}{|c|c|c|c|c|}
\hline Information & | Bibliographic & Directory & Full Text & Images \\
\hline Type: & $\begin{array}{l}\text { Video } \\
\text { Other }\end{array}$ & Audio & Relational & Numeric \\
\hline Media & CD-ROM & Magnetic Tape & - & Diskette \\
\hline Format: & $\begin{array}{l}\text { On-line Service } \\
\text { Other }\end{array}$ & Internet & & BBS \\
\hline Restrictions: & $\begin{array}{l}\text { Classified } \\
\text { Other }\end{array}$ & Government $\mathrm{O}$ & & |U.S. Only \\
\hline
\end{tabular}

\section{Content:}

US Patents Fulltext contains the complete text of U.S. patents issued from January 1, 1974, to present and partial coverage for 1971-1973 for all granted U.S. utility patents, defensive publications, design patents, reissue patents, statutory invention registrations, and plant patents.

DIALOG Alerts is a related service that provides all new records from the latest week or month (depending on the subscription ordered) that meet user-specified search criteria.

\section{Update Date, Frequency:}

Weekly

\section{Sources, Number of Records:}

U.S. Patent and Trademark Office

\section{Restrictions on Distribution of Derived Data:}

(See general discussion of DIALOG.)

\section{Hardware/Operating System:}

(See general discussion of DIALOG.) 
Database Title: US Patents Fulltext

Special Hardware Requirements:

(See general discussion of DIALOG.)

Special Software Requirements:

(See general discussion of DIALOG.)

Restrictions on Interface Mechanisms:

(See general discussion of DIALOG.)

\section{Initial Costs:}

$\$ 2.50 /$ connect minute, $\$ 2.50 /$ full format on-line type or off-line print, $\$ 0.30 /$ preformatted report element, $\$ 10.00$ /weekly or monthly DIALOG Alert plus prints

\section{Subsequent Costs:}

\section{Availability of Demonstration Copies or Demonstration Licenses:}

\section{Comments:}

As with other DIALOG services, this database has a low fixed cost but high variable costs that could mount quickly. The completeness of the database is an asset. 
ANL Investigator Name: Jeff Keịsler

Date: $8 / 24 / 94$

Technology Information Management System Database Study

Preliminary Investigation

Database Title: Wilson Applied Science \& Technology Abstracts

Point of Contact:

Hillary Cantell

Technical Support Department

Roberta McCosh

H.W. Wilson Company

Suite 336

950 University Avenue

1555 Sherman Ave.

Bronx, NY 10452

Evanston, IL 60201

800-367-6770, ext. 2030

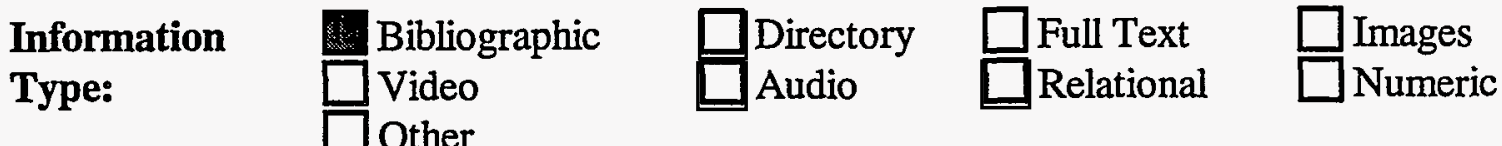

Media

CD-ROM
On-line Service
$\square$ Other

Magnetic Tape

$\square$ Internet

Diskette

Format:

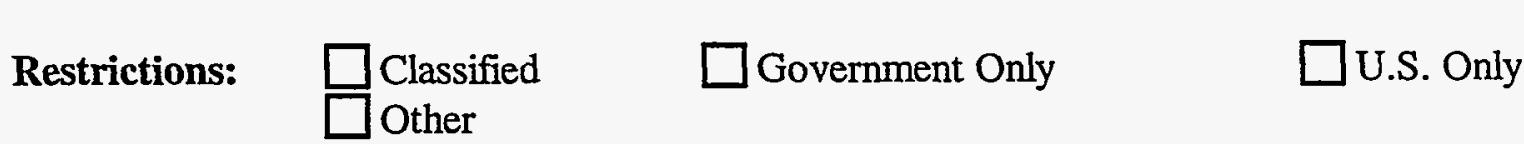

$312-465-4870$

\section{Content:}

Contains citations with abstracts (March 1993-present) to all articles in the Applied Science \& Technology Index. Includes citations to product reviews, conferences, and seminars.

This database is a superset of Wilson Applied Science \& Technology Index in that it contains the citations plus the abstractions. The only difference is that the Wilson Applied Science \& Technology Index starts with information from October 1983 rather than from March 1993.

Update Date, Frequency:

Tape and $C D$ versions: updated monthly.

On-line version: updated twice a week.

Sources, Number of Records:

Applied Science \& Technology Index, product reviews, conferences, and seminars.

Approximately 645,544 records 
Database Title: Wilson Applied Science \& Technology Abstracts

Restrictions on Distribution of Derived Data:

No charges are made for distributing bibliographic or datasets derived from queries. H.W. Wilson's copyright should be put on this information.

\section{Hardware/Operating System:}

IBM PC/PS2 or compatible, at least version 3.11 of DOS; 640-K RAM

Special Hardware Requirements:

CD-ROM drive with a $680-\mathrm{MB}$ read capacity

\section{Special Software Requirements:}

\section{Restrictions on Interface Mechanisms:}

No known legal restrictions on writing our own interface to these products

\section{Initial Costs:}

The CD-ROM version, WILSONDISC, costs $\$ 2,495$ for an annual subscription. No charges are made for networking at a single institution. Multiple institutions pay a $\$ 500$ fee for the first additional institution and a $\$ 100$ fee for each additional user for that institution.

Also, purchasing a CD-ROM from Wilson allows full access to that database through WILSONLINE.

WILSONLINE, the on-line service, has an initial license charge that ranges from $\$ 300-\$ 2,400$ per year.

For WILSONTAPE, the magnetic tape product, the rate is $\$ 3,100$ for $1-10$ users at a single institution, and $\$ 6,200$ for up to 20 users. Multiple institutions are charged an additional $\$ 600$.

\section{Subsequent Costs:}

WILSONLINE has a complicated rate structure similar to that used by DIALOG and other on-line services. The general rate structure is a $\$ 50-\$ 65$ per hour connect charge, a $\$ 10$ telecommunications charge, and additional charges for printing of under $\$ 1$ per reference, with a $\$ 10$ minimum per day. Annual license fees also apply.

Update fees would apply to the tape and CD products.

Availability of Demonstration Copies or Demonstration Licenses: ANL has received a 90-day trial $C D$.

\section{Comments:}

ANL Investigator Name: Dave Blodgett Date: 8/25/94

Technology Information Management System Database Study 
Preliminary Investigation

Database Title: Wilson Applied Science \& Technology Index

Point of Contact:

Hillary Cantell

Technical Support Department

Roberta McCosh

H.W. Wilson Company

Suite 336

950 University Avenue

1555 Sherman Ave.

Bronx, NY 10452

Evanston, IL 60201

800-367-6770, ext. 2030

$312-465-4870$

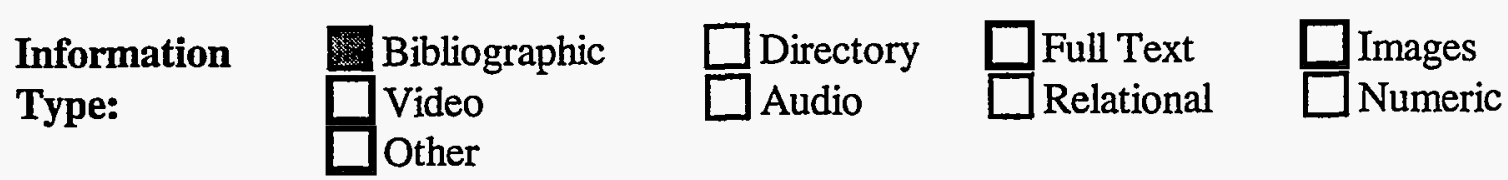

\begin{tabular}{|c|c|c|c|}
\hline Media & CD-ROM & Magnetic Tape & Diskette \\
\hline Formàt: & $\begin{array}{l}\text { On-line Service } \\
\text { Other }\end{array}$ & Internet & BBS \\
\hline Restrictions: & $\begin{array}{l}\text { Classified } \\
\text { Other }\end{array}$ & Government Only & Only \\
\hline
\end{tabular}

\section{Content:}

Contains more than 600,000 citations to articles, books, reviews, interviews, new product reviews, and selected editorials and letters to the editor in 390 English-language publications in the applied sciences and technology.

Update Date, Frequency:

Tape and $C D$ versions: updated monthly.

On-line version: updated twice a week.

Sources, Number of Records:

645,544 citations 
Database Title: Wilson Applied Science \& Technology Index

Restrictions on Distribution of Derived Data:

There is no charge for distributing bibliographic or data sets derived from queries. The user should include H.W. Wilson's copyright on this information.

\section{Hardware/Operating System:}

IBM PC/PS2 or compatible; at least version 3.11 of DOS; $640-\mathrm{K}$ RAM

\section{Special Hardware Requirements:}

CD-ROM drive with a $680-\mathrm{MB}$ read capacity

\section{Special Software Requirements:}

\section{Restrictions on Interface Mechanisms:}

No known legal restrictions on writing our own interface to these products

\section{Initial Costs:}

The CD-ROM version, WISONDISC, costs $\$ 2,495$ per year for a subscription. Networking at a single institution is free; multiple institutions are charged a $\$ 300$ fee for the first additional institution and a $\$ 100$ fee for each additional user for that institution. Also, purchasing a CD-ROM from Wilson allows full access to that database through WILSONLINE.

\section{Subsequent Costs:}

WILSONLINE has a complicated rate structure similar to that used by DIALOG and other on-line services. The general rate structure is a $\$ 50-\$ 65$ per hour connect charge, a $\$ 10$ telecommunications charge, and additional charges for printing of under $\$ 1$ per reference, with a $\$ 10$ minimum per day. Annual license fees also apply.

Update fees would apply to the tape and CD products.

Availability of Demonstration Copies or Demonstration Licenses:

ANL has received a 90-day trial disk.

Comments:
ANL Investigator Name: Dave Blodgett
Date: $8 / 25 / 94$ 
Technology Information Management System Database Study

Preliminary Investigation

Database Title: World Patents Index

Point of Contact:

Derwent Publications Ltd.

Derwent House, 14 Great Queen St.

London WC2B 5DF, England

011-44-71-344-2800 (Jill Feldt)

U.S. office: $800-451-3551$

Information

Type:

Media

Format:

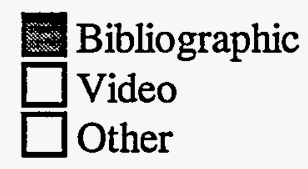
$\square$ CD-ROM
On-line Service
Other

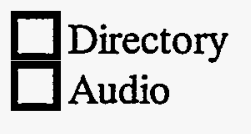

Full Text
Relational

$\square_{\text {Images }}$ $\square$ Diskette
$\square$ BBS

Internet

$\square$ Government Only
U.S. Only

Restrictions:

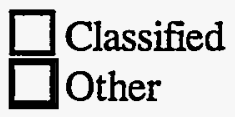

\section{Content:}

WPI contains 6 million citations, with abstracts issued by 31 patent issuing authorities, including title, assignee name, inventor name, patent number, member country, priority date, publication date, classifications, and subject codes. The WPI books include 1.5-M drawings, some of which are available on-line.

Update Date, Frequency:

Weekly

Sources, Number of Records:

Worldwide patent specifications, 6 million records

Restrictions on Distribution of Derived Data:

(See general discussion of DIALOG.)

Hardware/Operating System:

(See general discussion of DIALOG.)

Special Hardware Requirements:

(See general discussion of DIALOG.) 
Database Title: World Patents Index

Special Software Requirements:

(See general discussion of DIALOG.)

Restrictions on Interface Mechanisms:

(See general discussion of DIALOG.)

\section{Initial Costs:}

Subsequent Costs:

DIALOG prices:

Nonsubscribers:

$\$ 210 /$ hour

Type: $\$ 1.90 /$ full record; $\$ 2.40 /$ full record + patent image

Print: $\$ 2.30, \$ 3.30$

Report cost: $\$ 0.30 /$ record

Weekly alerts: $\$ 13$

Subscribers:

WPI: $\$ 123 /$ hour

Type: $\$ 0.80 /$ full record; $\$ 1.05 /$ full record + patent image

Print: $\$ 1.00, \$ 1.50$

Weekly alerts: $\$ 13$

(See general discussion of DIALOG.)

Availability of Demonstration Copies or Demonstration Licenses: (See general discussion of DIALOG.)

\section{Comments:}

A satisfactory service, most valuable for its international coverage 
APPENDIX B:

SECONDARY INVESTIGATION INFORMATION 


\section{Patent Office - PTO Gopher Server}

Query results

05321627: Battery monitor and method for providing operating parameters 05280231: Battery condition detecting apparatus and charge control apparatus for 05340670: Lithium secondary battery and method of manufacturing carbonaceous 05341503: Battery operated computer having improved battery gauge and system for 05315432: Thin film of lithium niobate single crystal 05278487: Battery conditioning system having communication with battery parameter 05349281: Battery charging system and method of using same 05306576: Battery coupler 05302887: Charging apparatus 05281955: Battery charge monitoring apparatus and method 05281919: Automotive battery status monitor 05337215: Pivoting battery compartment and door 05307000: Method and apparatus for charging, thawing, and formatting a battery 05330583: Solar battery module 05316873: Position adjustable battery adapter 05307001: Battery charging method and apparatus 05322745: Storage battery system 05276960: Method for the manufacture of lead-acid batteries and an associated 05316875: Secondary battery with nonaqueous electrolyte and method of 05315228: Battery charge monitor and fuel gauge 05321347: Battery charger device and method 05324599: Reversible electrode material 05284719: Method and apparatus for monitoring battery capacity 05287286: Low-battery state detecting system and method for detecting the residual 05355073: Battery pack sensor for an AC adapter 05275525: Battery changer on a mobile machine 05305513: Vehicle battery decking device 05304917: Compact low noise low power dual mode battery charging circuit 05352969: Battery charging system having logarithmic analog-to-digital converter 05295078: Method and apparatus for determination of battery run-time in 05332958: Battery disconnect device 05311441: Battery powered unit with battery sensor and resume processing control 05344466: Method for the assembly of lead-acid batteries and associated apparatus 05339018: Integrated circuit monitor for storage battery voltage and temperature 05296797: Pulse modulated battery charging system 05346781: Alkaline storage battery 05319298: Battery maintainer and charger apparatus 05350993: Power supply 05350317: Battery pack 
The following pages summarize the fields included in a record from this database. This summary is condensed from the full record, which consisted of more than 50 pages of material.

Originator-Name: keymaster@town.hall.org

Originator-Key-Asymmetric:

PATN Patent Bibliographic Information

WKU Patent Number:

SRC Series Code:

APN Application Number:

APT

ART

Application Type:

Art Unit:

APD

Application Filing Date:

TTL Title of Invention:

ISD Issue Date:

NCL Number of Claims:

ECL Exemplary Claim Number:

EXA Assistant Examiner:

05321627

7

8504059

1

234

19920311

Battery monitor and method for providing operating parameters

19940614

139

1

Zanelli; Michael

EXP Primary Examiner:

Black; Thomas G.

NDR Number of Drawings Sheets:

NFG Number of Figures:

5

5

INVT Inventor Information

NAM Inventor Name:

CTY Inventor City:

STA Inventor State:

Reher; Michael T.

Milwaukee

WI

ASSG Assignee Information

NAM Assignee Name:

Globe-Union, Inc.

CTY Assignee City:

Milwaukee

STA Assignee State:

WI

COD Assignee Type Code:

02

CLAS Classification

OCL Original U.S. Classification:

364483

Cross Reference Classification: $\quad 364557$

$\mathrm{XCL}$

Cross Reference Classification:

324427

Cross Reference Classification:

324431

$\mathrm{XCL}$

Cross Reference Classification:

340636

Cross Reference Classification:

32043

Cross Reference Classification:

32048

$\mathrm{XCL}$

International Classification Edition Field:

5

ICL International Classification:

G01R 3136 


\begin{tabular}{|c|c|c|}
\hline ICL & International Classification: & H01M 1048 \\
\hline FSC & Field of Search Class: & 364 \\
\hline FSS & Field of Search Subclass: & $550 ; 551.01 ; 481 ; 483 ; 557$ \\
\hline FSC & Field of Search Class: & 324 \\
\hline FSS & Field of Search Subclass: & $426 ; 427 ; 428 ; 431$ \\
\hline FSC & Field of Search Class: & 340 \\
\hline FSS & Field of Search Subclass: & 636 \\
\hline FSC & Field of Search Class: & 320 \\
\hline FSS & Field of Search Subclass: & $48 ; 43$ \\
\hline UREF & U.S. Patent Reference & \\
\hline PNO & Patent Number: & 3906329 \\
\hline ISD & Issue Date: & 19750900 \\
\hline NAM & Patentee Name: & Bader \\
\hline OCL & Original U.S. Classification: & 324428 \\
\hline UREF & U.S. Patent Reference & \\
\hline PNO & Patent Number: & 3936718 \\
\hline ISD & Issue Date: & 19760200 \\
\hline NAM & Patentee Name: & Melling et al. \\
\hline OCL & Original U.S. Classification: & 32020 \\
\hline UREF & U.S. Patent Reference & \\
\hline PNO & Patent Number: & 4390841 \\
\hline ISD & Issue Date: & 19830600 \\
\hline NAM & Patentee Name: & Martin et al. \\
\hline OCL & Original U.S. Classification: & 324427 \\
\hline UREF & U.S. Patent Reference & \\
\hline PNO & Patent Number: & 4558281 \\
\hline ISD & Issue Date: & 19851200 \\
\hline NAM & Patentee Name: & Codd et al. \\
\hline OCL & Original U.S. Classification: & 324427 \\
\hline UREF & U.S. Patent Reference & \\
\hline PNO & Patent Number: & 4595880 \\
\hline ISD & Issue Date: & 19860600 \\
\hline NAM & Patentee Name: & Patil \\
\hline OCL & Original U.S. Classification: & 324427 \\
\hline
\end{tabular}


UREF U.S. Patent Reference

PNO

Patent Number:

4876513

ISD

Issue Date:

19891000

NAM

Patentee Name:

Brilmyer et al.

OCL Original U.S. Classification:

324427

UREF U.S. Patent Reference

PNO

Patent Number:

4888716

ISD Issue Date:

NAM Patentee Name:

19891200

Ueno

OCL Original U.S. Classification:

364550

UREF U.S. Patent Reference

PNO Patent Number:

4947123

$\begin{array}{ll}\text { ISD } & \text { Issue Date: } \\ \text { NAM } & \text { Patentee Name: }\end{array}$

19900800

Minezawa

OCL

Original U.S. Classification:

324427

UREF U.S. Patent Reference

PNO Patent Number:

4949046

ISD Issue Date:

19900800

NAM Patentee Name:

Seyfang

OCL Original U.S. Classification:

324427

UREF U.S. Patent Reference

PNO Patent Number:

4968942

ISD

Issue Date:

19901100

NAM Patentee Name:

Palanisamy

OCL Original U.S. Classification:

324427

UREF U.S. Patent Reference

PNO Patent Number:

5047961

ISD

Issue Date:

19910900

NAM

Patentee Name:

Simonsen

$\mathrm{OCL}$

Original U.S. Classification:

364550

UREF U.S. Patent Reference

PNO Patent Number:

5218288

ISD

Issue Date:

19930600

NAM Patentee Name:

Mickal et al.

OCL

Original U.S. Classification:

32048 
FREF Foreign Reference

PNO Patent Number:

0420530

ISD Issue Date:

CNT Foreign Reference Country Code:

19900900

FREF Foreign Reference

PNO Patent Number:

0505333

ISD Issue Date:

19920300

CNT Foreign Reference Country Code:

EPX

FREF Foreign Reference

PNO Patent Number: $\quad 89 / 01169$

ISD . Issue Date: 19890200

CNT Foreign Reference Country Code: WOX

FREF Foreign Reference

PNO Patent Number: $\quad 90 / 13823$

ISD Issue Date: 19901100

CNT Foreign Reference Country Code: WOX

FREF Foreign Reference

PNO Patent Number: $\quad 91 / 08494$

ISD Issue Date: 19910600

CNT Foreign Reference Country Code: WOX

LREP Legal Information

FRM Legal Firm: Foley \& Lardner

ABST Abstract

A battery monitor which monitors the operating parameters of a battery to provide an indication of, for example, the absolute state of charge, the relative state of charge, and the capacity of the battery under battery discharge, rest, and recharge conditions. The battery monitor includes a current sensor for sensing battery current, a voltage sensor for sensing battery voltage, and a temperature sensor for sensing battery temperature.

A processor approximates to a high level of accuracy the battery parameters utilizing an iterative process based upon predetermined relationships, employing empirically determined constants and parameters determined in the immediately proceeding iteration stored in memory. Output signals indicative of the determined parameters are provided and may be utilized for many different battery applications.

BSUM Brief Summary

BACKGROUND OF THE INVENTION 
The present invention is ...

\section{SUMMARY OF THE INVENTION}

The present invention provides ...

DRWD Drawing Description

\section{BRIEF DESCRIPTION OF THE DRAWINGS}

The features of the present invention...

DETD Detail Description

\section{DETAILED DESCRIPTION}

Referring now to FIG. 1, it illustrates ...

\section{CLMS Claims}

STM Claim Statement:

NUM Claim Number:
What is claimed is:

1 .

1. A battery monitor for monitoring operating parameters of a battery, said battery monitor comprising ...

NUM Claim Number:

139.

139. A method as defined in claim 138 including ... 


\section{US PatentSearch}

Search results

This screen is used to enter the query for records that contain the words Lithium and Battery.

F1: Help F2: Browse F3: Display F4: Query F9: Options F10: Quit

1.1

Title/Abstr/Claim Search Screen

Micro Patent . US PatentSearch Jan. 1993-July 1994

Patent Number

_ Status

Issue Date

Appl. No./Date

Inventor(s)

_ State

Assignee

U.S. Class

IPC

U.S. Refs

Foreign Refs

Other Refs

Priority

PCT Data

Related Data

Primary Examiner

Agent

Title/Abst/Claim Lithium and battery

Connection

Total: 48 
This list of patents was generated by the sample query:

\begin{tabular}{|c|c|}
\hline F1: Help & : Full F3: Search F4: Actions F5: Links F9: Options F10: Quit \\
\hline 1.1 .1 & list: 1 of 48 \\
\hline Patent No. & Title \\
\hline 5176969 & Electrode for secondary battery \\
\hline 5187030 & Electrochemical battery having high energy per unit mass \\
\hline 5187033 & Lithium secondary battery \\
\hline 5194341 & Silica elecrolyte element for secondary lithium battery \\
\hline 5196278 & Lithium secondary battery with a cathode comprising lithium, cob \\
\hline 5196279 & Rechargeable battery including a Li.sub. $1+x$ Mn.sub. 2 O.sub. 4 cat \\
\hline 5198162 & Microporous films \\
\hline 5206456 & Ordinance thermal battery \\
\hline 5213908 & Alkali metal carbon dioxide electrochemical system for energy st \\
\hline 5219680 & Lithium rocking-chair rechargeable battery and electrode therefo \\
\hline 5219683 & Diol diesters and alkoxyalkylesters as solvents for nonaqueous b \\
\hline 5225297 & Copper vanadium bronz intercalation electrodes for lithium secon \\
\hline 5227264 & Device for packaging a lithium battery \\
\hline 5238760 & Molded article for negative electrode, method of producing the s \\
\hline 5244757 & Lithium secondary battery \\
\hline 5256504 & Monaqueous electrolyte secondary batteries \\
\hline 5258245 & Lithium rechargeable battery and method of making the same \\
\hline
\end{tabular}


This is the first record retrieved:

Patent Number 5176969

Issue Date 19930105

Appl. Data 68952319910423

$\begin{array}{ll}\text { Assignee } & \text { Mitsubishi Petrochemical Co., Ltd. } \\ \text { Inventor(s) } & \text { Miyabayashi, Mitsutaka } \\ & \text { Hayashi, Manabu } \\ & \text { Yasukawa, Eiki } \\ & \text { Miyata, Kikuko } \\ & \text { Kaitoh, Mitsumasa } \\ & \text { Yui, Hiroshi }\end{array}$

State/Country JPX

Title_Electrode for secondary battery___ battery

Abstract Disclosed is an electrode for secondary battery___ battery, which comprises lithium_lithium or an alkali metal composed mainly of lithium___ lithium doped as the active substance in a carrier composed of a mixture of a carbonaceous material satisfying the following conditions (A) and an organic polymer having ion conductivity of lithium___ lithium.

- (A) a carbonaceous material with a hydrogen/carbon (H/C) atomic ratio of less than 0.15 , a spacing (d.sub.002) of the (002) plane according to the X-ray wide angle diffaction method of 3.37 to 3.75 .ANG. and a crystallite size in the c-axis direction (Lc) of 5 .ANG. or more.

Exmp. Claim 1 Ex Claim text

An electrode for a secondary battery with lithium lithium or lithium battery, comprising: a carrier doped metal as the active substance, said carrier composed of a mixture of (i) from 30 to $98 \%$ by weight of a carbonaceous material having a hydrogen/carbon (H/C) atomic ratio of less than 0.15 , a spacing (d.sub.002) of the (002) plane as determined by $\mathrm{X}$-ray wide angle diffraction of 3.37 to 3.75 .ANG., a total fine pore volume of 1.5.times.10.sup. $3 \mathrm{ml} / \mathrm{g}$ or more and a crystallite size in the c-axis direction (Lc) of 5 .ANG. or more, and (ii) from 2 to $70 \%$ by weight of a conductive polymer composition composed of lithium lithium ion or lithium lithium containing another alkali metal and an ion conducting polymer selected from the group consisting of (A) a polymer gel electrolytic composition comprising (a) a vinyl series polymer, as a matrix polymer which is obtained by polymerizing a monomer selected from the group consisting of alkyl(meth)acrylates, (meth)acrylonitrile, vinyl acetate, $\mathrm{N}$ vinyl lactams, (meth)acrylic acid, hydroxyalkyl(meth)acrylates, (meth)acrylamide, 
glycerin mono(meth)acrylate, polyalkylene glycol(meth)acrylates, alkoxypolyalkylene glycol mono(meth)acrylates and siloxane-modified polyalkylene glycol(meth)acrylates, (b) an orangic solvent, and (c) 1,3,2,4dibenzylidene sorbitol derivatives having at least one -COOR group, wherein $R$ represents a hydrocarbon group having 1 to 20 carbon atoms, and

(B) a polymer composition comprising polyphosphazene represented by the formula: \#STR5\# wherein R.sup.1 and R.sup.2 each represent an alkyl group having 1 to 6 carbon atoms, $\mathrm{n}$ is an integer of 5 or more and $\mathrm{m}$ is an integer of 1 to 100 , said polymer composition having an ion conductivity at $20^{\circ} \mathrm{C}$. or 10 .sup.$8 \mathrm{~S} / \mathrm{cm}$ or greater.

U.S. Class

IPC

U.S. Refs

Foreign Refs

Other Refs

Examiner

Agent

Image Disc \#
$429 / 212 \quad 429 / 218 \quad 252 / 518$

H01M 4/60

4517265472542249450144980250

EPX 198401098772

EPX 198812293946

EPX 198908328131

EPX 199012404578

EPX 199101409192

Patent Abstracts of Japan vol. 12, No. 474 (E-692) (3321)

Dec. 12, 1988 \& JP-A-63 193463 (Toshiba Battery Co. Ltd.)

Aug. 10, 1988 *Abstract*.

Bell, Mark L.

Oblon, Spivak, McClelland, Maier \& Neustadt

This patent is on PatentImages disc\# 19931002 and PatentImages(chemical) disc\# 1993lc01 


\section{NASA RECON Demonstration Program}

This search report is for the search you ran on Nov 3 15: 05: 07 1994. It is a temporary file and will expire about an hour after the search.

Searching /usr/local/wais/indexes/recon...

Your query was:

lithium and battery

The database contains $35,876,272$ words in 227,085 documents. There are 592,598 different words.

lithium occurs 4,587 times in 2,175 documents and does not occur in the database.

The search found 2,945 documents. It took about 5 seconds.

The search was performed by a WAIS Inc server: WAIS Server 1-0-11. For more information send email to info@wais.com.

Gopher Menu

SBIR reports on the chemistry of lithium battery technology

Lithium battery safety and reliability LEVY,

Rechargeable lithium battery technology - A survey HALPERT, G

Lithium-containing manganese dioxide (composite dimensional manganese oxide: $\mathrm{CDMO}$ ) as posi

Temperature compensated lithium battery energy monitor

Assessment of battery technologies for electric vehicles. Volume 2, part

Bipolar rechargeable lithium battery for high power applications HOSSAI

Performance of polyaniline positive in a lithium battery YANG, LAN-SHE

A modified lithium-iodine battery LUEHDER, K.; LOBITZ, P.; WEHLAN,

Smart battery controller for lithium sulfur dioxide batteries ATWATER, TERRILL;

Evaluation of lithium secondary battery for load-conditioner use:

Performance and characteri

Spinel electrodes from the Li-Mn-O system for rechargeable lithium battery

STS lithium/CF( $x$ ) battery GNACEK, DE

First year testing of prototype magnesium/manganese dioxide BA-4590/U

Characteristics and development report for the MC3246A thermal battery SCHA

Application of $\mathrm{FeOCl}$ derivative for a secondary lithium battery. I-Discharge and charge ch

A low temperature, high performance lithium sulphur dioxide battery for a

Lithium sulphur dioxide battery failure following high frequency vibration

Fabrication and characterization of amorphous lithium electrolyte thin films a 
Failure analysis of the lithium battery: A study of the header deposit on the cell top and diff A rechargeable lithium battery employing cobalt Chevrel-phase compound as NASA Center update: Jet Propulsion Laboratory DI Approach to extending the cycle life of lithium secondary battery KUMAI, K Current status of solid-state lithium batteries employing solid redox The DELTA 181 lithium thionyl chloride battery SULLIVAN, RALPH M.; Research and development of lithium/polyacenic semiconductor (PAS) battery Research and development of carbon black anodes for lithium secondary Research and development of lithium/polyaniline battery, part 2 TAKEI, Effect of shrapnel penetration on lithium-carbon monofluoride and lithiumLithiated Vanadium Oxide (LVO), gamma-lithium vanadium bronze (Gamma-LIV2O5) and vanadium d

Advances in lithium and calcium high-rate oxyhalide batteries HAGAN, W. P.; Lithium nitrate and lithium trifluoromethanesulfonate ammoniates for elec Anode for rechargeable ambient temperature lithium cells HUANG, CHEN-KUO; SURAMP Improvement in the capacity and safety of lithium/inorganic electrolyte sulfur Research and development of lithium secondary batteries for load co Lithium/sulfur dioxide battery design changes HAR The improvement of rechargeable lithium battery electrolyte performance Lithium polymer electrolyte battery, electrochemical behavior of cathode Characteristics and development report for the MC3714 thermal battery S

The following record illustrates the format of a typical record from the NASA RECON demonstration database.

SBIR reports on the chemistry of lithium battery technology

KILROY, W. P.

Naval Surface Weapons Center, Silver Spring, MD.

Published: November 1989 Pages: 00183 ․ Refs: 0

The following contents are included: Identification of an Improved Mixed Solvent Electrolyte for a Lithium Secondary Battery; Catalyzed Cathodes for Lithium-Thionyl Chloride Batteries; Improved Lithium/Thionyl Chloride Cells Using New Electrolyte Salts; Development of Calcium Primary Cells With Improved Anode Stability and Energy Density. 
COSATI Code:

NASA Subject Category:

Major Subject Terms:

Minor Subject Terms:

CASI Accession Number:

Contract Number:

Report Number:

Language:

Avail:

Document Class:
$10 \mathrm{C}$

033

ELECTRIC BATTERIES, ELECTROLYTIC CELLS, LITHIUM, PRIMARY BATTERIES, STORAGE BATTERIES

CALCIUM, CATALYSIS, CELL ANODES, CELL CATHODES, LITHIUM CHLORIDES, SULFUR COMPOUNDS

N9112012

N60921-86-C-A457; N60921-88-C-0058;

N60921-86-C-0274; N60921-88-C-0057

AD-A225139; NSWC-MP-89-242

ENGLISH

CASI HC A09/MF A02

COLLECTED WORK

\section{Cambridge Scientific}

001

007

008

009 I 619.1

I 522

I 723.5

$100 \mathrm{~A}$

$105 \mathrm{~A}$

$200 \mathrm{~A}$

$600 \mathrm{~A}$

$700 \mathrm{~A}$

$200 \mathrm{~S}$

$300 \mathrm{~S}$

$403 \mathrm{~S}$

$500 \mathrm{~S}$

9609

9909

\section{1}

I Mechanical Engineering Abstracts (ISMEC)

00J AS9

Pipe, Piping and Pipelines;

Gas Fuels;

Computer Applications

Merlie, Bradly A.

Transcontinental Gas Pipe Line Corp

How to analyze the benefits

En

The use of microprocessor-based electronic flow measurement (EFM) devices to record natural gas transmission data is considered. The article makes an attempt to qualify the economics of large-scale EFM system implementation. The advanced technology of metering and data collection is first briefly described and .then stages of implementation are discussed in greater detail. Some benefits are pointed out.

GAS IND (PARK RIDGE IL)

ISSN 0194-2468

1993

vol. 37 , no. $10,3 \mathrm{pp}$

Economics; Gas industry; Data acquisition; Flow measurement; Digital devices

Electronic flow measurement 


\section{H.W. Wilson Database}

SINGLE SUBJECT SEARCH Lithium and battery

$\begin{array}{cl}\text { ENTRIES SUBJECT } \\ 3 & \text { LITHIUM ALUMINUM HYDRIDE } \\ 9 & \text { LITHIUM AMIDE } \\ 1 & \text { LITHIUM AMIDE/CRYSTALLOGRAPHY } \\ 11 & \text { LITHIUM AMIDE/DERIVATIVES } \\ 1 & \text { LITHIUM AMIDE/OXIDATION } \\ 3 & \text { LITHIUM AMIDE/SPECTRA } \\ 33 & \text { LITHIUM BATTERIES } \\ 24 & \text { LITHIUM BATTERIES/CHARGING } \\ 4 & \text { LITHIUM BATTERIES/DESIGN } \\ 14 & \text { LITHIUM BATTERIES/EFFICIENCY } \\ 163 & \text { LITHIUM BATTERIES/ELECTRODES } \\ 68 & \text { LITHIUM BATTERIES/ELECTROLYTES } \\ 1 & \text { LITHIUM BATTERIES/MANUFACTURE }\end{array}$

1 ASA

TITLE: Water: the key to electric cars?

SOURCE: Chemistry and Industry (ISSN 0009-3068) vno11 p393 June 6 '94

SUBJECTS COVERED:

Electric automobiles

Lithium batteries/Electrolytes

ABSTRACT: A team from Simon Fraser University in Burnaby, British Columbia, has developed a lithium battery that has the potential to power an electric automobile. The battery is rechargeable, light, cheap and safe, and capable of storing a large quantity of energy relative to its weight. The lithium battery employs a water-based electrolyte, making it easier to manufacture and cheaper than previous lithium batteries.

2 ASA

AUTHOR: Nagasubramanian, G.; Surampudi, S.; Halpert, G.

TITLE: Cycloaliphatic epoxide-based photocured gelled electrolytes for secondary lithium battery applications; electrochemical kinetic studies SOURCE: Journal of the Electrochemical Society (ISSN 0013-4651) v141 p1414-17 June '94 CONTAINS: bibliography; illustration(s)

SUBJECTS COVERED:

Epoxy resins

Electrodes/Efficiency

Lithium batteries/Electrolytes 